\title{
II. Die Abendländische Bewegung in der Bundesrepublik
}

\section{Wiederbeginn und Neuanfang: das „Abendland“ in der frühen Nachkriegszeit (1945-1948/49)}

Fragt man nun danach, wie die verschiedenen Elemente der abendländischen Idee, so wie sie bei Ende des Krieges auszumachen sind, den Weg in die Nachkriegszeit fanden, so läßt sich zunächst feststellen, daß der „Zeitgeist“ dem „Abendland“ günstig gesonnen war. Denn gerade weil das „Abendland“, im Gegensatz zum „Reich“, in der öffentlichen Wahrnehmung nicht mit dem Nationalsozialismus in Zusammenhang gebracht wurde, konnte der Begriff nach dem Ende des Zweiten Weltkrieges im öffentlichen Sprachgebrauch wieder stark in den Vordergrund treten. In der Folgezeit entwickelte sich das „Abendland“ zu einem der zentralen Schlagworte der unmittelbaren Nachkriegszeit. Die häufige Verwendung des Begriffs war wiederum Teil einer regelrechten Europa-Euphorie in Deutschland, welche aber auch andere europäische Länder erfaßte. ${ }^{1}$ Insbesondere die junge Generation war gewiß, die Katastrophe des Zweiten Weltkrieges habe das „Modell Nationalstaat" nun endgültig diskreditiert. An seine Stelle sollte ein vereintes Europa auf der Basis von Gleichberechtigung, Demokratie und Freiheit treten, das fortan den Frieden unter den Nachbarn garantieren würde. Viele Deutsche sahen den unmittelbaren Zusammenhang von totaler Niederlage und den nationalsozialistischen Europa-Plänen: Einer hegemonial-rassistischen Europa-Idee war fortan jede Chance auf Realisierung genommen. Bald war klar, daß ein anderes, ein nach westlichen Wertvorstellungen organisiertes Europa entstehen würde und daß die Deutschen, angesichts der unmittelbaren Vergangenheit, froh darüber sein mußten, in dieses Europa miteingebunden zu werden.

So führte der Zusammenbruch des „Dritten Reiches“, und damit einhergehend der staatlichen Ordnung in Deutschland, auch zum Zusammenbruch jener Werte, die sich durch immer wiederholte Formeln und Worthülsen im Denken eines Großteils der Deutschen festgesetzt hatten. Doch waren es die gleichen Menschen, die vor und nach dem 8. Mai 1945 in Deutschland lebten: Sie waren in ihrem Denken und in ihren Wertvorstellungen von längerfristigen Entwicklungen und Erfahrungen geprägt und nicht nur von politischen Daten, in diesem Fall der bedingungslosen Kapitulation am 8. Mai 1945. So hat die Forschung in den letzten Jahren verstärkt auf die biographischen und damit einhergehenden ideengeschichtlichen Kontinuitäten zwischen der Weimarer Republik, dem „Dritten

1 Vgl. etwa Lipgens, Die Anfänge der europäischen Einigungspolitik. Loth, Die EuropaBewegung in der frühen Bundesrepublik. Ders., Rettungsanker Europa. Ders., Deutsche Europa-Konzeptionen. Schwarz, Vom Reich zur Bundesrepublik. 
Reich" und der Bundesrepublik verwiesen. ${ }^{2}$ Die Deutschen griffen für den (auch geistigen) „Wiederaufbau“ mangels verwendbarer Alternativen einerseits, aufgrund generationenspezifischer Prägungen andererseits, in der unmittelbaren Nachkriegszeit auf Ordnungsvorstellungen zurück, die der Weimarer Republik entstammten und des „braunen“ Beigeschmacks unverdächtig schienen. ${ }^{3}$

Dies gilt auch für europäische Ideen, besonders in konservativen Bevölkerungsschichten. Hier wurde ebenfalls an Europa-Ideen zurückliegender Jahrzehnte angeknüpft. Doch konnte man nicht alle Elemente bürgerlich-konservativen Europaverständnisses der Weimarer Zeit aufgreifen. Vor allem die „Mitteleuropa“-Modelle waren, allein aufgrund der sich ab 1947 in zwei Blöcke spaltenden Welt, vorerst kaum zu reaktivieren, ebenso war an eine „deutsche Sendung“ nicht mehr zu denken. Auch das „Reich“ hatte nach 1945 als europäischer Topos ausgedient. Statt dessen kam nun in Deutschland das „Abendland“ zu neuen Ehren, wobei die frühere inhaltliche Nähe des Begriffes zum „Reich“ allerdings vollständig unthematisiert blieb. Im Zuge dieser Konjunktur konnte das „Abendland“ sogar seine üblicherweise im konservativ-katholischen Milieu verankerte Anhängerschaft vorübergehend ausweiten. ${ }^{4}$ Sicherlich hing dies mit den typisch abendländischen $\mathrm{Be}$ zügen auf eine historisch-kulturelle europäische Einheit zusammen. Nicht zuletzt spielte aber auch das nun wieder stark betonte christliche Element eine große Rolle. Beides kam den Bedürfnissen der Zeitgenossen entgegen: Die Beschwörung einer kulturellen Gemeinsamkeit des Kontinents einerseits ließ politische Fragen in den Hintergrund treten und ermöglichte es auch, die deutsche Nation als dem "Abendland" zugehörig zu betrachten. Die allgemeine Besinnung auf christliche Grundwerte andererseits entwickelte sich in den ersten Nachkriegsjahren vorübergehend zu einer breiten gesellschaftlichen Strömung, in der insbesondere der katholischen Kirche als vermeintlich vom Nationalsozialismus unberührter Institution ein hohes Maß an Akzeptanz und gesellschaftlichem wie politischem Einfluß zukam. ${ }^{5}$ Ganz ähnlich wie nach 1918 entstand daraus in katholischen Kreisen und auch innerhalb der katholischen Kirche ein „Hochgefühl“, verbunden mit der Hoffnung auf eine Rechristianisierung der säkularisierten Welt. $6 \mathrm{Zu}$ diesem Hochgefühl trug nicht zuletzt die Tatsache bei, daß sich in den westlichen Besatzungszonen durch den Wegfall der protestantischen Gebiete Mittel- und Ostdeutschlands die Relationen der konfessionellen Bevölkerungsanteile massiv verschoben hatten und auf diese Weise erstmals der katholische Bevölkerungsanteil größer war

2 Vgl. etwa die Diskussion um Werner Conze und die Kontinuität zwischen „Volks-“ und "Sozialgeschichte": Etzemüller, Sozialgeschichte als politische Geschichte. Siehe auch: Asmussen, Hans-Georg von Studtnitz. Herbert, Best. Schildt, Deutschlands Platz in einem „christlichen Abendland“.

3 Broszat/Henke/Woller (Hg.), Von Stalingrad zur Währungsreform, vor allem die Einleitung.

4 Jost, Der Abendland-Gedanke. Vgl. auch: Schildt, Ankunft im Westen, Kap. 5: Vom christlichen Abendland zum modernen Pluralismus, S. 149-180.

5 Schewick, Die katholische Kirche und die Entstehung von Verfassungen, S. 5-30. Gauly, Kirche und Politik in der Bundesrepublik.

6 Gotto, Zum Selbstverständnis der katholischen Kirche. Löhr, Rechristianisierungsvorstellungen. Zur Ähnlichkeit der Entwicklung nach dem Ersten Weltkrieg vgl. Greschat, „Rechristianisierung" und "Säkularisierung". 
als der protestantische. Insgesamt ähnelte die „Abendland“-Mode nach dem Ende des Zweiten Weltkrieges jener nach dem Ende des Ersten: Wie nach 1918 schien gerade der Topos vom Abendland geeignet, christlich-katholische Konzepte in eine breitere Öffentlichkeit hineinzutransportieren und zur Neugestaltung und zum geistigen „Wiederaufbau“ nutzbar zu machen. ${ }^{7}$ So verwundert es nicht, daß auch der Abendland-Kreis der Weimarer Republik sich nun rekonstituierte.

\section{Die Gründung des Neuen Abendlandes}

An unterschiedlichen Orten der westdeutschen Besatzungszonen bemühte man sich um eine Wieder- bzw. Neugründung der von Hermann Platz in der Zwischenkriegszeit herausgegebenen Zeitschrift Abendland. Johann Wilhelm Naumann, ${ }^{8}$ ein bereits in der Weimarer Republik tätiger katholischer Publizist, erhielt von den Alliierten mit der nötigen Lizenz den Zuschlag: 1946 gründete er die Zeitschrift Neues Abendland. Zeitschrift für Politik, Kultur und Geschichte und legte damit den Grundstein für die Abendländische Bewegung der Nachkriegszeit. Bald versammelten sich um die neugegründete Zeitschrift katholische Abendländer und Reichsvisionäre der Weimarer Republik. Die „Brückenbauversuche“ letzterer zum „Dritten Reich“ blieben im Neuen Abendland verständlicherweise unerwähnt. Im Gegenteil: Man stellte sich selbst in die Tradition des Widerstandes gegen den Nationalsozialismus. Dazu diente dem Neuen Abendland insbesondere die Erinnerung an Benedikt Schmittmann, auch er ein Vertreter der katholischen Reichs-Idee der Weimarer Republik. ${ }^{9}$

\section{Der Bezug auf Benedikt Schmittmann}

Schmittmann stand zwar mit den Kreisen um die Zeitschrift Abendland und dem Katholischen Akademikerverband (KAV) am Rande in Kontakt, ${ }^{10}$ entfaltete dar-

7 Vgl. hierzu: Brelie-Lewien, Abendland und Sozialismus.

8 Johann Wilhelm Naumann, geb. am 7. 7.1897 in Köln, war nach dem Studium der Philosophie, Geschichte und Literatur bereits in der Weimarer Republik in der katholischen Presse tätig. Nach dem Ende des Nationalsozialismus, welchen er beim Päpstlichen Missionswerk in Aachen überdauert hatte, wurde er zum Vorsitzenden des „Vereins der Bayerischen Zeitungsverleger" gewählt und erhielt zusammen mit dem Sozialdemokraten Curt Frenzel eine Lizenz für die Schwäbische Landeszeitung. Sein eigentliches Ziel blieb aber die Herausgabe einer katholischen Tageszeitung. Dies erreichte er 1948 mit der Augsburger Tagespost. Das Neue Abendland erschien bis 1951 im Hausverlag der Schwäbischen Landeszeitung.

${ }^{9} \mathrm{Zu}$ Schmittmann vgl.: Kuhlmann, Das Lebenswerk Benedikt Schmittmanns. Lotz, Benedikt Schmittmann. (Albert Lotz hatte übrigens in der Zwischenkriegszeit regelmäßig in der Zeitschrift Abendland geschrieben). Stehkämper, Benedikt Schmittmann. Strickmann, Benedikt Schmittmann. Vgl. folgende Artikel zu Schmittmann im Neuen Abendland: Benedikt Schmittmann, Hermann Platz, Theodor Haecker, in: Neues Abendland 1 (1946), Heft 1, S. 25 f. Ferber, Walter: Historisch-politische Betrachtungen, in: Neues Abendland 1 (1946), Heft 2, S. 20-2. Ein historisch politisches Dokument, in: Neues Abendland 1 (1946), Heft 6, S. 27 f.

10 Schmittmann war z. B. auf soziologischen Sondertagungen des KAV anwesend. Vgl. Müller, Der katholische Akademikerverband, FN 27. 
über hinaus aber eine eigenständige Aktivität, auf die sich nach 1945 die Abendländer leichter beziehen konnten als auf den Rechtskatholizismus und seine „Brückenbauversuche“ zum Nationalsozialismus. Denn die Reichs-Idee der Weimarer Republik konnte auch das Verlangen nach einer inneren - föderativen Neugestaltung des Deutschen Reiches spiegeln. ${ }^{11}$ Das Lebenswerk des gläubigen Katholiken Schmittmann war auf diese innenpolitische Variante, in seinem Fall auf die Loslösung des Rheinlandes von preußischer „Vorherrschaft“, damit aber auch auf eine vollständige Neuorganisation des Deutschen Reiches und Europas, ausgerichtet. Der Kampf des 1872 geborenen Juristen und Bonner Professors für Sozialpolitik galt dem "falschen" Staatsbegriff einer preußisch-zentralistischen Gesellschaft. An ihre Stelle sollte eine konsequent föderalistisch, nach den Prinzipien der Subsidiarität im Sinne der katholischen Soziallehre aufgebaute Gesellschaft treten, die vom einzelnen Menschen ausging, Stände, Stämme und das Volk statt den Staat zum Maßstab nahm. Diese würde in einem ersten Schritt die kleindeutsche Lösung überwinden und dann auch übernational zu einem föderativ gegliederten "Abendland“ führen. ${ }^{12}$ Das Rheinland sollte in diesem Zusammenhang in souveräne Eigenständigkeit entlassen werden. Allerdings setzte die Nationalversammlung den Artikel 18 der Weimarer Reichsverfassung, der eine territoriale Neuordnung des Reichsgebietes ermöglicht hätte, noch 1919 für zwei Jahre außer Kraft, und im Dezember 1921 beschlossen die Parteien im Rheinland, diese Sperre für die Dauer der Besetzung aufrechtzuerhalten. Schmittmann, der 1919 für das Zentrum in die Verfassunggebende Preußische Landesversammlung gewählt worden war, bewarb sich daraufhin nicht mehr um ein neues Mandat, sondern konzentrierte seine politischen Aktivitäten fortan auf außerparlamentarische Kreise. Im November 1924 gründete er mit dem „Reichs- und Heimatbund deutscher Katholiken “, dessen Vorsitz er übernahm, eine eigene Plattform, um seine föderalistischen Überzeugungen (auch publizistisch) in die Tagespolitik einzuspeisen. ${ }^{13}$ Schon bald bemühte sich der Reichs- und Heimatbund auch mit anderen föderalistischen Organisationen in Kontakt zu treten. Als Ergebnis dieser Verhandlungen bildete sich im Oktober 1925 zusammen mit dem protestantischen „Deutschen Föderalisten-Bund“ die „Reichsarbeitsgemeinschaft Deutscher Föderalisten “. ${ }^{14}$ Nach 1945 sollte sich diese enge Zusammenarbeit fortsetzen: Auch in der Abendländischen Bewegung bestanden personelle Überschneidungen mit dem Bund deutscher Föderalisten, über dessen Arbeit im Neuen Abendland konsequent und regelmäßig berichtet wurde. ${ }^{15}$

11 Sontheimer, Antidemokratisches Denken, S. 243.

12 Deuerlein, Föderalismus, S. 182-193. Schulz, Zwischen Demokratie und Diktatur.

13130 Männer waren an dieser Gründung beteiligt: davon 48 aus dem Rheinland, 38 aus Bayern, 13 aus der Pfalz, 8 aus Westfalen, 6 aus Niedersachsen und je 5 aus Baden und Hessen. Vgl. Stehkämper, Benedikt Schmittmann, S. 213. Zwei Zeitschriften, die Reichsund Heimatblätter. Mitteilungen des Reichs- und Heimatbundes deutscher Katholiken und ab 1926 auch die Wochenzeitschrift Volk und Heimat ergänzten - unter Schmittmanns Schriftleitung - seine Bemühungen um eine föderale Neugliederung.

$14 \mathrm{Vgl}$. den Artikel Arbeitsgemeinschaft Deutscher Föderalisten, in: Reich und Heimat 2 (1926), S. 19 f.

$15 \mathrm{Zu}$ den Kontinuitäten zwischen der „Reichsarbeitsgemeinschaft deutscher Föderalisten“ 
Schmittmann stieß mit seinen Aktivitäten jedoch bald auf deutliche Kritik von beinahe allen politischen Richtungen - selbst das Zentrum rückte von ihm ab. Der Vorwurf des Separatismus ließ die Aktivitäten in schlechtes Licht rücken. ${ }^{16}$ Selbst im Zusammenhang mit der in der zweiten Hälfte der zwanziger Jahre aufflackernden Diskussion um eine Reichsreform gelang es Schmittmann nicht, seine Vorstellungen in breiteren Kreisen wirksam zu machen, sicherlich auch, weil seine Konzepte ein erhebliches Maß an reichsvisionären Schwärmereien beinhalteten. ${ }^{17}$ Nach der „Machtergreifung“ im April 1933 wurde Schmittmann „beurlaubt“ und wegen separatistischer Umtriebe ein erstes $\mathrm{Mal}$ - vorübergehend - verhaftet. Am 1. September 1939 verhaftete ihn die Gestapo erneut: Im Konzentrationslager Sachsenhausen verstarb er wenige Tage später an den Stiefeltritten eines SS-Mannes.

Schmittmann und sein „Reichs- und Heimatbund“ boten sich aus zwei Gründen für die Abendländer der unmittelbaren Nachkriegszeit zur Identifikation an. Zum einen sah man in Schmittmanns Föderalismus ein Leitbild für die deutsche Neuordnung nach dem Zusammenbruch, die man sich - das wird noch genauer zu zeigen sein - in Ablehnung des "preußischen Zentralismus" stark föderalistisch gegliedert wünschte. Der Bezug auf den „Märtyrer“ Schmittmann ermöglichte es den Abendländern nach dem Ende des „Dritten Reiches“ jedoch auch, sich selbst in die Tradition des Widerstandes zu stellen. Den Abendland-Gedanken auf diese Weise für immun gegenüber dem Nationalsozialismus zu erklären, sollte die Realitäten der frühen dreißiger Jahre und die Annäherung der „Reichskatholiken“ an die „Bewegung" vergessen machen.

Doch diesen Bemühungen zum Trotz waren die Jahre 1946 bis 1948 zunächst eine Phase der Sammlung für die Abendländische Bewegung. Noch gingen die Aktivitäten über die Publikation einer Zeitschrift nicht hinaus. Auch war die An-

und der „Arbeitsgemeinschaft deutscher Föderalisten“, die 1947 in Bad Ems (als Vorläuferin des „Bundes deutscher Föderalisten“) gegründet wurde, vgl. den insgesamt sehr ergiebigen Aufsatz von Heil, Föderalismus als Weltanschauung. S. 172. Die Nachkriegsgründung erfolgte im übrigen durch Ella Schmittmann, der Witwe Benedikt Schmittmanns, und Adolf Süsterhenn, die beide auch im Abendland-Kreis nach 1945 aktiv waren. Süsterhenn wiederum hatte Schmittmann nach dessen Entlassung aus der Haft 1933 im Leonardus-Stift in Bonn-Godesberg kennengelernt. Vgl. Stehkämper, Benedikt Schmittmann, S. 216.

Im Bundesvorstand des Bundes deutscher Föderalisten waren beispielsweise 1950 mit Friedrich August Freiherr von der Heydte, Paul Wilhelm Wenger, Max Freiherr von Fürstenberg, Richard Jaeger und Walter Ferber eine ganze Reihe von Protagonisten vertreten, die auch in der Abendländischen Bewegung zu finden waren.

16 Zum Separatismus im Rheinland, zum dem Schmittmann wohl nur am Rande zuzurechnen ist, vgl. Bischof, Rheinischer Separatismus 1918-1924. Köhler, Adenauer und die Rheinische Republik. Schmittmann klagte regelmäßig über unsachliche Presseberichte, sogar über Hausdurchsuchungen und Beschlagnahmungen durch das beim Kölner Regierungspräsidenten eingerichtete Sonderamt „zur Separatistenabwehr". Zweimal kam es im Reichstag zu Anfragen, ob die Bestrebungen Schmittmanns als „reichs“- bzw. „preußenschädigend" einzuschätzen seien: 1925 von der SPD, 1926 von einem NSDAP-Mitglied. Vgl. die Artikel Benedikt Schmittmanns: Unsere Abwehr, in: Reich und Heimat 1 (1925), S. 46-48 und ders.: Unser Bund, in: Reich und Heimat 2 (1926), S. $49 \mathrm{f}$.

17 Sontheimer, Antidemokratisches Denken, S. 243. 
fangszeit in organisatorischer Hinsicht alles andere als ruhig. In den ersten beiden Jahren wechselte der Chefredakteur des Neuen Abendlandes fünfmal, ehe mit Emil Franzel 1948 endlich für längere Zeit ein Schriftleiter gefunden war. ${ }^{18}$

\section{Zurück zu den Wurzeln: die abendländische Idee in der unmittelbaren Nachkriegszeit}

Mit der Gründung der Zeitschrift Neues Abendland 1946 stellte man sich bewußt in die Tradition des Abendlandes der zwanziger Jahre. Zahlreiche Autoren, die in den zwanziger Jahren im Abendland geschrieben hatten, griffen nun auch im Neuen Abendland zur Feder. Sie verliehen der Zeitschrift vor allem in den ersten beiden Jahrgängen ein ähnliches Profil, wie es das Abendland besessen hatte - vor allem jenes Abendland um 1925/26, das sich ganz überwiegend grundsätzlichen Überlegungen zur „abendländischen Kultureinheit“ und der Erneuerung einer christlich-übernationalen Gemeinschaft gewidmet hatte. ${ }^{19}$

Denn es ging in den ersten beiden Jahren abendländischer Aktivität nach dem Zweiten Weltkrieg kaum um konkrete politische Konzepte zur Einigung Europas bzw. zur politischen Wiedereingliederung Deutschlands in die europäische Staatengemeinschaft. Darüber nachzudenken, gab es angesichts der politischen Situation noch keinen Anlaß. Gleichzeitig jedoch entsprach die bewußt unpolitische Haltung der Abendländer der unmittelbaren Nachkriegszeit in vielem dem vermeintlich unpolitischen Verhalten des deutschen Konservatismus in der Weimarer Republik. Die Ablehnung aller Tagespolitik und der Rückzug auf eine übergeordnete Ebene weltanschaulicher Betrachtung in den späten vierziger Jahren glich der Suche nach dem "überparteilichen Baugesetz“ des „Abendlandes“ in den zwanziger Jahren. ${ }^{20}$ Und wie in den zwanziger und dreißiger Jahren war diese Haltung im Kern durchaus politisch: Die Rede vom „Abendland“, die Betonung der gemeinsamen kulturellen Werte der europäischen Völker, legitimierte nach 1945 Deutschlands Anspruch auf einen Platz in der ,abendländischen Gemeinschaft“" In für sie typischer Weise begründeten die Abendländer ihre Forderung auf Wiedereingliederung Deutschlands historisch mit dem "Sacrum Imperium“ und der ehemals gegebenen christlichen Kultureinheit des "Abendlandes“. Dabei treffen

18 Walter Ferber verließ die Zeitschrift aufgrund der religiösen Ausrichtung bereits nach einem halben Jahr wieder, um zu den Föderalistischen Heften hinüberzuwechseln. Nach ihm leitete Johann Wilhelm Naumann für sechs Ausgaben selber die Redaktion, ehe Rupert Sigl den Posten übernahm. Auch er verließ die Zeitschrift jedoch nach einem dreiviertel Jahr und wechselte zur Pressestelle der Bayernpartei. Danach war es wieder kurzfristig Naumann, der in die Bresche sprang. Vgl. Brelie-Lewien, Katholische Zeitschriften in den Westzonen, S. 80. Schildt, Zwischen Abendland und Amerika, S. 34. Zu Franzel vgl. Teil I, Kap. I.2.

19 U.a. Ferdinand Kirnberger, Walter Hagemann, Helmut Ibach, Friedrich Zoepfl, Robert John, Anton Mayer(-Pfannholz), Wilhelm Schmidt, Hermann Port, Andreas Andrae, Werner Bergengruen. Auch dominierte in den ersten beiden Jahrgängen des Neuen Abendlandes eine auffällige religiöse Bebilderung, die den beschriebenen allgemein weltanschaulichen Charakter der Zeitschrift unterstrich.

20 Schreyvogel, Friedrich: Kampf um das Abendland, in: Abendland 1 (1925/26), S. 10-13, hier S. 12. 
wir auf exakt jene Argumente, die bereits Mitte der zwanziger Jahre, während der Locarno-Ära, das Mittelalter-Bild der Abendländer und seine Verwendung dominiert hatten.

Weiterhin bildete eine rückwärtsgewandte Utopie, die Konstruktion eines heilsgeschichtlich "goldenen Zeitalters", den Kern des abendländischen Weltbildes. Die föderale Idee als „,integrierender Bestandteil der abendländischen Reichsidee“, welche die „Einheit in der Vielfalt" ermöglichen sollte, blieb auch weiterhin Leitbild der Abendländer. ${ }^{21}$ Diesen politischen Rahmen Europas habe der christliche Glaube wie eine Klammer umgriffen, so daß aus universaler Regierung und Religion nach abendländischer Auffassung eine einheitliche und universale Kultur entstanden sei, die den mittelalterlichen Menschen in "natürliche“, sprich: gottgewollte, soziale Gefüge eingebunden habe. ${ }^{22}$ Wie in den zwanziger Jahren ging es bei dieser Mittelalter-Beschwörung um die Konstruktion eines Zeitalters, in dem eine gottgewollte Ordnung von Staat und Gesellschaft europaweit verwirklicht gewesen sei. Dabei fielen die Anfang der dreißiger Jahre üblichen Verweise auf den "natürlichen“ Platz Deutschlands an der Spitze dieser politischen Ordnung nun allerdings fort.

Positive Bezugnahmen auf das Mittelalter waren in der Zeit kurz nach dem Ende des Zweiten Weltkrieges in Deutschland nicht selten, ${ }^{23}$ und gerade auf katholischer Seite tauchten sie im Rahmen der Schulddiskussion immer wieder auf. ${ }^{24}$ $\mathrm{Zu}$ Recht betont u.a. Vera Bücker, daß die Wiederbelebung der mittelalterlichen Reichsidee als "notwendiges Korrelat zum übersteigerten Nationalismus" des „Dritten Reiches“ diente, und so die Vergangenheit ein „Modell zur Neuordnung Europas“ lieferte. ${ }^{25}$ Während allerdings diese Referenz auf das Mittelalter Ende der vierziger Jahre insgesamt zurückging, nahm die Verherrlichung mittelalterlicher Zeiten und die Orientierung am „Ersten Reich“ innerhalb der abendländischen Bewegung nicht $a b$, sondern blieb bis weit in die fünfziger Jahre hinein erhalten.

Der „wunderbar wohlgefügte Kosmos der abendländischen Universitas“26 war nach abendländischer Auffassung mit der Reformation ins Wanken geraten und hatte sich durch Aufklärung und Säkularisierung endgültig aufgelöst. ${ }^{27}$ Spätestens seit der Französischen Revolution und der Proklamation der "Gleichheit" aller Menschen sei die organisch gewachsene Gesellschaft in eine gesichtslose „Masse“ verwandelt worden, in der sich alle der Mehrheit beugen müßten und niemand mehr eigenen Willen demonstrieren könne. Dies öffne Demagogen Tür und Tor, der Weg in die Diktatur sei frei. Der Individualisierung des Menschen habe gleich-

21 Ferber, Walter: Das historische Europa als Kultureinheit, in: Neues Abendland 4 (1949), S. 321-324, hier S. 322. Vgl. z. B. auch: Zoepfl, Friedrich: Abendländische Kulturgemeinschaft, in: Neues Abendland 1 (1946), S. 5-11.

22 Vgl. Kroll, Grundlagen abendländischer Erneuerung, S. 21-23.

23 Zur Kontinuität dieser „Mittelalter"-Konstruktionen in der deutschen Geschichtswissenschaft vgl.: Oexle, Das Mittelalter und das Unbehagen an der Moderne, S. 137-162.

24 Bücker, Schulddiskussion im deutschen Katholizismus, S. 258.

25 Ebenda, S. 260.

26 Politischer Universalismus, in: Neues Abendland 1 (1946), Heft 6, S. 26/27, hier S. 26.

27 Kroll, Grundlagen abendländischer Erneuerung, S. 10. 
zeitig der Nationalismus als Individualisierung der Staaten entsprochen, mit Krieg als zwangsläufiger Folge. Während dieses Geschichtsbild bereits in den abendländischen Publikationen der zwanziger Jahre zu finden gewesen war, erhielt es nach dem Ende des Zweiten Weltkrieges nun noch einmal besondere Bedeutung im abendländischen Weltbild. Denn die Abendländer setzten so die totalitären Systeme des 20. Jahrhunderts an das Ende einer teleologischen Entwicklung, die bereits (spätestens) zweihundert Jahre vorher begonnen habe. Keine der Katastrophen des 20. Jahrhunderts hätte nach dieser Argumentation verhindert werden können: Sie lagen begründet in der Abwendung des Menschen von Gott, von der göttlichen Gesellschaftsordnung, in Individualismus und Nationalismus.

Dieses Geschichtsverständnis bildete den geistigen Hintergrund, vor dem die Auseinandersetzung der Abendländer mit dem Nationalsozialismus erfolgte. In den Jahren von 1946 bis 1948 fand im Neuen Abendland eine recht offene Auseinandersetzung über die Schuldfrage statt. Den eigenen Anteil, die eigene Haltung $\mathrm{zu}$ thematisieren, welche die abendländischen „Reichsvisionäre“ gegenüber dem Nationalsozialismus eingenommen hatten, war damit, das kann kaum erstaunen, nicht gemeint. Dennoch stellte man schon früh fest, jeder einzelne müsse sich mit seiner Vergangenheit und seinem Gewissen auseinandersetzen. Aber auch das gesamte deutsche Volk wurde im Nenen Abendland wiederholt zur "Sühne“ aufgerufen: „Der Übel grösstes [sic!] ist die unbeweinte Schuld“, 28 hieß es in einem Heft des ersten Jahrgangs 1946, welches sich allein mit der Schuldfrage beschäftigte. Hier überwogen Artikel, die eine Schuld des deutschen Volkes, auch der Katholiken - einschließlich des Episkopates - anerkannten. Damit unterschied sich das Neue Abendland, zusammen mit anderen katholischen Publikationsorganen der frühen Nachkriegszeit, von den Interpretationen der katholischen Amtskirche, welche das Verhalten der Kirche und des Katholizismus im „Dritten Reich“ in der Regel positiv beurteilten. ${ }^{29}$

Da das Neue Abendland Schuld vor allem moralisch verstand, welche von Gott, nicht aber von anderen Menschen, geahndet werde, lehnte man die Kollektivschuldthese ab. ${ }^{30}$ Bereits im ersten Heft des Nenen Abendlandes 1946 hieß es, daß "keine geistliche und keine weltliche Autorität [das Recht habe], die Antwort auf die Frage nach der inneren Beteiligung des Einzelnen durch eine Entscheidung an der Oberfläche und von oben her vorweg zu nehmen und damit das Gewissen zu ersticken“. ${ }^{31}$ Deutlich spürt man hier die Spitze gegen die anlaufende „Entnazifizierung “ durch die Besatzungsmächte, der die Abendländer - wie die allermeisten Deutschen - extrem kritisch und im Laufe der Jahre immer unwilliger gegenüberstanden. ${ }^{32}$ Der Aufruf an die Deutschen, sich mit der eigenen Schuld auseinander-

28 Hengstenberg, Hans Eduard: Der Übel grösstes [sic!] ist die unbeweinte Schuld, in: Neues Abendland 2 (1947), S. 4-8.

$29 \mathrm{Zu}$ Äußerungen der deutschen Bischöfe zur Schuldfrage bzw. der unterschiedlichen Interpretation der Rolle der Kirche im "Dritten Reich“" siehe Bücker, Schulddiskussion im deutschen Katholizismus. Repgen, Selbstverständnis der deutschen Katholiken nach 1945.

30 Vgl. dazu insgesamt: Niethammer, Die Mitläuferfabrik.

31 Schneider, Reinhold: Der Mensch vor dem Gericht der Geschichte, in: Neues Abendland 1 (1946), S. 12-20, hier S. 19 f.

32 Vgl. Sp.: „Abschießen...“, in: Neues Abendland 2 (1947), S. 83 f. Sp.: „Primum vivere...“, 
zusetzen, bezog sich allerdings im Neuen Abendland nicht allein auf die Verbrechen des Nationalsozialismus innerhalb der deutschen Gesellschaft, er bezog sich explizit auch auf Europa. Deutschland habe sich aus der abendländischen $\mathrm{Ge}-$ meinschaft der Völker „schuldhaft [...] gelöst und wird und muß wieder durch christliche Selbstbestimmung und durch die Sühne seiner Schuld zur mater occidentalis zurückkehren". 33

Mit Verschärfung des Kalten Krieges und der beginnenden Eingliederung Westdeutschlands in das westliche Bündnis verstärkte sich eine allgemeine gesellschaftliche Tendenz, die Auseinandersetzung mit dem Nationalsozialismus abzubrechen. ${ }^{34}$ Auch im Neuen Abendland änderten sich die Positionen grundsätzlich. Wenn man sich nun überhaupt noch mit der unmittelbar zurückliegenden Vergangenheit beschäftigte, dann, indem man die Zwangsläufigkeit und die Kontinuität der historischen Entwicklung seit Beginn der Neuzeit stärker betonte. So gelang es den Abendländern, den Nationalsozialismus als ein europäisches Phänomen zu kennzeichnen. ${ }^{35} \mathrm{Da}$ alle Staaten des Abendlandes prinzipiell die gleiche Entwicklung seit dem Mittelalter durchgemacht hätten, liefen sie auch alle Gefahr, in totalitären Systemen zu enden. So hatte man Deutschland von seiner speziellen Schuld befreit und in die Reihe der abendländischen Nationen gleichberechtigt wieder eingereiht. Gleichzeitig, mit dem Beginn des Kalten Krieges, rückte im Neuen Abendland auch der Kommunismus als anderes "Kind der Französischen Revolution" in den Blickpunkt. Wenn der Nationalsozialismus nun überhaupt noch erwähnt wurde, so im Rahmen einer Totalitarismustheorie, die Nationalsozialismus und Bolschewismus bedingungslos in eins setzte und beide Totalitarismen im Sinne des abendländischen Welt- und Geschichtsbilds erklärte. ${ }^{36}$

Grundlage der moralischen Wiedereingliederung Deutschlands nach dem Ende des Zweiten Weltkrieges, aber auch der Erneuerung des „Abendlandes“, konnte angesichts dieser Entwicklung in den Augen der Abendländer nur eine radikale Umkehr sein. Es mußte darum gehen, sich vom Materialismus und Individualismus der Neuzeit zu lösen und sich rückzubesinnen auf die religiösen Grundlagen der „im Reiche Christi versammelten Völkerfamilie“:37 „Mit dem christlichen Glauben allein kann Europa wieder auferstehen", 38 diese Überzeugung bildete einen Kern abendländischen Denkens, in dessen Zentrum also ebenso wie in den zwanziger und dreißiger Jahren Rechristianisierungsvorstellungen standen. ${ }^{39}$

in: Neues Abendland 3 (1948), S. 57. Timon (= Emil Franzel), Innere Emigration, in: Neues Abendland 5 (1950), S. $332 \mathrm{f}$.

33 Naumann, Johann Wilhelm: Neues Abendland, in: Neues Abendland 1 (1946), S. 1-3, hier S. 2.

34 Vgl. Garbe, Äußerliche Abkehr. Siehe auch: Frei, Vergangenheitspolitik.

35 Vgl. exemplarisch: Kroll, Grundlagen abendländischer Erneuerung, S. 15-19.

36 Damit vollzog sich im Neuen Abendland eine ähnliche Entwicklung wie allgemein im westdeutschen Konservatismus, vgl.: Solchany, Vom Antimodernismus zum Antitotalitarismus.

37 Schmittmann, Ella: Demokratie als personale Volksordnung, in: Neues Abendland 2 (1947), S. 1-3, hier S. 3.

38 Speckner: Rückkehr zu Europa, in: Neues Abendland 3 (1948), S. 151.

39 Vgl. auch: Lübbe, Säkularisierung. Lück, Das Ende der Nachkriegszeit. 
Die Vorstellung von einer Rechristianisierung der europäischen (und damit auch der deutschen) Gesellschaft stand über die gesamten Jahre abendländischer Tätigkeit hinweg im Zentrum der Argumentation. Damit waren die Abendländer allerdings nicht allein: Sowohl die erste wie auch die zweite Nachkriegszeit kannten Rechristianisierungskonzepte, entstanden in der andauernden Auseinandersetzung mit der Moderne. ${ }^{40}$ Beide Phasen waren in der katholischen Kirche von der Überzeugung geprägt, als einzig moralisch integre geistige Kraft aus den Jahren der Katastrophe, sei es nun Erster Weltkrieg oder Nationalsozialismus, hervorgegangen zu sein. Das „Hochgefühl“ der Kirche wurde jeweils verstärkt durch eine (vorübergehende) allgemeine Besinnung auf christliche Grundwerte innerhalb der Bevölkerung und die dominante Stellung, welche die katholische Kirche als "politische" Macht in der Zeit nach der Niederlage 1918, vor allem aber nach dem Zusammenbruch 1945 einnahm. ${ }^{41}$ Waren also bereits nach 1918 bestimmte Rahmenbedingungen für den „Erfolg“ katholisch-konfessioneller Konzepte gegeben, verstärkte sich dies nach der Niederlage im Zweiten Weltkrieg erheblich. Nach dem Untergang des „Dritten Reiches“ konnten Katholiken ein weiteres Argument zugunsten ihrer Religion und Kirche ins Feld führen, das nicht zuletzt die gesamtgesellschaftlich einflußreiche Bedeutung des Katholizismus in der Zweiten Nachkriegszeit zusätzlich stärkte. Denn mit der Überzeugung, daß die historische Entwicklung hin zum Terror des Nationalsozialismus und zum Krieg auf der Abwendung der Menschen von Gott beruhe, boten sie ein Zukunftsmodell, welches zuverlässigen Schutz vor einer Wiederholung oder einer ähnlichen Entwicklung zu bieten schien: die gesellschaftliche Rückbesinnung auf den christlichen Glauben, eine Verchristlichung der säkularisierten Welt. ${ }^{42} \mathrm{Im}$ Glauben an eine mögliche Umkehrung der modernen Geschichte begriff man den Zusammenbruch 1945 als Herausforderung. Die historische Situation schien besonders günstig, und so ging man von katholischer Seite die Aufgabe der Umgestaltung der Gesellschaft mit besonderem Selbstbewußtsein an. ${ }^{43}$

Ähnlich wie in der Weimarer Republik schwammen die Abendländer in den ersten Jahren nach dem Zweiten Weltkrieg mit ihren Rechristianisierungvorstellungen also durchaus im „Strom der Zeit". Nach dem Zweiten Weltkrieg jedoch traten die Forderungen nach umfassender Rechristianisierung mit zunehmender Stabilisierung der gesellschaftlichen Verhältnisse gesamtgesellschaftlich in den Hintergrund, während die Abendländische Bewegung sie beibehielt. Nur ging es ihnen nun nicht mehr um bestmöglichen Schutz gegen eine Wiederkehr des $\mathrm{Na}$ tionalsozialismus, sondern um eine Verteidigung im Kalten Krieg. Dem „Osten“ warf die Abendländische Bewegung insbesondere vor, durch eine Ersatzreligion die Bedürfnisse des Menschen auszunutzen, denn „die im Menschen grundgelegten metaphysischen Sehnsüchte werden durch die Entlassung aus ihren religiösen Bindungen nicht ausgelöscht. Sie suchen einen neuen Herren. Das Geheimnis der

40 Greschat, „Rechristianisierung“ und „Säkularisierung“.

41 Vgl. u. a.: Schewick, Die katholische Kirche und die Entstehung der Verfassungen, S. 5-30. Gauly, Kirche und Politik.

42 Löhr, Rechristianisierungsvorstellungen.

43 Greschat, „Rechristianisierung“ und „Säkularisierung“. 
totalitären Mächte von rechts und links besteht ja gerade darin, die frei gewordenen Kräfte erneut zu binden, indem sie die irdischen Ziele in einem düsteren Ausmaß religiös verbrämen". ${ }^{44}$ So mußte nach abendländischem Verständnis der "Pseudoreligion“ des Ostens, diesem geschlossenen System, eine starke geistige Kraft in Form einer wahrhaften Religion gegenüberstehen, um sie wirklich zu „bezwingen“: „Der Bolschewismus kann wohl durch die Einigkeit und Stärke der freien Welt von Aggressionen zurückgehalten werden. Überwunden werden [...] aber kann er nur durch einen stärkeren Geist. Ob hierzu der Geist der Renaissance und der Aufklärung ausreicht, wie wir ihn in den Vereinten Nationen erleben, ist fraglich. Mit Sicherheit aber wäre ein starkes Christentum das Bollwerk, an dem der Bolschewismus scheitern würde. " 45 Die Einheit im Glauben bildete den Abendländern die notwendige Voraussetzung, um gegenüber dem Osten zu bestehen, vielleicht sogar „siegen“ zu können. Aber auch im Kampf gegen den westlichen „bunten Jahrmarkt, wo jeder seine Waren feilhält, wo jeder nach Belieben tun und lassen kann, was ihm gefällt", 46 bildete das Christentum das einzige Mittel, den „häretischen“ Liberalismus und einen in abendländischer Sicht überbordenden Kapitalismus zu überwinden. So bedeutete den Abendländern eine erfolgreiche Rechristianisierung der Gesellschaft die Überlebensgrundlage des Abendlandes schlechthin.

Doch die Rechristianisierungsforderung der Abendländer hatte auch noch eine weitere Dimension: Die Klage über die fortschreitende Säkularisierung bildete in den fünfziger Jahren innerhalb des westdeutschen Konservatismus eines der zentralen Motive überhaupt. Kurt Lenk hat beschrieben, daß der Begriff „Säkularisierung" hier in der Regel weit mehr umfaßte als die bloße Abkehr vom Christentum, sondern als Chiffre stand für die angebliche "Dekadenz der Moderne“ an sich. ${ }^{47}$ Der sich daraus ableitende Antimodernismus spielte auch im abendländischen Weltbild eine wichtige Rolle. Die Vorstellung von der Rechristianisierung der modernen Welt beruhte freilich auf dem Glauben, eine Umkehrung sei überhaupt noch möglich. ${ }^{48}$ Hier liegt einer der Gründe, warum das traditionelle Gedankengut der Abendländischen Bewegung Ende der fünfziger Jahre auch in konservativen Kreisen kaum noch Anhängerschaft zu mobilisieren vermochte. Die Überzeugung, daß eine grundsätzliche Rückkehr in vormoderne Zeiten, daß eine Rechristianisierung der Gesellschaft in diesem Sinne noch möglich sei, und mit ihr die Forderung nach einer solchen Umkehr hatten bereits Ende der vierziger Jahre ihre gesellschaftliche Grundlage verloren. Die Stimmen, die gut ein Jahrzehnt später, Ende der fünfziger Jahre noch immer eine Rechristianisierung forderten, waren endgültig nicht mehr zeitgemäß. Auch die Abendländer wurden sich dieses Dilemmas bewußt, und so war es nur konsequent, daß sie sich in den sechziger

${ }^{44}$ Hülsmann, Bernhard: Politische Axiome, in: Neues Abendland 10 (1955), S. 79-86, hier S. 83.

45 Roth, Paul: Rußland mit und ohne Marx, in: Neues Abendland 9 (1954), S. 291-294, hier S. 294.

46 Kroll, Grundlagen abendländischer Erneuerung, S. 8.

47 Lenk, Zum westdeutschen Konservatismus, S. 638. Vgl. auch: Ders., Deutscher Konservatismus.

48 Repgen, Selbstverständnis der deutschen Katholiken nach 1945, S. 138. 
Jahren mit Rechristianisierungsforderungen deutlich zurückhielten. Ganz verstummten sie indes nicht, und die Paneuropa-Union etwa trug Restbestände dieses Interpretationsmusters bis in die Gegenwart.

Das Entsetzen über die Schrecken von Nationalsozialismus und Zweitem Weltkrieg, aber auch darüber, daß Europa, „die einstige Herrin der Welt [...] nicht einmal mehr Herrin über ihre eigenen Geschicke " 49 sei, war bei den Abendländern in der unmittelbaren Nachkriegszeit deutlich zu spüren. Doch akzeptierte man vorübergehend, anders als etwa in der Z wischenkriegszeit und anders auch als in den fünfziger Jahren, in der unmittelbaren Nachkriegszeit diesen Machtverlust. Die politische Dominanz der beiden Supermächte USA und UdSSR mußten zu diesem Zeitpunkt auch die Abendländer anerkennen. Zu kompensieren war dieser Machtverlust nur durch eine utopische und vor allem unkonkrete "Sendung“ des Abendlandes: Der „Reichtum der Kulturen“ sichere einen „Vorsprung des Abendlandes", der auch heute nicht eingeholt sei. ${ }^{50}$ Der christliche Geist des Abendlandes müsse in die Welt ausstrahlen, und so komme dann Europa auch wieder eine (nun ausschließlich geistig gedachte) Führungsrolle in der Welt zu.

Angesichts des am Boden liegenden Europa zogen sich die Abendländer also in den Jahren zwischen 1945 und etwa 1948 vollständig auf theologisch-kulturelle Argumentationslinien zurück. Politische Argumente im engeren Sinne blieben weitgehend ausgeklammert: Die Abendländer beschränkten sich darauf, die ihnen notwendig erscheinende Rückgliederung Deutschlands in den Kreis der abendländischen Nationen kulturell und historisch zu begründen. Dabei ähnelten die Argumente ebenso wie Wortwahl und Duktus der Artikel stark jenen der zwanziger Jahre. ${ }^{51}$ In den Augen der Abendländer hatte die von ihnen bereits nach dem Ersten Weltkrieg erhobene Forderung nach „Umkehr" durch den Zweiten Weltkrieg und den Nationalsozialismus nur an Bedeutung gewonnen. Wenn man den Deutschen durchaus auch Schuld zusprach, so lag diese vor allem darin begründet, $\mathrm{da}$ man sich nicht rechtzeitig von nationalistisch-militaristischen Traditionen abgewandt und einen abendländisch-universalistischen Neubeginn gewagt hatte. Der eigene Anteil an Diktatur und Krieg blieb dabei ebenso unthematisiert wie die Verführung der universalistischen Abendland- und Reichs-Idee durch eine nationalistische Variante in den Jahren des Nationalsozialismus. Indem die Autoren diese Traditionen völlig ausblendeten und allein an die "positiven“ Inhalte des Begriffs anknüpften, konnte man das Abendland als leuchtenden Stern präsentieren, der den Weg in die Zukunft weisen würde.

49 Schmidt, Wilhelm: Gegenwart und Zukunft des Abendlandes, in: Neues Abendland 3 (1948), S. 129-135, hier S. 130.

50 Ebenda, S. 131.

51 Als Beispiel seien etwa die Artikel Wilhelm Schmidts genannt, denen man den Abstand von knapp zwei Jahrzehnten kaum anmerkt: Ders.: Werden, Entwerden und Neuwerden des Abendlandes, in: Schönere Zukunft 6 (1930/31), S. 275 f. und S. 299 f. und ders.: Gegenwart und Zukunft des Abendlandes, in: Neues Abendland 3 (1948), S. 129-135. 


\section{Abendländische Föderalisten}

Als leuchtender Stern erschien das Abendland allerdings überwiegend Konservativen, war doch die abendländische Idee in der deutschen Geistesgeschichte traditionell ein konservatives Ordnungsmodell. Jedoch bedeutet dies nicht, daß sich die Abendländer auch selbst als konservativ bezeichneten. Mitte der zwanziger Jahre zum Beispiel läßt sich noch eine spürbare Zurückhaltung gegenüber der Verwendung des Begriffs „konservativ“ zur Charakterisierung der eigenen Positionen ausmachen. Dies hing nicht zuletzt mit der seit dem Kaiserreich im Sprachgebrauch vorherrschenden Verbindung zwischen „konservativ“ und „preußischprotestantisch" zusammen. Meist bezeichneten sich die Abendländer lediglich als „katholisch“, was allerdings nach ihrem Selbstverständnis inhaltlich eine deutlich konservative Konnotation einschloß. Erst Ende der zwanziger, Anfang der dreißiger Jahre finden wir im Umfeld der „Reichsvision“ auch eine Annäherung an den Begriff der „Konservativen Revolution“".52 Hier handelte es sich zum ersten Mal um die Einbindung des "Abendlandes“ in die Bemühungen, einen erneuerten Konservatismus zu schaffen, der über konfessionelle und parteipolitische Grenzen hinweg wirksam werden sollte. Als einheitsstiftendes Schlagwort diente in diesem Zusammenhang das „Reich“. Damit ergab sich Anfang der dreißiger Jahre eine Situation, die sich in ähnlicher Weise in den fünfziger Jahren wiederholen sollte: Nun aber diente das Abendland selbst als Integrationsbegriff für Bemühungen um einen „erneuerten“ Konservatismus.

Zwischen 1945 und etwa 1950 hingegen war es in Deutschland insgesamt um den Begriff „Konservatismus merkwürdig still“ geworden, und kaum eine politische Gruppierung bezeichnete sich selbst als konservativ. ${ }^{53}$ Auch die Abendländer machten hier keine Ausnahme. "Konservativ" war ihnen in der unmittelbaren Nachkriegszeit gleichbedeutend mit „restaurativ“, im Sinne einer Restauration der „preußisch-militaristischen“ Staats- und Gesellschaftsordnung und ihrer Werte, und konnte deshalb zur Beschreibung der eigenen Position in der zweiten Hälfte der vierziger Jahre nicht verwandt werden. Statt dessen beschrieben die Abendländer sich selbst in diesen Jahren mit Bezug auf Benedikt Schmittmann vornehmlich als „föderal“. Der Föderalismus stellte in der unmittelbaren Nachkriegszeit eines der „politischen Leitworte“ und eine der entscheidenden Theorieströmungen dar. ${ }^{54}$ Dabei handelte es sich - auch für Abendländer - um weit mehr als ein staatsrechtliches Organisationsprinzip, nämlich ein „zweiseitiges, synthetisches Gesellschaftssystem“, welches den Liberalismus und den Sozialismus in

52 Schreyvogel spricht 1924 von Reformbewegungen als Teil „Katholischer Revolution“, zitiert nach: Pöpping, Dagmar, Abendland, S. 119. Emil Franzel etwa bezog sich ganz deutlich auf die „Konservative Revolution“, vgl. Teil I, Kap. I.2.

53 Greiffenhagen, Das Dilemma des Konservatismus in Deutschland, S. 7. Siehe auch Schildt, Konservatismus in Deutschland. S. 213.

54 Herbst, Die zeitgenössische Integrationstheorie, S. 163 und S. 197. Mit dem „politischen Leitwort" zitiert Herbst Carl Jacob Burckhardt (vgl. ebenda, FN 9), wohl in Anlehnung an Heinrich Schneider, Leitbilder der Europapolitik. Bd. 1, S. 225, allerdings ohne Vermerk. Vgl. auch: Merkel, Die europäische Integration und das Elend der Theorie. 
einem dritten, ausgewogenen Modell verbinden sollte. ${ }^{55}$ Man verstand Föderalismus als eine "Weltanschauung",56 deren Leitbild die "Einheit in Vielfalt" bildete. ${ }^{57}$

Ausgehend vom personalistischen Gesellschaftsbild der katholischen Soziallehre, ${ }^{58}$ in der die einzelne Person in die soziale Gemeinschaft eingebunden ist, übernahmen die Abendländer die Vorstellung, das soziale Gefüge entwickele sich in „Lebenskreisen "59 um die Einzelpersönlichkeit herum: Gewissermaßen in Stufen, von der untersten Ebene, der Familie, über größere Gemeinschaften bis hin zum Staat und zur übernationalen Ordnung verlief so der gesellschaftliche Aufbau. Die einzelnen sozialen Gebilde, regional oder berufsständisch organisiert, sollten nach Auffassung der katholischen Soziallehre in weitmöglichstem Maße selbstverantwortlich sein. Erst wenn die Möglichkeiten der einzelnen Gesellschaftseinheit sich erschöpft hätten, dürfte und müßte die höherstehende Einheit Hilfe leisten. ${ }^{60}$ Dieses Subsidiaritätssystem stärke Solidarität und Gemeinschaft zwei für das abendländische Denken seit den zwanziger Jahren zentrale Begriffe. Eine föderal und subsidiär strukturierte Gesellschaft sollte nach den Vorstellungen der Abendländer helfen, die „formaldemokratische Vermassung " zu überwinden. ${ }^{61}$ Aber auch totalitären Tendenzen konnte nach abendländischer Auffassung auf diese Weise vorgebeugt werden: „Allein das System des universalen Föderalismus mag die Lehre vom totalen Staat überwinden, das rechte, natürliche Verhältnis der Person zur Gemeinschaft und das der Gemeinschaft zum Staat wiederherstellen." 62 Wie aber eine föderale Verfassung konkret auszusehen habe, darauf gab das Neue Abendland zwischen 1946 und 1948 kaum Hinweise. Es blieb bei Beschwörungen und allgemeinen weltanschaulichen Überlegungen. Damit entsprach die Behandlung nationaler Fragen in den ersten Jahren nach dem Zweiten Weltkrieg exakt dem Umgang mit europäischen Fragen, wo man sich ja ebenfalls „unpolitisch“ auf Überlegungen zur christlich-abendländischen Kultureinheit beschränkte.

55 Zwei Klassiker des Föderalismus, in: Neues Abendland 1 (1946), Heft 1, S. 23-25, hier S. 23.

56 Der Begriff „Föderalismus als Weltanschauung“ wurde durch Edgar Julius Jungs gleichnamige Veröffentlichung 1931 geprägt. Zur Tradition dieser „Weltanschauung “ siehe: Heil, Föderalismus als Weltanschauung.

57 In diesem Sinne auch: „Föderalismus“, in: Schrenck-Notzing (Hg.) Lexikon des Konservatismus.

58 Zur katholischen Soziallehre siehe z. B.: Furger, Christliche Sozialethik. Klüber, Katholische Gesellschaftslehre. Sutor, Politische Ethik.

$59 \mathrm{Vgl}$. im Abendland der Zwischenkriegszeit (in Auswahl). Hugelmann, Karl Gottfried: Der Sinngehalt des Föderalismus, in: Abendland 3 (1928), S. $147 \mathrm{f}$. Im Neuen Abendland: F.: Karl Oskar von Soden, in: Neues Abendland 1 (1946), Heft 3, S. 26-28, hier S. 26.

60 Vgl. insb.: Süsterhenn, Das Stufungsprinzip, in: Staat, Volk und übernationale Ordnung, S. 50-68. Zum Subsidiaritätssystem siehe: Riklin/Batlinger (Hg.), Subsidiarität. Waschkuhn, Was ist Subsidiarität.

61 Ferber, Walter, Historisch-politische Betrachtungen, in: Neues Abendland 1 (1946), Heft 2, S. 20-22, hier S. 22.

62 Ders.: Das Wesen des Föderalismus, in: Neues Abendland 1 (1946), S. 4f., hier S. 4. 
Die Abendländer legten in den Jahren 1946 bis 1948 großen Wert darauf, die langen Traditionslinien des Föderalismus in Deutschland nachzuweisen. ${ }^{63}$ Sie stilisierten ihn zum historischen Erbe der Deutschen, identifizierten ihn im Katholizismus des 19. Jahrhunderts, bei den „Vätern“ der katholischen Soziallehre wie Ketteler oder Vogelsang, aber auch in den päpstlichen Enzykliken. Bei der enormen moralischen Bedeutung, die die katholische Kirche nach dem Ende des Zweiten Weltkrieges hatte, stellte man so den abendländischen Föderalismuskonzepten geschickt glaubwürdige und vertrauenerweckende Zeugen zur Seite.

Damit war, ähnlich wie bereits in der Zwischenkriegszeit, eine stark anti-preußische Grundhaltung verbunden. Die ersten Jahrgänge des Neuen Abendlandes strotzten von Angriffen auf vermeintlich „preußische Tugenden“ wie Zentralismus, Militarismus und Nationalismus ebenso wie sie sich im Abendland der zwanziger Jahre gefunden hatten. Und in beiden Zeiten verbanden sich mit der anti-preußischen Ausrichtung konkrete politische Forderungen und Interessen. In der Zwischenkriegszeit hatten diese sich auf die Ablösung des Rheinlands von Preußen durch eine Reichsreform bezogen. ${ }^{64}$ Nach 1945 ging es den Abendländern um eine föderative Neugestaltung Deutschlands, in der nicht zuletzt Bayern, wohin sich das Zentrum abendländischer Aktivität verlagert hatte, eine erhebliche Selbständigkeit bewahren sollte. ${ }^{65}$

Einhergehend mit diesem Einsatz für ein föderalistisches Deutschland plädierten die Abendländer massiv für ein verändertes Geschichtsbild. Auch dies war zwar bereits in der Zwischenkriegszeit Bestandteil der abendländischen Idee gewesen. Die beschriebene Mittelalter-Beschwörung ist nur ein mögliches Beispiel dafür. ${ }^{66}$ In teils identischer Argumentation jedoch kam diesem Thema in der unmittelbaren Nachkriegszeit ungleich größere Bedeutung zu. Nun schien sich die seit Jahrzehnten in katholisch-konservativen Kreisen beschworene Auffassung einer seit der Aufklärung „abwärts“ verlaufenden Entwicklung durch Nationalsozialismus, Zweiten Weltkrieg und Holocaust bestätigt zu haben. Die grundsätzliche geschichtsphilosophische Überzeugung, daß bereits mit der Aufklärung die endgültige Abwendung des Menschen von Gott erfolgt und damit der Weg in die Katastrophen des 20. Jahrhunderts vorgezeichnet gewesen sei, wurde in diesem Zusammenhang ergänzt durch eine konkrete historische Schuldzuweisung. Die Tradition von Machtpolitik und Militarismus, mit der Preußen seit dem 19. Jahrhundert die deutsche Geschichte dominiert habe, verbunden mit der Fixierung auf den kleindeutschen Nationalstaat, habe zu deren Übersteigerung und Perversion im „Dritten Reich“ geführt. Nach dem Zusammenbruch all dieser Traditionen habe nun eine völlige Umorientierung zu erfolgen. Neben die Verchristlichung der Gesellschaft müsse insbesondere eine „Revision des preußisch-militaristi-

63 Auch damit standen die Abendländer nicht allein, siche: Huhn, Lernen aus der Geschichte.

64 Weinzierl, Hans: Reichsreform und Deutsche Frage, in: Der Ring 5 (1932), S. 91 ff. Ders.: Kettelers Stellung zur Deutschen Frage, in: Allgemeine Rundschau vom 27. 8. 1932.

$65 \mathrm{Vgl}$. z. B. Heydte, Das Weiß-Blau-Buch zur deutschen Bundesverfassung.

66 Emil Franzels „Abendländische Revolution“ bspw. begann mit den Worten: „Diese Schrift will ein neues Geschichtsbild zur Diskussion stellen“, vgl. ders., Abendländische Revolution, S. 7. 
schen Geschichtsbildes“ treten. Bereits in der ersten Ausgabe des Neuen Abendlandes wurde dies als Aufgabe der Zeitschrift definiert: „Es geht vornehmlich darum, der seit Treitschke, Droysen und Sybel verpreußten deutschen Geschichtsauffassung entgegenzutreten [...]. Unsere Aufgabe soll es sein, den Ungeist eines preußischen Hochmutes, der Geschichtsfälschung und des vermassenden Militarismus zu bekämpfen. "67 Dabei befanden sich die Abendländer mitten in der Auseinandersetzung, welche die Geschichtswissenschaft selbst um eben jene „Revision“ austrug, ${ }^{68}$ ein Wort, welches in den ersten Nachkriegsjahren geradezu inflationär verwendet wurde. ${ }^{69}$ Schon kurz nach dem Zusammenbruch hatten Vertreter aller Richtungen der deutschen Geschichtswissenschaft verlangt, die traditionelle Sicht auf die deutsche Geschichte der letzten Jahrhunderte, die Orientierung am Nationalstaat und an reiner Machtpolitik zu überdenken. Wie allerdings eine Revision auszusehen habe, darüber gingen die Meinungen bald deutlich auseinander. Es ergab sich ein Konflikt zwischen Vertretern einer protestantischpreußisch-nationalstaatlichen und einer katholisch-föderalen Richtung. Gerhard Ritter, der sich bereits kurz nach Kriegsende zwar für ein „Überdenken“, aber gegen "vorschnelle Geschichtskonstruktionen" ausgesprochen hatte, zu denen er auch jene des "Abendlandes" zählte, ${ }^{70}$ geriet für diese Thesen und sein Festhalten an der Kategorie des Nationalstaates nicht nur, aber gerade auch im Nenen Abendland unter Beschuß.71 Direkte Angriffe gegen Ritter waren in den ersten Ausgaben keine Seltenheit; Artikel, die eine Revision des Geschichtsbildes forderten, erschienen in jedem Heft. ${ }^{72}$ Die abendländischen Positionen fanden jedoch bereits in den Jahren der Besatzung innerhalb der Geschichtswissenschaft keine Unterstützung. Das abendländische Geschichtsverständnis entzog sich „dem methodischen Instrumentarium der professionalisierten Geschichtswissenschaft weitgehend ". ${ }^{73}$ Ein vorwiegend moralisch argumentierendes und die Historie für den Dienst an der Politik instrumentalisierendes Verständnis konnte sich in der Geschichtswissenschaft nicht durchsetzen. Die etablierten Historiker waren schon bald nicht mehr zu einer völligen Umorientierung bereit, zumal weder methodisch noch konzeptionell wirkliche Alternativen vorlagen; jedenfalls bildete

67 Naumann, Johann Wilhelm: Neues Abendland, in: Neues Abendland 1 (1946), S. 1-3, hier S. 3.

68 Zur Entwicklung der deutschen Geschichtswissenschaft nach dem Zweiten Weltkrieg siehe z.B.: Schulin, (Hg.), Deutsche Geschichtswissenschaft. Schulze, Deutsche Geschichtswissenschaft.

69 Schulze, Deutsche Geschichtswissenschaft, S. 169 und S. 207-227.

70 Ebenda, S. 63/64. Zu Gerhard Ritter: Cornelißen, Gerhard Ritter.

71 Diese Auseinandersetzungen sind nach Winfried Schulze bisher nur in Ansätzen aufgearbeitet, böten aber eine Möglichkeit, die Entwicklung der deutschen Geschichtswissenschaft nach 1945 auch auf konfessionelle Gegensätze hin zu untersuchen.

72 Vgl. u. a.: Naumann, Johann Wilhelm: Neues Abendland, in: Neues Abendland 1 (1946), Heft 1, S. 1-3. Revision der Geschichtsauffassung, in: Neues Abendland 1 (1946), Heft 3, S. $27 \mathrm{f}$. Revision der Geschichtsschreibung, in: Neues Abendland 1 (1946), S. 24 f. Deuerlein, Ernst: Preußen oder Europa, in: Neues Abendland 2 (1947), S. 265-269. Folgen der Säkularisierung, in: Neues Abendland 3 (1948), S. 84-86. Franzel, Emil: München 1938, in: Neues Abendland 3 (1948), S. 297-302, hier S. 301.

73 Schulze, Deutsche Geschichtswissenschaft, S. 211 und S. 218. 
die "Abkehr vom Christentum“ als Erklärungsmodell keine. Dennoch kann man mit Winfried Schulze davon ausgehen, „daß sich die bedeutendste Revisionsbewegung der Jahre nach 1945 am Abendlandbegriff orientierte". ${ }^{4}$

\section{Die Abendländische Bewegung in den fünfziger Jahren}

Die frühe Nachkriegszeit war für die Abendländische Bewegung noch eine Phase der Sammlung gewesen. Zwar finden wir in den in der Zeitschrift Neues Abendland vertretenen Konzepten manch wohlbekanntes Argument, und unter den Autoren manch bekannten Namen. Die Organisation der Abendländer ging aber über die Herausgabe des Neuen Abendlandes nicht hinaus, man war also ähnlich unverbunden wie der Abendland-Kreis der Weimarer Republik. Doch selbst wenn man über eine engere Organisationsstruktur nachgedacht hätte, wäre sie in den ersten Nachkriegsjahren mit ihren Beschränkungen kaum zu verwirklichen gewesen. Diese Zeitumstände prägten auch die inhaltlichen Positionen des Neuen Abendlandes. Denn trotz aller vertrauten Argumentationsmuster blitzen in den ersten Jahrgängen des Neuen Abendlandes zum Teil auch unerwartet "linke“ Ideen auf. Was früher und auch später nicht denkbar war, etwa die Forderung von Gewinnbeteiligung von Arbeitnehmern, der Ruf nach Neuverteilung des Eigentums oder generell der Wunsch nach wirtschaftlicher Neuordnung durch Sozialisierung - in der frühen Nachkriegszeit gehörten solche Ideen vorübergehend zum „Abendland“. Dabei scheint diese Phase ausgesprochen stark beeinflußt gewesen zu sein von einer gesamtgesellschaftlichen Strömung, in welcher die Rede von der wirtschaftlichen Neuordnung angesichts der Nachkriegsnöte opinio communis war. Das „Ahlener Programm“ der CDU von 1947 oder die Bestimmungen in verschiedenen westdeutschen Landesverfassungen sind hier nur Beispiele. ${ }^{75}$ Auch der westdeutsche Katholizismus machte hier keine Ausnahme, sondern schloß sich in dem Ruf nach einem „christlichen Sozialismus“ an. ${ }^{76}$

Solche Argumentationen verloren sich im Neuen Abendland indes sehr schnell wieder. So erschienen die ersten Jahrgänge der Zeitschrift als inhaltlich zum Teil recht uneinheitlich, sie ergeben kein ideologisch klares Bild. Dies hatte seinen Grund freilich auch in den häufigen Wechseln in der Redaktion. Ändern sollte sich das erst in dem Moment, in dem Emil Franzel 1948 zum Neuen Abendland fand. Nun begann die Blütezeit der Abendländischen Bewegung in der Nachkriegszeit, und all jene Elemente der abendländischen Idee, die wir als ihre Wurzelstränge ausmachen konnten, tauchten wieder auf und bildeten den Kern des "Abendlandes“ als Vision eines zukünftigen Europas.

${ }^{74}$ Ebenda, S. 222.

75 Vgl. Focke, Sozialismus aus christlicher Verantwortung.

76 Langner, Wirtschaftliche Ordnungsvorstellungen im deutschen Katholizismus, insb. S. 27-55. 


\section{Das Neue Abendland auf dem Weg zum rechten Rand der politischen Zeitschriftenlandschaft}

Mit dem Einzug Emil Franzels in die Chefredaktion des Neuen Abendlandes 1948 veränderte die Zeitschrift ihr Profil deutlich. Unter seiner Leitung rückte das Blatt an den „äußersten rechten Rand der katholischen Zeitschriftenlandschaft". ${ }^{77}$ Anfangs dominierte Franzel beinahe jede Ausgabe mit einer Vielzahl von Artikeln und schrieb, wie bereits seit Jahrzehnten, mit Vorliebe unter zahlreichen Pseudonymen. ${ }^{78}$ Das katholisch-theologische Moment trat zurück, während gleichzeitig die Tagespolitik ins Zentrum rückte. Damit einhergehend wurde der Ton insgesamt deutlich schärfer, die vertretenen Positionen deutlich konservativer. Außerdem fanden, entsprechend Franzels Herkunft und ideologischer Ausrichtung, nun erstmals „Mitteleuropa“, das Schicksal der Vertriebenen sowie die Idealisierung monarchischer Vorbilder Eingang in das Neue Abendland. Der Bezug auf Schmittmann, mit dem Franzel nichts verband, hingegen verschwand. Schließlich machte Franzel auch den Antikommunismus zum „typischen“ Element des Neuen Abendlandes. Hier fielen biographische Prägungen des Chefredakteurs und die weltpolitische Entwicklung im Zeichen des Kalten Krieges zusammen.

Die Jahre von 1948 bis 1951 wurden so für das Neue Abendland zu einer Transformationsphase: Von den inhaltlich disparaten ersten Jahrgängen, in denen sich zum Teil noch ausgesprochen „linke“ Stellungnahmen fanden, schlug die Zeitschrift unter Emil Franzel einen „dezidiert rechtskonservativen Kurs"79 ein. Die Bedeutung, die Franzel in diesem Prozeß zukam, ist kaum zu überschätzen. Erst indem er die Zeitschrift "auf Kurs" brachte, konnte das Neue Abendland zum Sprachrohr einer konservativ-katholischen Gruppierung werden, die sich seit Anfang der fünfziger Jahre um die Zeitschrift bildete. Damit sollte dann erstmals ein fest organisierter Zirkel entstehen, in dem sich die Träger abendländischen Denkens versammelten und der unter dem Namen Abendländische Bewegung bekannt geworden ist.

Damit fand das „Abendland“ endlich zu eigenen und institutionalisierten Organisationsformen. Der Abendland-Kreis der Zwischenkriegszeit hatte sich um die Zeitschrift Abendland geschart. Darüber hinaus lassen sich keine spezielleren Organisationsformen dieser Gruppe nachweisen. $\mathrm{Zu}$ erklären ist dies durch die Tatsache, daß der Abendland-Kreis nach 1918 weitaus enger mit katholischen Laienverbänden, wie dem Katholischen Akademikerverband, aber auch der GörresGesellschaft, verbunden gewesen war. Im Gegensatz dazu hat die abendländische Bewegung nach 1945 diesen engen Anschluß an das katholische Verbandsleben nicht mehr gesucht. In den ersten Jahren nach Kriegsende, als sich das politischgesellschaftliche Leben in den westlichen Besatzungszonen nur langsam wieder organisierte, und Reisen nur unter erschwerten Bedingungen möglich waren, reichte die Publikation einer Zeitschrift weiter als ein kaum zu realisierendes akti-

77 Brelie-Lewien, Katholische Zeitschriften in den Westzonen, S. 207.

78 So z. B. Spectator, Pacificus, Lynkens, Franz Murner, Timon, Witiko, Corolian, Fortinbras, Franciscus, Bohemicus, Capitaneus.

79 Schildt, Zwischen Abendland und Amerika, S. 34. 
ves „Verbandsleben“, das sich ohnehin nur auf engstem geographischem Raum hätte konzentrieren können. So begann die organisatorische Formation erst nach Gründung der Bundesrepublik Anfang der fünfziger Jahre. Zu diesem Zeitpunkt war der Kontakt zur katholischen Kirche zwar über die Mitgliedschaft verschiedener ihrer Vertreter in der abendländischen Bewegung gegeben, doch waren die neuen treibenden Kräfte etwa der Abendländischen Aktion oder Abendländischen Akademie nicht mehr in jenem Maße der katholischen Kirche als Organisation und ihrer Verbandsstruktur verbunden, wie es in der Zwischenkriegszeit der Fall gewesen war. ${ }^{80} \mathrm{Wichtig}$ aber ist, daß die in vielem offene, noch ungestaltete $\mathrm{Si}$ tuation in Westdeutschland Anfang der fünfziger Jahre den Abendländern offenbar das Gefühl gab, mit einer eigenständigen Organisation durchaus erfolgreich sein zu können. Die Verschiebung der Bevölkerungsstruktur hin zum Katholizismus, der Sieg der neugegründeten CDU bei den Bundestagswahlen 1949, ein rheinisch-katholischer Kanzler, die offenkundige Europa-Begeisterung und die Präsenz des Abendland-Begriffes im öffentlichen Sprachgebrauch - all dies schienen ideale Voraussetzungen für die erfolgreiche Arbeit einer eigenen Organisation der Abendländischen Bewegung.

\section{Die Abendländische Aktion}

Nach der rechtskonservativen Ausrichtung durch Franzel geriet das Neue Abendland allerdings 1950 erst einmal in wirtschaftliche Schwierigkeiten: Ob dies auf Folgen der Währungsreform zurückzuführen ist oder auf durch die neuen inhaltlichen Akzentsetzungen abgewanderte Leser, läßt sich nicht sagen. Die Angaben Emil Franzels, der Verleger Naumann hätte immer mehr Kapital in die katholische Tageszeitung Deutsche Tagespost investiert, so daß das Neue Abendland auf den "Aussterbe-Etat" gerutscht sei, entbehrt nicht einer gewissen Logik: ${ }^{81} \mathrm{Nau}-$ mann hatte der Herausgabe von katholischen Tageszeitungen wohl immer mehr Bedeutung zugemessen als der einer Monatsschrift. Zwar entschloß man sich noch, den Heftpreis zu halbieren, um so den Abonnentenstamm zu vergrößern doch ohne Erfolg. Im April 1951 wurde das Neue Abendland schließlich an Erich Fürst von Waldburg-Zeil verkauft. Dieser nannte nun mit dem Neuen Abendland, wie bereits mit dem Geraden Weg in den zwanziger Jahren, wiederum eine „Weltanschauungszeitschrift" sein eigen - und wie in den späten zwanziger Jahren unterstützte und förderte der Fürst die politische Ausrichtung des Blattes im Sinne eigener Vorstellungen. Um nun allerdings diese Vorstellungen durchzusetzen, bekam das Neue Abendland einen neuen Herausgeber, den bereits erwähnten Gerhard Kroll. ${ }^{82}$ Kroll gehörte ins Zentrum jener katholischen Streiter, die nach dem Ende des Zweiten Weltkrieges die „Revision“ des nationalstaatlich orientierten Geschichtsbildes für unerläßlich hielten. Als kommissarischer Leiter des Instituts

80 Emil Franzel oder Gerhard Kroll waren z. B. zwar fest im katholischen Glauben verwurzelt, hatten aber nicht jene Prägung durch die katholischen Verbände, die den AbendlandKreis der Zwischenkriegszeit geprägt hatte.

81 Franzel, Gegen den Wind der Zeit, S. 424.

82 Vgl. Teil I, Kap. I.2. 
zur Erforschung der nationalsozialistischen Zeit, des späteren Instituts für Zeitgeschichte, geriet der Nicht-Historiker Kroll Ende der vierziger Jahre insbesondere mit Gerhard Ritter in Konflikt. Es ging um die Besetzung der Stelle des ersten Institutsvorsitzenden, ein Posten, den Kroll für sich vorgesehen hatte, was allerdings auf den erbitterten Widerstand Ritters traf. ${ }^{83}$ Den Kampf um eine „Befreiung“ der deutschen Geschichtswissenschaft von ihren „preußisch-nationalen" Traditionen verlor der CSU-Mann Kroll und zog sich dann in jenes publizistische Lager zurück, welches seinen Auffassungen am nächsten stand. Die antipreußische Ausrichtung des Neuen Abendlandes kam ihm entgegen, und die Zeitschrift bot ihm ein exzellentes Forum, um den „Kampf“ gegen die „verpreußte Restauration“, die er allenthalben aufdeckte, weiterzuführen. Hinzu kam das katholische Fundament der Zeitschrift. Kroll, der ähnlich wie Emil Franzel vor 1933 Mitglied der SPD gewesen war, hatte sich im Verlauf des „Dritten Reiches“ dem Katholizismus und der katholischen Soziallehre angenähert. Ähnlich wie Fritz Gerlich, der Chefredakteur des Geraden Wegs, den Waldburg-Zeil Anfang der dreißiger Jahre gegründet und finanziert hatte, entwickelte sich auch Kroll - man ist versucht zu sagen: in typischer Renegatenmanier - zum katholischen Vorkämpfer. Kroll und Waldburg-Zeil scheinen sich im übrigen, ebenso wie Gerlich und Waldburg-Zeil, aus dem „Konnersreuther Kreis“ gekannt zu haben. ${ }^{84}$ So war es wohl auch Kroll, der Waldburg-Zeil auf das Neue Abendland, seine desolate finanzielle Lage und die sich daraus ergebenden Möglichkeiten aufmerksam machte. ${ }^{85}$

Gerhard Kroll zog mit Übernahme der Herausgeberschaft zunehmend auch in publizistischer Hinsicht die Zeitschrift an sich, ganz im Gegensatz zu dem früheren Herausgeber Naumann. Diese Ansprüche Krolls liefen der Stellung Emil Franzels schon bald entgegen, und es kam zu Rivalitäten zwischen den beiden selbst- und machtbewußten Männern. Franzel verließ das Neue Abendland, wie er selbst schreibt, "nach einem grundsätzlichen Konflikt mit dem Herausgeber" .86 Allerdings kehrte Franzel 1956 zurück und blieb auch in der Zwischenzeit der Abendländischen Bewegung treu, indem er an Tagungen der Abendländischen Akademie oder des CEDI teilnahm und publizistisch darüber berichtete. Nicht zuletzt redigierte er die Dokumentation der Woche, die Zeitschrift des CEDI. Neuer Chefredakteur des Neuen Abendlandes wurde der bereits erwähnte Historiker Helmut Ibach. ${ }^{87}$

Dem Aktivitätsdrang Gerhard Krolls reichte die Publikation einer Zeitschrift indes nicht aus. Die sich um Waldburg-Zeil und Kroll bildende Gruppierung beschloß Anfang der fünfziger Jahre, über die Gründung von Organisationen gezielt weitere Kreise zu erreichen, als dies mit der Publikation einer Zeitschrift möglich war. Kroll kündigte in der ersten Nummer des Nenen Abendlandes, die er heraus-

${ }^{83}$ Schulze, Deutsche Geschichtswissenschaft, S. 229-242. Zur Gründung des Instituts für Zeitgeschichte: Möller/Wengst (Hg.), 50 Jahre Institut für Zeitgeschichte. Auerbach, Die Gründung des Institutes für Zeitgeschichte.

${ }^{84}$ Vgl. Teil I, Kap. I.2.

85 Bewerbung Gerhard Krolls beim Bundesverteidigungsministerium, 15. 9. 1955, ACDP, Nachlaß Gerhard Kroll, I-153-001/1.

${ }^{86}$ Franzel, Gegen den Wind der Zeit, S. 424.

87 Schildt, Zwischen Abendland und Amerika, S. 61. Vgl. Teil I, Kap. I.2. 
gab, den Lesern an, „daß die geistige Richtung unverändert“ bleibe, daß man allerdings nun „in die Phase kämpferischer Auseinandersetzungen eintrete“. ${ }^{88}$ Man annoncierte die Gründung einer Abendländischen Aktion. Bei dieser sollte es sich „um eine Vereinigung von Kräften [handeln], die [beabsichtigte], nicht nur die Ursachen der gegenwärtigen katastrophalen Situation der Gesellschaft genau zu untersuchen, sondern aus dieser Bilanz auch die nötigen konstruktiven Folgen zu ziehen" .89 Wie diese "konstruktiven Folgen" aussehen sollten, machte Kroll in zwei kleinen Schriften deutlich, ${ }^{0}$ in denen er Ordnungsmodelle vorschlug, die, in jeder Beziehung antimodern, die Errungenschaften der Moderne vom Parlamentarismus bis zur Großindustrie überwinden helfen sollten.

Am 25. August 1951 fand die Gründungsversammlung der Abendländischen Aktion in München statt. Deren Banner zierte auf weißem Grund das rote Georgskreuz, in dessen goldenem Zentrum sich der Doppeladler befand: „Wir haben ein Symbol gewählt, das voll des Bezugs zu unserer Geschichte ist und das uns auszudrücken scheint, was wir wollen: Das Bekenntnis zu deutscher Staatlichkeit in der Bejahung übervölkischer Rechtsordnung, denn das ist das alte, jahrtausendalte Symbol des Doppeladlers [...], umschlossen [...] durch das Kreuz, ausdrükkend die Überzeugung, daß eine Politik den sittlichen Boden verliert, wenn sie

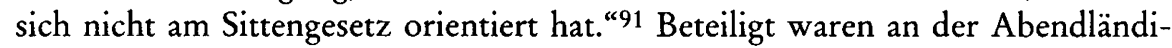
schen Aktion auch zahlreiche Mitglieder der späteren Abendländischen Akademie. ${ }^{92}$ Auch eine Verbindung zum ebenfalls 1952 ins Leben gerufenen Europäischen Dokumentations- und Informationszentrum (CEDI) bestand, und so verkündete der Briefkopf der Aktion den Anschluß an ein „übernationales Comité zur Verteidigung der christlichen Kultur" ${ }^{\circ 93}$ Kroll wies übrigens darauf hin, daß nach seiner Übernahme der Herausgeberschaft des Neuen Abendlandes von vorneherein die parallele Gründung der Aktion und der Akademie geplant gewesen sei: „Ich erblickte in der Möglichkeit einer eigenen Zeitschrift ein geeignetes Instrument, um jenes Gedankengut zu vertreten, daß ich für eine Erneuerung als notwendige Voraussetzung ansah. Die Zeitschrift bildete indessen nur ein Instrument der beabsichtigten geistigen Erneuerung, hinzu kamen die Gründung der Abendländischen Akademie und der Abendländischen Aktion. Während die Aktion [...] mehr die Verbesserung der politischen und sozialen Verhältnisse anstrebte, war die Akademie als ein geistiges Forum gedacht, das die grundsätzliche Voraussetzung zu einer Überwindung der babylonischen Sprachverwirrung um

88 An die Leser, in: Neues Abendland 6 (1951), S. 145.

89 Abendländische Aktion. Zur Gründung am 25. 8. 1951 in München, in: Neues Abendland 6 (1951), S. 508-512, hier S. 508.

90 Kroll, Grundlagen der abendländischen Erneuerung. Ders., Das Ordnungsbild der Abendländischen Aktion.

91 Georg Stadtmüller bei der ersten öffentlichen Kundgebung der Abendländischen Aktion, zit. nach: Zur ersten Kundgebung der Abendländischen Aktion am 4. 3. 1952 in München, in: Neues Abendland 7 (1952), S. 242-245, hier S. 242.

92 Neben der Finanzierung durch Erich Fürst Waldburg-Zeil waren etwa Friedrich August Freiherr von der Heydte, Georg Stadtmüller und Georg von Gaupp-Berghausen Mitglieder der Aktion.

93 Bspw. Brief Gaupp-Berghausen, Abendländische Aktion, an Hermann Pünder, 10.6. 1963, BA N 1005/538. 
den weltanschaulichen Bereich schaffen und zugleich die Christen aller Konfessionen einander näher [...] bringen" sollte. ${ }^{94}$

Über Vorträge und Diskussionsforen versuchte die Abendländische Aktion in den folgenden Monaten, auf Politik und Gesellschaft Einfluß zu nehmen. Doch noch vor ihrer ersten öffentlichen Kundgebung am 4. März 1952 geriet sie, insbesondere wegen der beiden Schriften Krolls, in die öffentliche Kritik. ${ }^{95}$ Eine deutlich artikulierte Ablehnung der Realität der frühen fünfziger Jahre und das Ziel einer vollständigen Veränderung der Gesellschafts- und Staatsordnung scheinen die Popularität der Abendländischen Aktion nicht gesteigert zu haben. Eher im Gegenteil: Die positive Resonanz blieb insgesamt gering, wirklich aktiv konnte die Aktion nicht werden. ${ }^{96}$ Außerdem kam es offenbar recht bald zu Spannungen zwischen Kroll und Waldburg-Zeil, die vermeintliche Interessenkongruenz war wohl doch nicht in allen Bereich so groß, wie man gedacht hatte. Kroll maß - im Gegensatz zu Waldburg-Zeil - der europäischen Dimension des „Abendlandes“ relativ wenig Bedeutung bei und konzentrierte seine Arbeit vorwiegend auf Wirtschafts- und Sozialreformen. Hier setzte er sich, sehr zum Ärger des auch unternehmerisch tätigen Waldburg-Zeil, für Gewinnbeteiligungen von Arbeitnehmern ein, und über dieser Frage kam es zum Bruch zwischen beiden. Erst legte Kroll den Vorsitz der Abendländischen Aktion nieder; nach weiteren Spannungen folgte die Entlassung als Herausgeber des Neuen Abendlandes. ${ }^{97}$ "Das war zugleich das Ende der Abendländischen Aktion, die formell zwar zunächst noch weiterbestand, ihre Mitglieder indessen in die Abendländische Akademie überführte und selbst jede Tätigkeit einstellte."98

\section{Die Abendländische Akademie}

Daß die Aktion mit ihrem offensiv vertretenen Veränderungsanspruch bereits unmittelbar nach ihrer Gründung in die Kritik geraten war, mag den Entschluß im Umfeld Waldburg-Zeils verstärkt haben, zusätzlich die Abendländische Akademie zu gründen, welche die Möglichkeit zum Austausch auf intellektuell-wissenschaftlichem Niveau bieten sollte. Dies war ein defensiveres Konzept als das der Abendländischen Aktion, es bot aber gerade aus diesem Grunde die Chance, wirkungsvoller arbeiten zu können. Man wollte „Menschen, die sich zum Geist des Abendlandes bekennen, eine Arbeitsstätte und eine sichtbare Heimat ihres gemeinsamen Bemühens zur Verfügung stellen". ${ }^{99}$ Ziel war es, den einzelnen Mitgliedern und Tagungsbesuchern Europa als das „Abendland“ erfahrbar zu ma-

94 Bewerbung Gerhard Krolls beim Bundesverteidigungsministerium, 15. 9. 1955, ACDP, Nachlaß Gerhard Kroll, I-153-001/1.

$95 \mathrm{Vgl}$. die abendländische Verteidigung: Aus der Abendländischen Aktion, in: Neues Abendland 6 (1951), S. 652 f. Zur ersten Kundgebung der Abendländischen Aktion, in: Neues Abendland 7 (1952), S. 242-245.

96 So auch Schildt, Zwischen Abendland und Amerika, S. 46.

97 Vgl. Bewerbung Gerhard Krolls beim Bundesverteidigungsministerium, 15.9. 1955, ACDP, Nachlaß Gerhard Kroll, I-153-001/1.

98 Ebenda.

99 Die Abendländische Akademie. Wesen, Ziel und Organisation, Juli 1953, S. 3. 
chen, indem „Persönlichkeiten des geistigen Lebens aller Nationen, die sich für eine Erneuerung aller Lebensbereiche in abendländischem Geiste aus den Grundwahrheiten des christlichen Glaubens einsetzen, [zusammengebracht] und eine geistige Klärung der Grundfragen abendländischer Neuordnung [herbeigeführt werden sollte]“. ${ }^{100}$ Daraus ergab sich, neben der europäischen Ausrichtung auch ein formell ökumenischer Anspruch - der allerdings letztlich nicht eingelöst werden konnte.

Über die Organisationsform der Abendländischen Akademie lassen sich im Gegensatz zur Aktion konkrete Angaben machen. ${ }^{101}$ Ihr erster Vorsitzender war der bereits bekannte Friedrich August Freiherr von der Heydte. Dieser leitete den Vorstand, der das oberste Entscheidungsgremium bildete und über die "geistigen Richtlinien" der Akademiearbeit entschied. Zum Vorstand gehörten neben von der Heydte zwei Vertreter der Familie Waldburg-Zeil, der Sohn Erich von Waldburg-Zeils, Georg, und Pater Franz Georg Waldburg, ein Vetter Erichs. Hinzu kam mit Eberhard Fürst von Urach (als Leiter des Kuratoriums) ein weiterer Vertreter des süddeutschen Adels. Der Philosophie-Professor Wolfgang Heilmann, ${ }^{102}$ die bereits erwähnten Georg Stadtmüller, Helmut Ibach und der Bischof der lutherischen Landeskirche Wilhelm Stählin bildeten die anderen Mitglieder des Vorstands, der schließlich durch Georg Ritter von Gaupp-Berghausen als Generalsekretär der Abendländischen Akademie komplettiert wurde. Will man die Familie Waldburg-Zeil als finanzielles Herz der Abendländischen Bewegung bezeichnen, so kann man Gaupp-Berghausen getrost als deren organisatorisches bezeichnen: Vom Anfang der fünfziger Jahre bis zum Ende des hier betrachteten Zeitraums 1970 lag die Geschäftsführung von Abendländischer Akademie und CEDI größtenteils in Händen Gaupp-Berghausens.

Ein Beirat beriet den Vorstand und die Akademieleitung vornehmlich in inhaltlichen Fragen. In diesem Gremium finden wir die bereits erwähnten Hans Assmussen, Ernst von Hippel, Johannes Pinsk, Michael Schmaus und Thomas Michels. ${ }^{103}$ Hinzu kamen der Historiker Karl Buchheim und Kirchenrat Karl Bernhard Ritter. Daß man den Anspruch erhob, übernational - „abendländisch“ - tätig zu sein, drückte sich auch in der Mitgliedschaft von „Beiräten“ aus anderen europäischen Ländern aus. ${ }^{104}$ Ein Kuratorium schließlich unterstützte die Tätigkeit des Vorstands und beriet diesen vor allem in Fragen der Verwaltung und Finanzierung. Es sollte nach der Satzung der Abendländischen Akademie aus ,hervorragenden Persönlichkeiten des geistigen, kulturellen, politischen oder wirtschaftlichen Lebens bestehen", und in der Tat setzte es sich aus einer ganzen Reihe prominenter Persönlichkeiten des öffentlichen Lebens der jungen Bundesrepublik

100 Ebenda, S. 13.

101 Vgl. zum folgenden: Ebenda. Und: Weg und Ziel der Abendländischen Akademie.

102 Vgl. Heilmann, Versuch einer Wesensbestimmung des Abendlandes.

103 Vgl. Teil I, Kap. I.1. und Teil I, Kap. I.2.

104 Aus Österreich Thomas Michels, aus der Schweiz Werner Bergengruen, Max Picard, Alfons Rosenberg; aus Frankreich M.A. Dauphin-Meunier, Comte Robert d'Harcourt, Paul Lesourd, Prof. Gabriel Marcel; aus Spanien Alfredo Sánchez Bella, Prof. Francisco Elias de Tejada y Spinola; aus England Valentin Tomberg. 
zusammen, darunter eine erstaunliche Anzahl von Politikern der CDU/CSU, 105 Vertretern der katholischen Kirche ${ }^{106}$ und Adeligen. ${ }^{107}$ Die große Anzahl von Adeligen in der Abendländischen Bewegung, die schon Zeitgenossen auffiel, 108 hatte ihren Ursprung neben „attraktiven“ konservativen Positionen auch darin, $\mathrm{da}$ mit der Familie Waldburg-Zeil eine in Süddeutschland einflußreiche Adelsfamilie an der Spitze der Akademie stand, ihr Schloß für Veranstaltungen zur Verfügung stellte ${ }^{109}$ und die in Adelszirkeln nicht unerhebliche Netzwerkbildung nutzen konnte, um Standesgenossen zur Teilnahme zu motivieren. Neben Vertretern des europäischen Auslandes ${ }^{110}$ waren im Kuratorium der Akademie schließlich auch einige Protestanten vertreten.111 Jedoch hat bereits Axel Schildt darauf hingewiesen, daß diese protestantischen Abendländer wohl eher als "randständige" denn als typische Vertreter ihrer Kirche gelten konnten. Führende Kräfte der evangelischen Kirchen, aber auch evangelische Vertreter der CDU wahrten dagegen immer Distanz zur Abendländischen Bewegung. ${ }^{112}$

Die Mitgliedschaft im Kuratorium war nicht an eine Mitgliedschaft in der Abendländischen Akademie gebunden. Insofern ist davon auszugehen, daß ein erheblicher Teil der Kuratoriumsmitglieder nicht aktiv und regelmäßig am Akademieleben teilnahm. Letztendlich wird man nur einen kleineren Kreis als festen abendländischen Kern ausmachen können. ${ }^{113}$ Dieser Kreis legte selbstverständlich auf die klangvollen Namen im Kuratorium wert. Nicht zuletzt konnte die

105 Z.B. Heinrich von Brentano (Fraktionsvorsitzender der CDU im Bundestag, ab 1955 Bundesaußenminister), Alois Hundhammer (CSU, Präsident des Bayerischen Landtages), Hans Hutter (CSU, Oberbürgermeister von Eichstätt), Richard Jaeger (CSU, später Vizepräsident des Deutschen Bundestages), Hans-Joachim von Merkatz (DP/CDU, später Bundesratsminister), Hermann Pünder (CDU), Hans Schuberth (CSU, Bundespostminister), Theodor Steltzer (CDU, Ministerpräsident a.D. von Schleswig-Holstein), Theodor Oberländer (BHE/CDU, Bundesvertriebenenminister), Franz-Joseph Wuermeling (CDU, Bundesfamilienminister).

106 Z.B. Basilius Ebel (Abt von Maria Laach), Lorenz Jaeger (Erzbischof von Paderborn), Hugo Lang (Abt von St. Bonifaz und Andechs, München), Joseph Schröffer (Bischof von Eichstätt).

107 Neben Vertretern des Hauses Waldburg-Zeil z.B. Eberhard Fürst von Urach, Freiherr Elimar von Fürstenberg, Rudolf Lodgman von Auen (Vorsitzender des Verbandes der Landsmannschaften), Hasso von Manteuffel, Walter von Keudell, Ernst von Hippel, Hans-Joachim von Merkatz.

108 Vgl.: Die missionäre Monarchie, in: Der Spiegel, 10. 8. 1955.

109 Beispielsweise am 10. 9. 1951 zu einem sog. „Gespräch über abendländische Erneuerung “, zit. nach: Neues Abendland 6 (1951), S. 585. Auch diverse CEDI-Veranstaltungen fanden auf Schloß Zeil statt. Vgl. auch das Protokoll der Kuratoriums- und Beiratssitzung der AA, 22. 11. (Jahr nicht lesbar), auf der es hieß, Waldburg-Zeil würde „der Akademie ein eingerichtetes Schloß mit 40 Räumen zur Verfügung stellen und auch dessen Erhaltung weiterhin selbst tragen“. BA NL Keudell (N1243).

110 Aus Österreich Gustav Canaval, Theodor von Hornbostel, Carl Baron Karwinsky, Erik von Kuehnelt-Leddhin, Peter Graf Revertera, Alfons Tomicic-Dalma; aus Frankreich René Gillouin, aus Liechtenstein Heinrich Prinz von Liechtenstein.

111 So z. B. Wilhelm Stählin (ehem. Landesbischof von Oldenburg), Hans Assmussen, Hans Dombois, Karl-Bernhard Ritter oder auch Hans-Joachim von Merkatz.

112 Schildt, Zwischen Abendland und Amerika, S. 47.

113 Dazu gehörten neben den Waldburg-Zeils und von der Heydte, Merkatz und Franzel vor allem auch die Mitglieder des CEDI, vgl. Teil I, Kap. II.3. 
„Randmitgliedschaft“" etwa dem engeren Kern Kontakte verschaffen und auf diese Weise Anliegen weitertragen. Da sich die Abendländer, im Gegensatz zur EuropaUnion, die auch in weiten Bevölkerungskreisen wirken wollte, als intellektuelle Elite verstanden, die Anregungen zur gesellschaftlichen Neugestaltung geben wollte, bemühte man sich immer wieder um Politikberatung auf höchster Ebene. ${ }^{114}$ Dies sollte zum Beispiel über verschiedene Referate für Kultur, Kunst und Geistesgeschichte (unter Leitung Wolfgang Heilmanns), für übervölkische Ordnung (Georg Stadtmüller), für Wirtschafts- und Sozialpolitik, für Publizistik und Rechtsfragen geschehen, deren „Arbeitsergebnisse, die für die praktische Politik bedeutsam sind“, an die „verantwortlichen Regierungsstellen“ herangetragen werden sollten. ${ }^{115}$

\section{„Die Erneuerung des Abendlandes wird eine Erneuerung des Reiches sein":116 die abendländische Idee in den fünfziger Jabren}

\section{Antikommunismus}

Die Idee des „Abendlandes“, so wie sie die Abendländische Akademie, die Abendländische Aktion und die Zeitschrift Neues Abendland in den fünfziger Jahren vertraten, unterschied sich grundsätzlich von den eher theologisch-kulturellen Überlegungen der frühen Nachkriegszeit. Für diesen Wandel spielte der Kalte Krieg eine zentrale Rolle. Er rückte den Antikommunismus stärker als je zuvor in den Mittelpunkt der abendländischen Idee und machte ihn neben dem Bezug auf das Christentum zur geistigen Grundlage der Abendländischen Bewegung. ${ }^{117}$ Man sah sich fortan in einem „Krieg der Weltanschauungen“ stehen, der weitaus mehr umschloß als nur die militärische Dimension: Vielmehr ging es im Verständnis der Abendländer ganz grundsätzlich um die Entscheidung zwischen Freiheit und Versklavung, zwischen geistigen Werten, sprich: abendländischchristlicher Lebensform, und Atheismus. Bedrohlich an der Situation war nach abendländischer Interpretation insbesondere, daß der Osten „als ein geschlossenes System in Erscheinung [tritt], das zu allen Fragen des persönlichen, des politischen, aber auch des wissenschaftlichen Lebens jeweils eine apodiktisch verkündete Antwort bereithält; ein politisches System, das in seinen Zielsetzungen

114 Schildt, Zwischen Abendland und Amerika, S. 51.

115 Weg und Ziel der Abendländischen Akademie, S. 4. Auch in praktischen Belangen erwiesen sich die Kontakte für die Abendländer als nützlich. Vgl. etwa den Brief Gaupp-Berghausens an Hermann Pünder vom 24. 3. 1954: „Ich bin überzeugt, daß durch Ihr so ausgezeichnetes Schreiben in Stuttgart das Verständnis für die Lage des Fürsten geweckt wurde. Der Fürst beabsichtigt in nächster Zeit einen Besuch bei Herrn Staatspräsidenten Müller zu machen. Den Weg haben Sie ja vorzüglich geebnet." BA N 1005/538.

116 Ibach, Helmut: Oradour und das Reich, in: Neues Abendland 8 (1953), S. 177 f., hier S. 177.

117 Gewissermaßen im Gegenzug zu dieser starken Betonung des Antikommunismus innerhalb der abendländischen Idee häuften sich die Angriffe aus der DDR: Das "Abendland“ wurde hier als "klerikal-faschistische Ideologie“ par excellance beschrieben. Vgl. Bergner, Die Ideologie des politischen Klerikalismus. Herz, Morgenland-Abendland. Büttner, „Abendland“-Ideologie und Neo-Karolingertum. 
ebenso weitsichtig wie kaltblütig ist und das in seiner weltanschaulichen Konzeption von einem geschlossenen diesseitigen atheistischen Weltbild geleitet wird" ${ }^{118}$ Der Westen habe diesem System aufgrund der Abwendung von christlichen Werten nur wenig entgegenzusetzen: „Die westliche Welt ist geistig längst ein Trümmerfeld, nur will sie es nicht wahr haben, sie gibt vor, den hohen Wert der Freiheit zu verteidigen, und übersieht, daß diese Freiheit längst [...] die innere Zersetzung fördert, da sie, an keinen echten Wert gebunden, dem Bösen mehr Chancen läßt als dem Guten." 119 In vielem knüpften diese Argumentationen übergangslos an den Antibolschewismus früherer Jahrzehnte an. Nun nahm er jedoch innerhalb der abendländischen Idee einen, auch angesichts der weltpolitischen Situation, noch weitaus prominenteren Platz ein als in früheren Jahren. Dazu trugen auch biographische Erfahrungen der Abendländer wie Flucht und Vertreibung bei. So entwickelte sich im abendländischen Selbstverständnis die Vorstellung eines "Zweifrontenkampfs“: nach außen gegen die Bedrohung durch ein totalitäres Gedankengebäude, ergänzt durch die ganz reale militärische Bedrohung des Kalten Krieges, nach innen der Kampf gegen ,liberale Beliebigkeiten`.

\section{Westbindung}

Der militante Antikommunismus sorgte dafür, daß die Abendländer bereits Ende der vierziger Jahre eindeutig für die Westbindung der Bundesrepublik plädierten, denn ,jeder Versuch eines ,modus vivendi' mit dem Osten kann für Deutschland zum ,modus moriendi" werden". ${ }^{120}$ Insofern schien den Abendländern die Notwendigkeit, beim Wiederaufbau auf den Westen zu setzen, selbstverständlich, „da die Fortdauer des Kalten Krieges für Deutschland als Niemandsland zwischen den Fronten eine ungeheure Gefahr"121 darstelle. Daran schloß sich ein unbedingtes Plädoyer für militärische Stärke und atomare Abschreckung an. ${ }^{122}$ Die ersten Anzeichen einer friedlichen Koexistenz nach der Genfer Konferenz 1955 empfanden die Abendländer daher als bedrohlich, man brandmarkte die Entspannungstendenzen als ,internationale Epidemie der Selbstverdummung“ ${ }^{123}$ Der UngarnAufstand $1956 \mathrm{kam}$ den Abendländern aus diesem Grunde geradezu gelegen. Nun konnte man konstatieren, daß „die Maske der Koexistenz gefallen [sei], sichtbar wurde die Maske Stalins. In Ungarn verendete unter den Raupenketten sowjeti-

118 Kroll, Grundlagen abendländischer Erneuerung, S. 8.

119 Ebenda, S. 9. Vgl. auch: Kroll, Gerhard: Politik ohne Gnade, in: Neues Abendland 8 (1953), S. 25-32.

120 Franzel, Emil: Nach der Konferenz, in: Neues Abendland 4 (1949), S. 245.

121 Ders.: Pariser Konferenz, in: Neues Abendland 4 (1949), S. 244.

122 "Wenn die Vereinigten Staaten darauf verzichten wollten, die Atombonbe zu erzeugen oder die Atombombe weiterzuentwickeln, so würde das nicht bedeuten, daß es den Weltfrieden fördern oder gar sichern und die Anwendungen der furchtbaren Waffen verhindern, sondern lediglich, daß sie die Sowjets zum Angriff provozieren." Franzel, Emil: Ein notwendiges Nachwort, in: Neues Abendland 5 (1950), S. 181-183, hier S. 182. Zu Argumentationsmustern dieser Art vgl. ausführlicher: Stölken-Fitschen, Atombombe und Geistesgeschichte, S. 54-90. Allerdings berücksichtigt die Autorin das Neue Abendland in ihrer Analyse deutscher Zeitschriften zum Thema der nuklearen Frage nicht.

123 Ingrim, Robert: Die Kopfgrippe, in: Neues Abendland 10 (1955), S. 559 f., hier S. 560. 
scher Panzer der ,Geist von Genf', wurde unter den Stiefeln der Rotgardisten die Illusion eines friedlichen ,Miteinanders' zerstört".124 Mit dem "Sputnik-Schock“" 1957 war den Abendländern dann die „Notwendigkeit einer militärischen Stärkung der freien Welt noch größer geworden“..125

$\mathrm{Da} ß$ die Abendländer die Westbindungspolitik Adenauers unterstützten, kann vor diesem Hintergrund kaum verwundern. Die USA erkannte man als militärisch und wirtschaftlich überlegene Schutzmacht an und zweifelte keinen Moment am Platz der Bundesrepublik im westlichen Bündnis. Glücklich war man mit dieser Konstellation indes nicht. Der Antiliberalismus, welcher der abendländischen Idee schon in der Zwischenkriegszeit innegewohnt und der sich auch nach dem Zweiten Weltkrieg nicht relativiert hatte, verhinderte dies. Denn schließlich repräsentierten für die Abendländer sowohl "Ost“ als auch „West“ „unchristliche Ideen“, und es war für sie eigentlich „selbstverständlich, daß der Christ [...] sich weder für den, Westen' noch für den ,Osten' entscheiden kann“. ${ }^{126}$ Mit der notwendigen politischen Entscheidung für den Westen „scheinen wir uns für den Liberalismus zu entscheiden, der - wie die jüngere Geschichte lehrt - geradenwegs dorthin führen kann, wo der Kollektivismus des Ostens schon steht". ${ }^{127}$ Der Westen war den Abendländern allenfalls das „kleinere Übel"..128 Um so wichtiger wurde daher die überlegene geistige Position des Abendlandes: In der „Hoffnung, daß der [...] Liberalismus noch bekehrbar" 129 sei, kam deshalb Europa im westlichen Bündnis nach Vorstellung der Abendländer der geistige Führungsanspruch zu.

Insgesamt war die Haltung der Abendländer gegenüber Amerika gekennzeichnet von einer Verachtung des amerikanischen "Way of Life“ bzw. dessen, was sie darunter verstanden. Darin unterschieden sich die Abendländer nicht von anderen konservativen Intellektuellen in der jungen Bundesrepublik. ${ }^{130}$ „Fortschrittsgläubig“ einerseits, „naiv“ und „kulturlos" andererseits waren typische Argumentationsmuster des deutschen Amerikabildes, das nach 1945 nicht neu entstand, sondern sich bereits in der Weimarer Republik entwickelt hatte. Über diese Kulturkritik hinaus fand sich in abendländischen Äußerungen in nicht unerheblichem Maße auch politische Kritik an den USA, sei es an der „Reeducation“, oder an der Entnazifizierung, sei es an der vermeintlich zu nachgiebigen Haltung gegenüber der Sowjetunion in den letzten Kriegsjahren, ${ }^{131}$ sei es an der vermeintlichen

124 Herre, Franz: Morgenrot in Osteuropa, in: Neues Abendland 11 (1956), S. 379-383, hier S. 382.

125 Ders., Von Gipfel zu Gipfel, in: Neues Abendland 13 (1958), S. 78-81, hier S. 79.

126 Heilmann, Wolfgang: Christliches Gewissen zwischen Ost und West, in: Neues Abendland 6 (1951), S. 597-606, hier S. 602.

127 Ibach, Helmut: Die andere Möglichkeit. Das Kriegsrisiko der Friedenspolitik, in: Neues Abendland 8 (1953), S. 33-38, hier S. 35.

128 Ebenda.

129 Ebenda.

130 Generell zur Orientierung an Amerika bzw. dem deutschen Gefühl der Überlegenheit gegenüber amerikanischer Kultur in den 50er Jahren siehe: Schildt, Moderne Zeiten, S. 398-423. Zum Amerika-Bild Robert Ingrims vgl. auch: Schildt, Reise zurück aus der Zukunft, S. 25-45, hier S. 31/32.

131 Vgl. z.B. Uhlig, Heinrich: In aller Offenheit, in: Neues Abendland 4 (1949), S. 375 f. 
Leichtgläubigkeit gegenüber dem Osten im Kalten Krieg132 oder auch an der Verantwortung für die in ihren Augen mißlungene staatliche Neuordnung Deutschlands. Gleichzeitig spürte man aber ebenso deutlich das Bemühen, diese Kritik nicht zu laut werden zu lassen, vor allem jedoch keine politische Kritik an der generellen Westbindung zu üben. Wenn man kritisierte, dann an abgelegener Stelle. Und man vernahm im Neuen Abendland auch immer wieder Stimmen, die sich bemühten, die USA als „Kind“ des Abendlandes auszugeben und damit die „unnatürliche" atlantische Bindung zu rechtfertigen. Axel Schildt hat dies passend als "Drahtseilakt zwischen Westoption und Antiliberalismus" bezeichnet. ${ }^{133}$ In der Tat handelt es sich bei diesem Changieren zwischen Antiwestlichkeit einerseits und der Forderung nach politischer und militärischer Westbindung andererseits um einen der eklatantesten Widersprüche innerhalb des abendländischen Gedankengebäudes, der erstmals auftrat, als man sah, daß (West-)Europa in den Zeiten des Kalten Krieges politisch und militärisch auf die USA angewiesen war. Demgegenüber hatten der Antiamerikanismus und Antiwestlichkeit in der Weimarer Republik und auch im Dritten Reich viel selbstverständlicher zur abendländischen Idee hinzugehören können. Selbst Mitte der zwanziger Jahre, zu dem Zeitpunkt, als eine Wendung nach Westen, in Richtung Frankreich, im „Abendland“ noch am stärksten zu bemerken ist, ging man nicht davon aus, daß durch eine Verständigung das "Abendland“ zu einem westlichen Gebilde werden würde. Vielmehr hatte man sich eine fruchtbringende Symbiose der "romanischen" und „germanischen" Kulturkreise erhofft, deren Eigenständigkeit jedoch im Kern unangetastet bleiben sollte. In den Jahren, in welchen das „Abendland“ zunehmend mit „Mitteleuropa “ identifiziert wurde, definierte es sich über das deutsche Selbstverständnis, das sich abgrenzte vom Westen wie vom Osten. Was also vor den fünfziger Jahren fundamentaler Bestandteil des „Abendlandes“ gewesen war, die Überzeugung, daß Deutschland kein Teil des „Westens" sei und eine europäische Ordnung nach anderen Kriterien zu verwirklichen sei als den „westlichen“, verlor angesichts der militärisch-politischen Situation der Bundesrepublik in den fünfziger Jahren an Prägekraft. Nachdem sich Antiwestlichkeit und Antikommunismus in früheren Jahrzehnten die Waage gehalten hatten, war das Gefühl der existentiellen Bedrohung durch den Kommunismus erstmals dominierender als die antiwestlichen Vorbehalte. So machte die Konstellation des Ost-West-Konfliktes einem Jahrzehnte alten antiwestlichen ideengeschichtlichen Traditionsstrang vorerst ein Ende: Das Abendland mußte sich nach Vorstellung der Abenländer notwendigerweise in eine atlantisch-westliche Gemeinschaft begeben. Auch wenn sie grundsätzlich ein starkes, eigenständiges Europa immer vorgezogen hätten, sahen die Abendländer dafür in der Gegenwart der fünfziger Jahre keine Realisierungschan-

Ders.: Das Erbe Roosevelts, in: Neues Abendland 5 (1950), S. 317-321. Vemanianus: Verschweizerung, nicht Amerikanisierung, in: Neues Abendland 6 (1951), S. 85 f. Sexau, Richard: Der verlorene Friede, in: Neues Abendland 9 (1954), S. 245-248.

132 Vgl. z. B. Ingrim, Robert: Der Machtausgleich, in: Neues Abendland 6 (1951), S. 574-576. Ders.: Der breite Ozean, in: Neues Abendland 10 (1955), S. $225 \mathrm{f}$.

133 Schildt, Zwischen Abendland und Amerika, S. 40. Vgl. auch ders., Konservatismus, S. 233. 
cen. Die abendländische Position war eindeutig: „Es gibt keine Dritte Kraft. Es gibt nur noch zwei Kräfte, und wer überleben will, muß zu wählen wissen!" 134

Insofern rückte das „Abendland“ nun stärker als je zuvor in den „Westen“. Man kann Anselm Doering-Manteuffel in der Feststellung Recht geben, daß konservative bürgerliche Schichten über das „Abendland“ langsam zum "Westen“ fanden, gerade weil der Topos „Abendland“ ihnen die Möglichkeit bot, ihren traditionellen Kulturdünkel gegenüber dem „Westen“ vorerst weiterzutragen. Indem sie sich jedoch politisch immer stärker im "Westen “ einlebten, verlor langsam aber sicher auch die traditionelle kulturelle Antiwestlichkeit an Bedeutung. ${ }^{135}$ So zahlte die junge Bundesrepublik mit diesem (nicht nur) abendländischen Kulturdünkel, der sich wiederum einbettete in eine breite kulturkritische, technikfeindliche und elitäre Momente beschwörende konservative Publizistik,136 auch den "Preis für die Integration nicht zuletzt des konservativen Bildungsbürgertums" in die Westbindungspolitik. ${ }^{137}$ Vollständig gelang diese Integration indes nicht. Gerade an den Abendländern wird sich zeigen, daß in den sechziger Jahren, als man stärker auf ein politisch von den USA unabhängigeres Europa als Zielvorstellung verwies, der tiefverwurzelte Antiamerikanismus (von Antiwestlichkeit war nun kaum noch die Rede) wieder zum Vorschein und die abendländische Kritik an der westlichen Schutzmacht wieder unbefangener daher kam als in der Hochphase des Kalten Krieges.

Diese abendländische Option für die Westintegration in den fünfziger Jahren führte auch dazu, daß die durchaus nationale Interessen vertretenden und die $\mathrm{Ka}$ tegorie der Nation hochhaltenden Abendländer bereits 1949 die „Unvermeidlichkeit der Teilung Deutschlands“ proklamierten. ${ }^{138}$ Man wollte nun „dem deutschen Volk oder seiner großen Mehrheit zunächst im Westen und in Verbindung mit den vom Bolschewismus nicht beherrschten europäischen Völkern eine neue Lebensform [...] schaffen" ${ }^{139}$ In diese neue Lebensform könnten dann auch die befreiten Ostdeutschen aufgenommen werden. Bis dahin allerdings komme der Bundesrepublik - in Übernahme der seit 1955 sogenannten Hallstein-Doktrin der Alleinvertretungsanspruch zu. „Eine Nation wird immer durch ihre freien Glieder, sie wird durch ihre staatsbildenden Funktionen vorgestellt. [...] Deutschland ist eben seit 1945 die Bundesrepublik." 140 Erst gegen Ende der fünfziger, Anfang der sechziger Jahre, als langsam offensichtlich wurde, daß die Adenauersche „Politik der Stärke“ die Wiedervereinigung nicht näherbrachte, sollte die deutsche Frage auch in der abendländischen Idee wieder einen größeren Stellenwert bekommen.

134 Ingrim, Robert: Der Rat der Tse-Tse-Fliege, in: Neues Abendland 9 (1954), S. 475 f., hier S. 476.

135 Doering-Manteuffel, Katholizismus und Wiederbewaffnung, S. $252 \mathrm{f}$.

136 Schildt, Konservatismus, S. 221-240.

137 Schildt, Zwischen Abendland und Amerika, S. 40.

138 Franzel, Emil: Staatsform und geschichtlicher Raum, in: Neues Abendland 4 (1949), S. 47-51, hier S. 51.

139 Ders.: Die restaurativen Tendenzen der Epoche, in: Neues Abendland 6 (1951), S. 529 542, hier S. 540.

140 Ebenda. 
So lehnten die Abendländer der fünfziger Jahre eine Neutralisierung Westdeutschlands, angelehnt an die Konzepte Ulrich Noacks, ${ }^{141}$ als unrealistisch ab. ${ }^{142}$ Ebenso schalteten sie sich in die Wiederbewaffnungsdiskussion ein, die von Ende der vierziger bis weit in die fünfziger Jahre hinein innerhalb der westdeutschen Öffentlichkeit und der Kirchen geführt wurde. Dabei setzten die Abendländer sich vehement für eine Wiederbewaffnung ein: „Verteidigung ist auch lediglich das Ziel der sogenannten Remilitarisierung, Verteidigung ist das primitivste Recht jedes Menschen, jedes Volkes, Verteidigung aller an eine göttliche Ordnung glaubenden Menschen gegen die neue aus dem Osten kommende antigöttliche Ordnung. " ${ }^{143}$ Die frühe Zustimmung zu einer deutschen Wiederbewaffnung ${ }^{144}$ war allerdings - wie auch in anderen Kreisen der katholischen Wiederbewaffnungsdiskussion - begleitet von Warnungen vor militaristischen, „preußischen“ Traditionen, welche wiederaufleben könnten. ${ }^{145}$ Im Gegensatz etwa zur Europa-Union, die der Idee einer deutschen Wiederbewaffnung skeptisch gegenüberstand, aber hoffte, es ließe sich aus der Europäischen Verteidigungsgemeinschaft (EVG) eine Politische Gemeinschaft entwickeln, sah man innerhalb der Abendländischen Bewegung die EVG primär unter verteidigungspolitischen Erwägungen. Man begrüßte sie als Möglichkeit einer deutschen „Wiederbewaffnung“, Elemente der europäischen Integration traten demgegenüber in den Hintergrund. Wenn man das Scheitern der EVG 1954 auch bedauerte, so erfüllte die Aufnahme der Bundesrepublik in die NATO nach abendländischen Vorstellungen doch den gleichen Zweck. Darin spiegelt sich schon eine gewisse Skepsis gegenüber dem institutionalisierten Einigungsprozeß, auf den nun näher einzugehen sein wird.

\section{Europäische Einigung}

In allen abendländischen Äußerungen ab etwa 1948 finden sich Appelle für eine europäische Einigung. Deutlich geworden ist bereits, daß Europa und insbesondere Westeuropa den Abendländern mit Beginn des Kalten Krieges zunehmend nicht nur als geistig-kulturelle Einheit wichtig war, sondern auch als Verteidigungsblock gegenüber dem Osten. Die europäische Einigung war für die Abend-

141 Zu Ulrich Noack, der ab Mitte 1947 bis an die Schwelle der fünfziger Jahre die Idee eines blockfreien Deutschland vertrat, siehe: Dohse, Der Dritte Weg. Schwarz, Vom Reich zur Bundesrepublik, S. 355-384.

142 Vgl. z.B. Franzel, Emil: Europäische Zwischenbilanz, in: Neues Abendland 3 (1948), S. 321-326. Ders.: Von Bismarck zu Adenauer, in: Neues Abendland 6 (1951), S. 51-65. Ingrim, Robert: Spinat und Marzipan, in: Neues Abendland 6 (1951), S. 97 f. Ders.: Die neutralistische Maske, in: Neues Abendland 7 (1952), S. $362 \mathrm{f}$.

143 Gaupp-Berghausen, Georg von: Ist Verteidigung - Remilitarisierung?, in: Neues Abendland 6 (1951), S. 253 f., hier S. 254.

144 Zum Teil wurde dies von der Forschung bisher anders beurteilt, siehe z.B.: DoeringManteuffel, Katholizismus und Wiederbewaffnung, S. 252, der eine „zwar nicht ablehnende, aber doch reservierte Haltung gegenüber der Wiederbewaffnung" auf abendländischer Seite konstatiert.

145 Vgl. Defensor: Grundzüge einer neuen deutschen Wehrpolitik, in: Neues Abendland 6 (1951), S. 543-57. Der Sieg des Kanzlers, in: Neues Abendland 7 (1952), S. 115-117. Ibach, Helmut: Die andere Möglichkeit. Das Kriegsrisiko der Friedenspolitik, in: Neues Abendland 8 (1953), S. 33-38. 
länder insofern auch eine Defensivmaßnahme gegen den Osten, die neben militärischer Stärke die geistige Einheit im „Kampf“" garantieren sollte, ohne die man gegen den weltanschaulichen Block des Kommunismus nicht bestehen zu können glaubte. So wurden die ersten Schritte in Richtung Integration aufmerksam verfolgt, kommentiert und in aller Regel gutgeheißen. ${ }^{146} \mathrm{Als}$ Kern der europäischen Integration lagen den Abendländern enge deutsch-französische Beziehungen besonders am Herzen - hier finden sich Elemente des abendländischen Denkens der zwanziger Jahre wieder: „Ohne sie [Deutschland und Frankreich] ist die Geschichte des Abendlandes nicht denkbar, ohne sie aber und ihre Zusammenarbeit hat das Abendland auch keine Zukunft." 147

Trotz der grundsätzlich positiven Einstellung gegenüber der beginnenden europäischen Integration konnten kritische Stellungnahmen auf abendländischer Seite aufgrund ihres Weltbildes auf Dauer nicht ausbleiben. Vor allem die Richtung, in die sich die westeuropäische Gemeinschaft entwickelte, mußte mit den nach 1945 nicht schwächer gewordenen abendländischen Vorbehalten gegenüber dem parlamentarischen System in Konflikt geraten. So zog der Europarat nach der ersten Euphorie über seine Gründung den Unmut der Abendländer auf sich: „Niemand wird bestreiten, daß in den Völkern eine geradezu leidenschaftliche Anteilnahme für die Erneuerung des Abendlandes in einem geeinten Europa besteht. Aber die Formaldemokratie besitzt eine ausgezeichnete Fähigkeit, die besten Idealisten zu zermürben und den großartigsten Schwung in Lethargie zu verwandeln. Künftige Zeiten werden sich einmal wundern, mit welcher Tatenlosigkeit kostbarste Zeit nutzlos vertan wurde." 148 Immer wieder betonte man, daß „Europa mehr sein muß als ein Abfallprodukt einer Entwicklung, die sich außerhalb seiner Grenzen vollzieht ${ }^{\text {“ }}{ }^{149}$ Die Europäer müßten zu einer inneren Ordnung und geistigen Einheit finden - diese aber könne die „formaldemokratische“ Organisation des westeuropäischen Zusammenschlusses nicht leisten: Insofern waren für die Abendländer alle Bemühungen um die europäische „Reißbrett-Union“ nicht mehr als „gutgemeinte Versuche“. 150

Gleichzeitig mit dieser Kritik entwickelten die Abendländer auch eigene Vorstellungen eines erneuerten "Abendlandes“. Diese Konzepte erklären sich aus der antiliberalen Grundhaltung der abendländischen Idee: Ablehnung des Vertragsrechtes und des Parlamentarismus und statt dessen eine hierarchisierte Gesellschaft mit erkennbarer Autorität - so erhofften sich die Abendländer die Gestaltung Europas. Dabei lehnte man supranationale Elemente jedoch immer stärker ab: die nationale Souveränität wollten die Abendländer letztlich nicht in Frage ge-

146 Vgl. z.B. Goergen, Josef M.: Gespräche um die Saar, in: Neues Abendland 5 (1950), S. 129-135. Cube, Walter von: Gefühls- oder Realpolitik, in: Neues Abendland 5 (1950),

S. 136-138. Salinger, Hans Dietrich: Heikle Europa-Fragen, in: Neues Abendland 10 (1955), S. 527-536.

147 Franzel, Emil: Frankreich und Deutschland als Träger des Abendlandes, in: Neues Abendland 5 (1950), S. 1-4, hier S. 4.

148 Straßburger Europarat lustlos, in, Neues Abendland 6 (1951), S. 391.

149 Salinger, Hans Dietrich: Heikle Europa-Fragen, in: Neues Abendland 19 (1955), S. $527-$ 536, hier S. 534.

150 Kroll, Grundlagen abendländischer Erneuerung, S. 78. 
stellt sehen, jedenfalls nicht durch „formaldemokratische“ Elemente. Auch in diesem Punkt schloß man also an alte ideengeschichtliche Kontinuitäten an: Bereits die Abendländer der $Z$ wischenkriegszeit hatten niemals supranationale Elemente in ihre Überlegungen einbezogen. Die europäischen Nationen bildeten wie in der Zwischenkriegszeit das Fundament des „Abendlandes“.

Im Gegensatz zur Zwischenkriegszeit hatte man in den fünfziger Jahren allerdings Vorbilder, wenn es um den zukünftigen politischen und gesellschaftlichen Aufbau Europas ging. Neben den Verweisen auf das mittelalterliche Reich waren es vor allem die politischen Systeme der iberischen Halbinsel, welche die Begeisterung der Abendländer auf sich zogen. Die autokratischen Regime Spaniens und Portugals schienen genau das zu verwirklichen, was man sich in abendländischen Kreisen von einer "natürlichen“ Ordnung versprach: hierarchische Gesellschaftsstrukturen, in denen jeder „seinen“ Platz fand, keine „Massendemokratie“, sondern elitäre „Führung" durch eine charismatische Führungspersönlichkeit, welche Parteiinteressen und politischen „Klüngel“ zurückdrängte, ein großer Einfluß der Kirchen auf Staat und Gesellschaft.

Portugal war nach Aussage des Nenen Abendlandes der „bestregierte Staat Europas“, 151 und mit dem francistischen Spanien verbanden die Abendländer enge organisatorische Kontakte. Jährlich trafen sie sich zu einem Kongreß des Europäischen Dokumentationszentrums (CEDI) im Escorial und leisteten in der Bundesrepublik Vorarbeit für die Einbeziehung Spaniens in die europäische Integration. Immer wieder forderte man, Spanien am Integrationsprozeß zu beteiligen: ${ }^{152}$ Sowohl seine historische Rolle in Europa wie seine "Verdienste" im Kampf gegen den „Bolschewismus“ während des Bürgerkrieges und nicht zuletzt seine strategische Lage im westlichen Mittelmeer ließen es den Abendländern unverantwortlich erscheinen, Spanien nicht in das entstehende Europa einzubinden. Dabei stellte das Land in den Augen der Abendländer mit seiner politischen und gesellschaftlichen Ordnung, in der ihnen die Moderne überwunden schien, ein Vorbild für die Bundesrepublik und Europa gleichermaßen dar: „Was Spanien dem Ausland geben kann, kann fundamental sein für die Wiedergeburt des Abendlandes. Es ist das durch Humanismus, Rationalismus und Liberalismus unterdrückte Leitbild einer christlich-universalen Staats- und Weltordnung. "153 Jenen Deutschen, die in Spanien ein faschistisches oder gar totalitäres System sahen, antwortete man überzeugt: „Totalitarismus? Wenn schon, dann gibt es in Spanien nur einen - das totale Gebot des Dekalogs und des katholischen Naturrechts."154 151 Franzel, Emil: Portugal, der bestregierte Staat Europas, in: Neues Abendland 7 (1952),
S. 266-272.

152 Vgl. hierzu Teil I, Kap. II.3.

153 Valdeiglesias, José Ignacio Escobar Marqués de: Der Beitrag Spaniens, in: Neues Abendland 10 (1955), S. 285-291, hier S. 287.

154 Dalma, Alfons: Europa ohne Angst, in: Neues Abendland 7 (1952), S. 623-626, hier S. 624 . 
Rückbesinnung auf „Mitteleuropa“ und das „Reich“

Während also Westbindung und begrenzte Zustimmung zur anlaufenden europäischen Integration die außen- und europapolitischen Äußerungen der abendländischen Bewegung in den fünfziger Jahren prägten, entwickelten die Abendländer der fünfziger Jahre gleichzeitig Konzepte, die diese politischen Grundentscheidungen in letzter Konsequenz in Frage stellten. ${ }^{155}$ Zwar wurden diese Gegenkonzepte vorerst völlig getrennt von den Plädoyers für die westeuropäische Integration und die atlantische Gemeinschaft vertreten, doch scheinen hier bereits Elemente durch, die die Wandlung der abendländischen Idee in den sechziger Jahren vorbereiten sollten. Denn im Verlauf der fünfziger Jahre eroberte sich ein Element zunehmend seinen Platz in der abendländischen Idee zurück, das diese Idee schon zu Beginn der dreißiger Jahre geprägt hatte: „Mitteleuropa“. Trotz ihres realpolitischen Einschwenkens auf das Westbindungskonzept der Regierung Adenauer, trotz aller Unterstützung der westeuropäischen Integration, wurden die Abendländer nicht müde zu betonen, daß man sich eigentlich an anderen Maßstäben orientieren müsse. Europa sei durch den „Eisernen Vorhang“ von einem „Großteil seiner Völker“ amputiert, aber kaum jemand führe sich das noch vor Augen: „Für viele kleine Geister hört Europa heute an der Yalta-Linie auf. Diese Menschen [...] halten die Westliche Union, wie sie in Straßburg als ein Notbehelf geschaffen wurde, für etwas Dauerndes und Dauerhaftes [...]. Sie vergessen, daß der Westen ohne den anderen Teil des Kontinentes nicht leben kann. Die Union ist ein weder in der Geographie noch in der Geschichte oder der Wirtschaft gerechtfertigtes Provisorium." ${ }^{156} \mathrm{Hier}$ unterschieden sich die Abendländer deutlich von der Europa-Union, für die spätestens seit Beginn der fünfziger Jahre Westeuropa - auch ideell - im Zentrum stand, während "Mitteleuropa“ so gut wie keine Rolle spielte.

Einerseits wollte man auf die abgetrennten Ostgebiete nicht verzichten. Deren Abtrennung könne auf Dauer nur bestehen, „wenn Gewalt vor Recht“ gehe:157 "Wir glauben aber, daß der Nachweis einer 700jährigen Kontinuität der Siedlung und kulturellen Leistung für unseren unveräußerlichen Anspruch auf den deutschen Osten ausreichend und entscheidend ist." 158 Das Interesse der Abendländer jedoch reichte über die verlorengegangenen Ostgebiete hinaus: Die mitteleuropäischen Staaten und der Donauraum bildeten auch in den fünfziger Jahren innerhalb der abendländischen Idee den „Kernraum Europas“. ${ }^{159}$ Ein föderalistisch angelegtes Reich, welches primär die mitteleuropäischen, besser noch alle abendländischen Nationen vereinen sollte, ermöglichte nach abendländischen Vorstellungen auch die Lösung des Vertriebenenproblems: Denn eine solche Ordnung, in der die

155 Vgl. auch: Plichta (jetzt Conze), „Eine Erneuerung des Abendlandes wird eine Erneuerung des Reiches sein".

156 Habsburg, Otto von: Amerika und die europäische Integration, in: Neues Abendland 7 (1952), S. 321-332, hier S. 324.

157 Fischer, Pius: Ostwärts der Oder und Neiße, in: Neues Abendland 4 (1949), S. 150 f., hier S. 150.

158 Mattausch, Rudolf: Herr Ulbricht tritt Ostdeutschland ab, in: Neues Abendland 4 (1949), S. 218.

159 Simon, Albert Karl: Grundlagen einer politischen Ordnung im Donauraum, in: Neues Abendland 11 (1956), S. 332-334, hier S. 333. 
Völker ohne Nationalismus zusammenlebten, garantiere auch den (vertriebenen) Minderheiten Platz und Raum. ${ }^{160}$

So trat auch das „Reich“ wieder auf die abendländische Bühne. Während der Begriff gesamtgesellschaftlich an Bedeutung verloren hatte, geisterte er weiter durch die abendländischen Publikationen der fünfziger Jahre. Hier reichen ideengeschichtliche Kontinuitäten im deutschen Konservatismus aus der ersten Hälfte des 20. Jahrhunderts weit in die Nachkriegszeit hinein. Nur unmittelbar nach Kriegsende waren sie vorübergehend in den Hintergrund getreten. Die Nähe von "Reich" und „Abendland“, die schon vor 1945 bestanden hatte, blieb auch nach dem Untergang des "Dritten Reiches“ erhalten. Um den Reichs-Begriff in den fünfziger Jahren verwenden zu können, mußten sich die Abendländer freilich gerade von nationalistischen Interpretationen im Sinne des „Dritten“, aber auch des preußisch-kleindeutschen "Zweiten Reiches“ abgrenzen. Das Neue Abendland wies wiederholt darauf hin, daß die Bezeichnung „Reich“ für Deutschland nach 1871 „Unsinn“ gewesen sei, daß das zweite „Reich“ mit dem historischen ersten „Reich“ nicht das geringste zu tun gehabt habe. ${ }^{161}$ Statt dessen hieß es: „Unsere Tradition ist die des alten Reiches. " 162 Diese Tradition müsse beim Neubau des Abendlandes wieder aufgegriffen werden.

Wie aber die vielen Völker, Sprachen und Kulturen innerhalb des Abendlandes verbinden? Während sich die Abendländer bis in die erste Hälfte der fünfziger Jahre mit genaueren politischen Konstruktionen zurückhielten und vor allem das Christentum als einheitsstiftendes Moment in Europa ansahen, tauchte nun gelegentlich ein neues Element auf, das allerdings ähnlich unzeitgemäß wirkte wie Rechristianisierungsvorstellungen: Ein abendländisches Kaisertum könne ein europäisches Bewußtsein schaffen, das bisher fehle, ein Kaisertum freilich, „befreit von den Aftervorstellungen eines entarteten Monarchismus und eines degenerierten Aristokratismus".163 Die Suche nach Autorität und nach Verankerung weltlicher Macht im göttlichen Willen ließ den Abendländern die historische Verbindung des mittelalterlichen Kaisertums mit dem Gottesgnadentum zur Orientierung werden: „Man kann das Abendland nicht gegen seine Vergangenheit erneuern wollen, sondern ausschließlich mit ihr. [...] Eine Erneuerung des Abendlandes wird deshalb auch eine Erneuerung des Reiches sein und an der kaiserlichen Gewalt als von Gott gestifteten Formen niemals vorbeikommen, wenn sie nicht ganz im Widergöttlichen enden will. Ja, die Erneuerung des universalen Reiches wird geradezu zum Symbol dafür werden, daß ein wiedererstandener Glaube an Gott

160 Vgl. z.B: Simon, Albert Karl: Die Sudetendeutsche Funktion, in: Neues Abendland 10 (1955), S. 116-118. Ders.: Die Sendung der ostdeutschen Landsmannschaften, in: Neues Abendland 11 (1956), S. 259-264.

161 Görlich, Ernst Joseph: Zum Begriff des „Heiligen Reiches“, in: Neues Abendland 7 (1952), S. 229f., hier S. 230.

162 Ludwig, Heinrich: Gegenwart, Elite und Tradition, in: Neues Abendland 12 (1957), S. 216-224, hier S. 222.

163 Ders.: Katholisches Universalkaisertum, in: Neues Abendland 5 (1950), S. 272-276, hier S. 272; vgl. auch Salinger, Hans Dietrich. Heikle Europa-Fragen, in: Neues Abendland 10 (1955), S. 527-536. 
vorhanden ist, weil anders ein Durchbruch zu dieser Form in unserer verweltlichten Zeit gar nicht zu denken ist." 164

Bereits in den dreißiger und auch vierziger Jahren hatten spätere Abendländer wie Emil Franz und Robert Ingrim, der mit Otto von Habsburg im Exil eng zusammengearbeitet hatte, in der Monarchie eine Staatsform gesehen, der es gelingen würde, die Idee einer österreichischen Identität gegenüber den großdeutschen Parolen des Nationalsozialismus zu verteidigen. Dabei setzten beide ihre Hoffnungen auf Otto von Habsburg, dem man die Aufgabe zuwies und zutraute, die gesamte österreichische Gesellschaft gegen die Bedrohung des Nationalsozialismus zu verbinden. „Sicher ist, daß er [Otto von Habsburg] im Nu die Herzen der kleinen Leute gewonnen hätte, der Bauern und nicht weniger der Arbeiter. Damit wäre er von Beginn an ein fester Mittelpunkt, eine zentripetale Kraft geworden, also das, was ein Land braucht, wenn man seine Zustände stabil und normal machen will. [...] Die Verkörperung der Staatsidee in einer Person kann gerade in Notzeiten Wunder wirken." 165

Franzel und auch Ingrim sollten diese ursprünglich österreichische Konzeption in das abendländische Denken der fünfziger Jahre tragen. In den zwanziger Jahren war in der Zeitschrift Abendland kaum von der Monarchie die Rede gewesen, und auch zwischen 1946 und 1948 spielte die Monarchie im abendländischen Denken kaum eine Rolle. Als Franzel jedoch Chefredakteur des Nenen Abendlandes wurde, führte er die Monarchie als Thema in die Zeitschrift ein. Zwar scheute er sich in den ersten Jahrgängen, die monarchische Staatsform offen als die der republikanischen überlegene zu preisen. Statt dessen würdigte er in meist historisch angelegten Artikeln die ,adelige Lebensform “ und das Königtum schlechthin, ${ }^{166}$ verbunden mit der Behauptung, daß immer noch eine allgemeine Sehnsucht nach einer Monarchie festzustellen sei: „Oder drückt sich in diesem Jubel um einen Herzog ohne Land [Otto von Habsburg, aus Anlaß seiner Hochzeit 1951], um einen Kaiser ohne Reich am Ende etwas ganz anderes aus, eine geheime Sehnsucht, ein Wunsch, eine Hoffnung, aus der Tiefe des Menschenherzen aufsteigend, bekundend, daß ein innerstes Bedürfnis nach Hoheit, Majestät und Würde in einer würdelosen Zeit so völlig ungestillt bleibt? [...] Viel eher schien es etwas Zukunftsträchtiges, zwar alt und ehrwürdig, aber im letzten unvergänglich, was hier bejubelt wurde. [...] Die Begeisterung für einen Herzog und Kaiser ohne Land galt dem Repräsentanten einer Ordnungsidee, nach welcher Krone und Zepter aus der Hand Gottes stammen und im Namen und Auftrage Christi zu verwalten sind, weshalb sich ihren Trägern auch der Glanz echter Autorität zu offenbaren vermag. Demgegenüber wird kaum jemand bestreiten, daß es der Reißbrettdemokratie unserer Tage an echter Symbolik ermangelt, daß sie keine Begeisterung zu

164 Kroll, Grundlagen abendländischer Erneuerung, S. 93/94.

165 Ingrim, Der Griff nach Österreich, S. 86. Siehe auch: Ebneth, „Der Christliche Ständestaat“, S. 170. Zum Legitimismus und seiner Sicht auf Otto von Habsburg als „Verkörperung der österreichischen Identität“ vgl. Tancsits, Katholischer Widerstand gegen den Nationalsozialismus in Österreich. Vgl. auch: Lovrek, Die legitimistische Bewegung.

166 Vgl. z. B.: Franzel, Emil: Franz Joseph. Revision eines Menschenbildes, in: Neues Abendland 5 (1950), S. 346-354. 
wecken vermag. “167 $\mathrm{Da}$ bei den Abendländern die republikanisch-parlamentarische Demokratie keine Begeisterung erwecken konnte, wurde um so häufiger in die Monarchie all das projiziert, was man sich von einem Staate wünschte und was die Republik nicht geben konnte und wollte: Autorität, Hierarchien und „echter“ Adel als Elite, Tradition, Geschichtsbewußtsein und Symbolik, Naturrecht statt Volkssouveränität.

Über solche Bekundungen fanden mit der Zeit auch erklärte Monarchisten wie Erik Kuehnelt-Leddihn ${ }^{168}$ ihren Weg zu den Abendländern, und 1951 bemerkte man stolz, daß Hans-Joachim von Merkatz sich im Bundestag als Monarchist bekannt habe. 169 Über Merkatz' führende Stellung in der DP festigten sich die abendländischen Beziehungen zu monarchistischen Strömungen zusätzlich, wenn auch weder das Haus der Welfen noch die Hohenzollern, jenen Häusern, denen das Engagement der DP galt, den Abendländern als geeignet für den Thron erschienen. Schließlich scheuten sich die Abendländer nicht mehr, die monarchische Staatsform gegenüber dem „republikanischen Parlamentarismus, der immer wieder seinen Hang zu absolutem Jakobinertum verrät“, als überlegen zu bezeichnen, „als besseren Garanten der demokratischen Lebensform, der Grundrechte, der Überparteilichkeit der Staatsführung und der Rechtsstaatlichkeit. Ganz zu schweigen von der gesellschaftsbildenden Kraft, die von einer Repräsentanz der christlichen Familie an der Spitze unserer Länder ausgehen würde." ${ }^{170} \mathrm{Da} ß$ das "Provisorium" Bundesrepublik in den Augen der Abendländer nur eine kurzfristige Zwischenlösung bedeutete, nährte die Hoffnung, daß es sich bei der "weltkaiserlosen, schrecklichen Zeit der Gegenwart" 171 nur um eine Zeit des „Interregnums" handele: „Die Monarchie [...] kommt ganz bestimmt zurück.“ 172

Bei aller Vermischung mit unrealistischen mittelalterlichen Kaiserideen blieb doch die Erinnerung an die Habsburger-Monarchie der reale Hintergrund, auf den abendländische Reichsvorstellungen projiziert wurden. Hier spiegelt sich die süddeutsch-katholische Verankerung der Abendländer ebenso wie die häufig sozialisatorische Bindung an die untergegangene Doppelmonarchie in ÖsterreichUngarn. So bemühte man sich festzustellen, daß die Reichsidee in Österreich „alle Unbilden der Zeit überwintert" habe. Zwar verlange „die Geschichte Geduld“, aber irgendwann würde das "mitteleuropäische Doppelreich“ schon wieder

167 Ders.: Epilog zu Nancy, in: Neues Abendland 6 (1951), S. 307. Vgl. auch: Ders.: Das Haus Habsburg, in: Neues Abendland 6 (1951), S. 209-222. Zum Tod Rupprechts von Bayern: Ders.: Ein Europäer, in: Neues Abendland 4 (1949), S. 152.

168 Zu Erik Maria Ritter von Kuehnelt-Leddhin vgl. Teil I, Kap. I.2. Auf die Begeisterung etwa Friedrich August Freiherr von der Heydtes für die österreichische Monarchie wurde bereits verwiesen, vgl. Teil I, Kap. I.2.

${ }^{169}$ Monarchiedebatte im Bundestag, in: Neues Abendland 6 (1951), S. 637-644, hier S. 643. Vgl. auch Teil I, Kap. I.2.

170 Ebenda, S. 644.

171 Ludwig, Heinrich: Vermächtnis und Arcanum des Reiches, in: Neues Abendland 13 (1958), S. 110-126, hier S. 111.

172 Kuehnelt-Leddhin, Erik: Monarchie oder Monokratie? in: Neues Abendland 8 (1953), S. 147-158, hier S. 151. 
Wirklichkeit werden, am besten unter Einschluß auch des süddeutschen Raumes. ${ }^{173}$

Allerdings ist anzumerken, daß es sich bei den Abendländern insgesamt nicht um Legitimisten handelte. Ebensowenig, wie sie in Deutschland eine Monarchie befürworteten, ging es ihnen im engeren Sinne um die Person des österreichischen Thronerben Otto von Habsburg. Dieser wurde zwar tief verehrt, doch primär war es der Abendländischen Bewegung um die Verwirklichung einer "gottgewollten Ordnung" für ein geeintes, politisch und geistig starkes Europa zu tun: Ein starker kaiserlicher Herrscher stellte für die Autoren des Neuen Abendlandes den bestmöglichen, wenn auch nicht einzig möglichen, Garanten für eine solche $\mathrm{Au}$ torität dar. Die abendländische Begeisterung für Salazar oder Franco macht deutlich, daß ebenso autoritäre, halbdiktatorische Herrscher den Ansprüchen der Abendländer genügt hätten. Mit dem Verzicht Otto von Habsburgs auf die Kaiserkrone im Mai 1961 verschwand die Monarchie als Teil ständisch-autoritärer Staatsformationen rasch und endgültig aus dem abendländischen Denken.

Mit dieser Aufnahme monarchistischer Elemente, aber auch der Mitteleuropaund der Reichs-Idee in die abendländischen Konzepte der fünfziger Jahre finden sich in den Jahrzehnten nach dem Krieg deutliche Kontinuitäten jener europäischen Ideen, die zwischen 1918 und 1945 in Deutschland so virulent gewesen waren und die auch im Nationalsozialismus, nun in enger Verbindung zu „Großraum"-Vorstellungen, hatten weiterexistieren können. Es zeigt sich, daß traditionelle deutsche Ordnungsvorstellungen die Brüche von 1933 und 1945 im Kern unbeschadet überstehen konnten, wenn sie auch unter unterschiedlichen politischen Rahmenbedingungen je unterschiedliche Ausprägungen annahmen.

\section{Vom abendländischen Staatsverständnis: die Abendländer und die Demokratie der Bundesrepublik}

Nicht nur europäische Ordnungskategorien des deutschen Konservatismus konnten die "Zäsur" von 1945 unbeschadet überstehen. Dies galt ebenso für jene Konzepte der Abendländer, die sich auf die Ordnung der deutschen Gesellschaft bezogen. Auch hier spannt sich ein großer Bogen von den zwanziger bis in die fünfziger Jahre. Denn die Rede vom „Abendland“ diente nicht zuletzt während des gesamten Zeitraumes auch dazu, weitergehende Interessen an einer grundsätzlichen Umgestaltung der deutschen Gesellschaft zu transportieren, die sich nicht zuletzt gegen die Entwicklung der modernen Gesellschaft richteten. ${ }^{174}$ So war das "Abendland“ mehr als eine politische „Antithese zum bürgerlichen Nationalstaat “. ${ }^{175}$ Vielmehr ging es um eine grundsätzliche Antithese zur Moderne. Die Unzufriedenheit konfessionell geprägter, bürgerlicher Schichten mit der modernen Gesellschaft, ihrem politischen und wirtschaftlichen System, schlug sich in

173 Ders.: Heiße Eisen. Über den Wiederaufbau Mitteleuropas, in: Neues Abendland 9 (1954), S. 707-718.

174 Heil, Föderalismus als Weltanschauung, S. 168.

175 Kurt Sontheimer in bezug auf das "Reich“, in: Ders., Antidemokratisches Denken, S. 243. 
geschlossenen "Gegenideologien“ nieder, wie sie nicht zuletzt, aber auch nicht ausschließlich, im „Abendland“ ihren Ausdruck fanden. Dies soll im folgenden durch einen Blick auf das abendländische Staatsverständnis gezeigt werden.

Ausgehend vom personalistischen Gesellschaftsbild der katholischen Soziallehre, entwickelte sich das abendländische Gesellschaftsverständnis, nach welchem dem einzelnen unveräußerliche Rechte zukamen. ${ }^{176}$ Allerdings verstanden die Abendländer darunter nicht liberale Freiheits- und Gleichheitsrechte. Denn während der Liberalismus den Menschen vermeintlich auf seine Individualität reduzierte, betonten die katholische Gesellschaftslehre und auch das abendländische Denken von den zwanziger bis weit in die fünfziger Jahre hinein den sozialen Bezug des einzelnen zur Gemeinschaft. Diese sei ebenso wie die Einzelpersönlichkeit Teil einer "gottgewollten Ordnung“, und insofern müsse der einzelne Pflichten gegenüber der Gesellschaft übernehmen und mit seinen Interessen ihr gegenüber im Zweifelsfall zurückstehen. Daraus ergab sich eine starke Betonung von Ordnung und Autorität. „Die Überwindung einer falsch verstandenen Freiheit [hin] zur echten Freiheit durch Bindung des einzelnen Menschen an Gott, seine Gebote, das eigene Gewissen und durch Bindung an den Ordo von Gemeinschaft", das war es, was im abendländischen Interesse stand. ${ }^{177}$ Aus der Tatsache, daß individuelle Freiheit immer nur begrenzte Freiheit innerhalb der gottgegebenen Gemeinschaft war, ließ sich rasch folgern, daß Ordnung unerläßliche Voraussetzung für Freiheit darstelle: „Freiheit und Ordnung sind Wechselbegriffe; keines kann ohne das andere bestehen. Darum sind sie auch von den gleichen Gefahren bedroht. Das verführerische Ideal der Gleichheit führt mit Notwendigkeit zu einer Einebnung aller Unterschiede, zur Aufhebung des Menschlichen selbst, und es vollendet sich in dem radikalen Willen, die Gleichheit nicht nur der äußeren Lage, sondern auch des menschlichen Denkens und Seins mit den brutalsten Mitteln zu erzwingen [...]. In der höllischen Trinität ,Freiheit, Gleichheit und Brüderlichkeit' schließt eines das andere, jedes das andere aus: Auf dem Boden der Gleichheit gibt es weder Freiheit noch Brüderlichkeit, weil nämlich Freiheit und Brüderlichkeit immer nur in der willigen Anerkennung des anderen als des anderen bestehen kann. " 178 Bei diesem auf dem Subsidiaritätsprinzip beruhenden Gesellschaftsmodell speziell abendländischer Ausprägung handelte es sich um ein festgefügtes soziales System mit hierarchischem Aufbau, das einem jeden einen festen Platz innerhalb der Ordnung zuwies. Das abendländische Gesellschaftsverständnis war gekennzeichnet von einer Ablehnung sozialer Mobilität, statt dessen

176 Diese Grundrechte des Menschen schlossen im abendländischen Verständnis neben der Religionsfreiheit auch das Recht auf „innere Freiheit“, auf „Ehre, Freiheit, Selbstbestimmung, Leben, Eigentum, Arbeit" und freie Berufswahl oder das Eigenrecht der Familie auf Erziehung ein. Vgl. z. B.: Boe, Ludwig: Bürgertum und Proletariat, in: Neues Abendland 4 (1949), S. 171-176, hier S. 175.

177 Ankündigung der Jahrestagung der Abendländischen Akademie vom 26.-31. 7. 1953 in Eichstätt, in: Neues Abendland 8 (1953), S. 447.

178 Stählin, Wilhelm: Das Begriffsfeld der Ordnung, in: Neues Abendland 8 (1953), S. 601608, hier S. 607. 
verlangte es feste soziale Gruppierungen, denen der einzelne angehören solle und die er auch nicht verlassen könne. ${ }^{179}$

Konsequenterweise wehrten sich die Abendländer wiederholt, gerade in den fünfziger Jahren, als den Zeitgenossen einerseits die durch die Umwälzungen der Kriegs- und Nachkriegszeit hervorgerufene erhöhte soziale Mobilität stärker ins Bewußtsein rückte, sich andererseits die sozialen Auswirkungen des „Wirtschaftswunders" bemerkbar zu machen begannen, gegen die "nivellierenden Tendenzen der Epoche“. ${ }^{180}$ Das Ergebnis solcher Auflösungstendenzen konnte in ihren Augen letztlich nur negativ sein: „Indem jedoch die Ordnung als solche negiert wird, mißlingt das eigentliche Ziel einer Gesellschaftsreform, an ihre Stelle tritt der Kampf aller gegen alle, das Ende ist das Chaos." 181 Nur durch Stärkung der gesellschaftlichen „Keimzelle“, der Familie, und durch religiös-moralische Erziehung könne dem Chaos vorgebeugt werden. ${ }^{182}$

Aus diesem Gesellschaftsbild leitete sich das abendländische Staatsverständnis ab. „Der Staat ist [...] ein Teil der natürlichen Schöpfungsordnung, im Menschen potentiell angelegt, dabei in seiner Ausgestaltung dessen Freiheit überantwortet, mit dem Ziel, dem Menschen zu dienen und die Ordnung menschlichen Zusammenlebens zu gewährleisten. " 183 Der Staat sei Teil der subsidiär geformten Gesellschaft, um die schwächeren Glieder der Gemeinschaft zu schützen. Daß der Staat dafür Macht und Autorität benötige, der sich der einzelne Mensch zu seinem eigenem Wohl beugen müsse, stand für die Abendländer außer Frage, leitete sich diese Überzeugung doch aus der Auffassung über eine hierarchische Gesellschaftsstruktur ab. ${ }^{184}$ Konsequenterweise beklagte die Abendländische Bewegung von den zwanziger bis in die fünfziger Jahre hinein den "Verfall von Autorität" als „Zeiterkrankung“. 185

Seine Macht bezog der Staat im abendländischen Verständnis „nicht durch einen Gesellschaftsvertrag, der eine reine Fiktion ist, sie steht ihm vielmehr wesensmäßig zu, so wie dem Vater in der Familie von Natur die väterliche Gewalt zukommt ". ${ }^{186}$ Staatliche Macht könne daher nur in Gottes Willen und damit im Naturrecht ihren Ursprung, damit freilich aber auch ihre Grenzen finden. „Das Recht bedarf zwar der Macht zu seiner Realisierung, aber es beruht nicht auf ihr,

179 Eine ideal geordnete Gesellschaft sahen die Abendländer im Mittelalter verwirklicht: „Im Bewußtsein der Menschen war diese Gesellschaftspyramide eine natürliche Ordnung, in dem Sinn, daß sie letzten Endes von Gott gewollt war. "Vgl. Kroll, Grundlagen abendländischer Erneuerung, S. 22.

180 Franzel, Emil: Die nivellierenden Tendenzen der Epoche, in: Neues Abendland 7 (1952), S. 17-30, hier S. 17.

181 Kroll, Grundlagen abendländischer Erneuerung, S. 23.

182 Vgl. zu diesen Themen auch die Magisterarbeit der Autorin: Plichta (jetzt Conze), Bollwerk christlicher Kultur.

183 Kroll, Grundlagen abendländischer Erneuerung, S. 49.

184 Ibach, Helmut: Politik auf kurze Sicht, in: Neues Abendland 7 (1952), S. 617-620, hier S. 620, in diesem Sinne vgl. auch: Ders.: An der falschen Front, in: Neues Abendland 8 (1953) S. 47-49.

185 Steeruwitz: Kulturkritik nach Weltwirtschaftsplan, in: Abendland 1 (1946), S. 135-138, hier S. 136.

186 Kroll, Grundlagen abendländischer Erneuerung, S. 49. 
sondern gibt umgekehrt jener erst den Charakter moralischer Gegründetheit und ihren Anordnungen Verpflichtungscharakter." 187 Vor und nach 1945 galt der Kampf der Abendländer also einer Durchsetzung bzw. Besinnung auf das Naturrecht. Nach dem Zweiten Weltkrieg verstärkte sich dieser Kampf noch einmal mit dem Argument, nur die sittlichen Grundlagen des Naturrecht könnten totalitären Tendenzen in Zukunft vorbeugen. Die Arbeiten Ernst von Hippels, Vorstandsmitglied der Abendländischen Akademie, zeigen diese Kontinuität im abendländischen Wirken beispielhaft. Bereits vor 1933 und auch in den Jahren des „Dritten Reiches“ hatte sich der Jurist für einen erneuerten Rechtsbegriff eingesetzt: „Das Recht ist [...] seinem Wesen nach Ausdruck der göttlichen Weltenordnung, die sich als Wissen um Recht und Unrecht im Menscheninnern offenbart." 188 Nur eine föderative Staats- und Gesellschaftsordnung, die sich auf naturrechtliche Grundlagen berufe, könne das Abendland vor dem Bolschewismus schützen, diese Argumentation vertrat Hippel vor wie nach 1945 unverändert. 189

Die Verfassung, als Fixierung der Ordnung menschlicher Gemeinschaft, bedeutete den Abendländern konsequenterweise "nicht einfach ein Rechenexempel und eine juristische Spielerei, sondern Dienst an der Idee des Rechts“. Sie könne „nur auf Gott gegründet werden. Eine Verfassung schaffen, heißt daher, die Wirklichkeit Gottes anerkennen“. ${ }^{190}$ Damit waren die Forderungen der Abendländer an die nach 1945 entstehenden Länderverfassungen bzw. das Grundgesetz vorbestimmt. Das Prinzip der Volkssouveränität wurde schlicht negiert: „Der Satz, daß alle staatliche Gewalt vom Volke auszugehen habe, ist in die neuen Verfassungen nicht aufzunehmen." 191

Aus der Vorstellung vom Staat als Ergebnis eines Gesellschaftsvertrages, einer der "großen Illusionen der Menschheit" ${ }^{192}$ habe sich das historische „Konzept der modernen Formaldemokratie" entwickelt, welche, dies ist bereits an früherer Stelle angeklungen, nach abendländischer Vorstellung von totalitären Systemen immer nur einen kleinen Schritt entfernt war. ${ }^{193}$ Aus der Ablehnung des Vertragsrechtes und des Gleichheitsprinzips, tragenden Säulen der parlamentarisch-demokratischen Ordnung, sowie der Auffassung von den "totalitären Tendenzen“ demokratischer Ordnungen ergab sich eine negative Haltung der Abendländer gegenüber dem demokratischen Verfassungsstaat.

187 Hippel, Ernst von: Staat und Moral, in: Neues Abendland 2 (1947), S. 161-164, hier S. 163.

188 Ders., Mensch und Gemeinschaft, S. 145. Vgl. auch: Teil I, Kap. I.2.

189 Aber auch andere Abendländer forderten diesen Bezug auf naturrechtliche Grundlagen, vgl. z.B. Kroll, Grundlagen abendländischer Erneuerung, S. 120-126.

190 Franzel, Emil: Zur Verfassung des Deutschen Bundes, in: Neues Abendland 3 (1948), S. 257-260, hier S. 257.

191 Laforet, Georg: Das Volk als Verfassungsgeber, in: Neues Abendland 1 (1946), S. 1-4, hier S. 4. Mit dieser Forderung an die verfassunggebenden Organe standen die Abendländer übrigens in einer Linie mit der katholischen Kirche, vgl. Schewick, Die katholische Kirche und die Entstehung der Verfassungen, S. 111-121.

192 Hippel, Ernst von: Rousseaus Staatslehre als Mystik der Menschheit, in: Neues Abendland 6 (1951), S. 337-345, hier S. 337.

193 Ders.: Ungeschriebenes Verfassungsrecht, in: Neues Abendland 7 (1952), S. 201-211, hier S. 210. 
Somit standen die Abendländer auch den deutschen Demokratien der zwanziger und der fünfziger Jahre skeptisch gegenüber. In den zwanziger Jahren, als man die Außenpolitik der Republik stützte, fanden sich zwar gelegentlich Stimmen, die der Meinung waren, die Demokratie sei die "Staatsform der Zukunft" ${ }^{194}$. Doch selbst das Bekenntnis „Wir sind stolz auf unsere junge Demokratie“ konnte bereits damals nicht ohne den Hinweis daherkommen: „... aber man zerrt sie hin und her im Parteikampf, der sie zermürbt und entnervt." ${ }^{195}$ Die grundsätzliche Überzeugung, es bestehe ein „unüberbrückbarer Gegensatz der Begriffswerte ,katholisch' und ,Partei“", machte bereits in der Zeitschrift Abendland das Bekenntnis zum Weimarer Staat nur zu einem halbherzigen. ${ }^{196}$ Selbst die mehr oder weniger „vernunftrepublikanischen" Vertreter im Abendland enthielten sich beinahe nie des Hinweises, daß grundsätzliche Veränderungen im Verfassungsgebäude unumgänglich seien und der Weg - weg von der „Formal-“ und „Massendemokratie“ - hin zu einer „christlichen Demokratie“ führen müsse. Diese sollte subsidiär und föderativ geordnet sein und bezog ihre Kernelemente im abendländischen Denken entweder aus der katholischen Staatslehre oder aber aus den ständestaatlichen Konzepten Othmar Spanns. Dessen „Universalismus“ gegenüber der „individualistischen Staatsauffassung“ des Liberalismus galt als theoretischer Leitfaden. ${ }^{197}$.

Diese, wenn auch zwiespältige Verbundenheit mit der Republik verlor sich allerdings im „Abendland“ Anfang der dreißiger Jahre vollständig: Je stärker das „Reich“ an Einfluß gewann und zur einheitsstiftenden Kategorie im deutschen Konservatismus wurde, desto deutlicher wurde die abendländische Kritik an der Demokratie und desto lauter wurden die Rufe nach „Führertum“ und „Gemeinschaft" als zentralen Elementen eines zu gründenden „Reiches“. Auch wenn die Hoffnungen, zusammen mit der nationalsozialistischen „Bewegung“ einen "Christlichen Ständestaat" bzw. ein erneuertes Sacrum Imperium verwirklichen zu können, schon bald nach der "Machtübernahme" verpufften, die Sehnsucht nach Autorität und Ordnung sollte dem „Abendland" erhalten bleiben.

Dies wurde mit der Gründung der Bundesrepublik Deutschland deutlich, als sich die Abendländer mit Kritik am neuen Staat nicht zurückhielten. Man begab sich in offene Opposition gegen die parlamentarische Demokratie. Das Werk des Parlamentarischen Rates wurde als „souveräne Verachtung der deutschen Geschichte“, als „zentralistischer deutscher Bund“, 198 als „künstliches Gebilde“199 bezeichnet. In den Augen der Abendländer hatte sich mit der „Formaldemokra-

194 Vgl. Platz, Hermann: Der Realismus der christlichen Demokratie Don Sturzos, in: Abendland 2 (1926/27), S. 135-137, hier S. 137.

195 Lauscher, Albert: Freie Reichsländer. Ein neuer Weg zur Lösung der deutschen Frage, in: Abendland 3 (1928), S. 67-70.

196 Moro, Gerolamo Lino: Die Krise im italienischen Popularismus, in: Abendland 1 (1925/ 26), S. 367-371.

197 Vgl. u. a. Richl, Hans: Othmar Spann, sein Werden und Werk, in: Abendland 1 (1925/26), S. 252-254.

198 Kroll, Grundlagen abendländischer Erneuerung, S. 51.

199 Laforet, Georg: Der Bonner Parteienstaat, in: Neues Abendland 4 (1949), S. 234-236, hier S. 234. 
tie“ genau jener Staat gebildet, „dessen Rechtsbegriffe von zufälligen Mehrheitsentscheidungen abhängen "200, und dem das gleiche Schicksal wie der Weimarer Republik drohe. Der nur unzureichend verwirklichte Föderalismus werde sich in Zeiten außenpolitischer Bedrohung wie jenen des Kalten Krieges als fatal erweisen: „Das ,Schottensystem' föderalistischer Staaten sichert sie [die Republik] gegen Einbrüche fremder Ideologien und Mächte, auch wenn an irgendeiner Stelle ein Leck vorhanden ist. Im zentralistischen Staat dringt durch solch ein Leck sogleich die Flut der fremden Ideologien ungehemmt ein. [...] Das zentralistische Deutschland wird es schwer haben, sich gegen die rote Flut zu wehren."201

Diese Kritik an der jungen Demokratie verbanden die Abendländer mit der Anschuldigung, daß der neue Staat eigentlich kein deutsches Gebilde sei: „Das Bonner Grundgesetz ist als Ganzes ein Werk der westlichen Besatzungsmächte" 202 , während die Deutschen eigentlich dem Ruf nach einer Verfassungsbildung nicht hätten folgen wollen: „Wir kennen kein Beispiel, daß jemals in der Geschichte eine Staatsordnung, eine Verfassung unter so trüben Auspizien geschaffen worden wäre. " ${ }^{203} \mathrm{Zu}$ diesen anti-alliierten Äußerungen gesellte sich die Feststellung, daß die „Republik“ eigentlich keine deutsche, sondern eine „westliche" Staatsform sei, ${ }^{204}$ und daß man sich besser auf andere, traditionelle Staatsformen, wie die Monarchie oder ständische Gliederungsmodelle, hätte besinnen sollen. Diese auf konservativer Seite seit langem zu findende Argumentationslinie eines nicht-westlichen deutschen Sonderbewußtseins setzte sich auf diese Weise bis weit in die fünfziger Jahre hinein fort.

Die Untauglichkeit des demokratischen Prinzips sahen die Abendländer schon bald in der Parteienlandschaft der Bundesrepublik bestätigt, und sie schütteten Hohn und Spott über den Parlamentarismus und seine Funktionsweise aus. Dabei wurden sie deutlicher, als dies in den Jahren der Weimarer Republik je der Fall gewesen war, selbst nach 1930. Daß die SPD in diesem Zusammenhang keine Sympathie der Abendländer erlangte, braucht kaum näher erläutert zu werden. Aber auch die bürgerlichen Parteien konnten die Abendländer in den frühen fünfziger Jahren nicht vom Wert des Parteienstaates überzeugen. Der einzige Trost, der sich den Abendländern in dieser Situation bot, war die Vorstellung, daß es sich bei dem neugegründeten Staat nur um ein stehendes „Behelfsheim [handele], das nicht den Anspruch darauf erheben kann, Abbild einer endgültigen Ordnung zu sein"205, und das mit der Wiedervereinigung seine Form verlieren werde. Gerade die 1951 entstehende Abendländische Aktion machte sich diesen Standpunkt zu eigen. Mit

200 Demokratie und Papier, in: Neues Abendland 6 (1951), S. 258.

201 Murner (i.e. Emil Franzel): Berlin und Bonn, in: Neues Abendland 4 (1949), S. 360-363, hier S. 363/364.

202 Laforet, Georg: Der Bonner Parteienstaat, in: Neues Abendland 4 (1949), S. 234-236, hier S. 234.

203 Franzel, Emil: Zur Verfassung des deutschen Bundes, in: Neues Abendland 3 (1947), S. 257-260, hier S. 257.

204 Martini, Wilfried: Die Entartung der Politik, in: Neues Abendland 7 (1952), S. 1-10, hier S. 10.

205 Zur ersten Kundgebung der Abendländischen Aktion, in: Neues Abendland 7 (1952), S. 242-245, hier S. 242. 
der Begründung, aus Angst vor dem „Einsturz“ des labilen gegenwärtigen Systems ein „Ordnungsbild“ für kommende Zeiten entwerfen zu wollen, machte die Abendländische Aktion fundamentale Umgestaltungsansprüche geltend. Umsturzabsichten waren damit jedoch nicht verbunden: „Die Abendländische Aktion erkennt darüber hinaus an, daß auch die in einer Formaldemokratie nach der Lehre vom Gesellschaftsvertrag zustande gekommene Staatsgewalt von Gott ist, sie fordert daher von ihren Anhängern gegenüber einem solchen Staat gebührenden Gehorsam." 206 Statt dessen ging es den Abendländern darum, die Bevölkerung, insbesondere intellektuelle Kreise, auf die mit der Wiedervereinigung zu erwartende Diskussion um die staatliche Gestalt Deutschlands vorzubereiten, um dann „Enttäuschungen“, wie man sie 1949 erlebt hatte, vermeiden zu können.

Die Enttäuschung der Abendländer über das westdeutsche Staatswesen war nicht zuletzt deshalb so groß, weil man sich nach dem Ende des Zweiten Weltkrieges große Hoffnungen auf eine christlich-autoritäre Ausformung des staatlichen Systems gemacht hatte, wohl auch in dem Glauben, aufgrund der starken moralischen Position, die der Katholizismus in dieser Periode einnahm, mit den eigenen Forderungen erfolgreich zu sein. Diese Hoffnungen hatten sich allerdings mit Gründung der Bundesrepublik zerschlagen, und so klammerten die Abendländer sich in den ersten Jahren an die Erwartung, die Wiedervereinigung werde die Frage nach der idealen Staatsform erneut stellen. Die weltpolitische Situation ließ allerdings die Aussicht auf Wiedervereinigung rasch schwinden und mit ihr jene auf eine grundsätzliche Veränderung des Staatswesens. Immerhin führte der abendländische Antikommunismus dazu, daß man der Westbindung der Bundesrepublik eindeutig den Vorzug gab vor einer Wiedervereinigung unter neutralistischen Vorzeichen. Dafür war man sogar bereit, sich gezwungenermaßen mit der „Formaldemokratie“ in Westdeutschland abzufinden.

Nur langsam veränderte die abendländische Bewegung ihre Haltung gegenüber der westdeutschen Demokratie. So wenig man den Grundregeln der „Formaldemokratie" positiv gegenüberstand, so sehr ermöglichte doch der erste Kanzler der Bundesrepublik, Konrad Adenauer, eine zumindest gewisse Annäherung der Abendländer an das bestehende System und söhnte sie zumindest partiell mit der freiheitlich-demokratischen Grundordnung der Bundesrepublik aus. ${ }^{207} \mathrm{Konrad}$ Adenauer nahmen die Abendländer von ihrer Kritik an der staatlichen Ordnung der Bundesrepublik und an den einzelnen Parteien aus. Das Neue Abendland zollte ihm, den man über den „Parteienzwist“ erhaben glaubte, schon bald über alle Maßen Respekt und Anerkennung. „Ein gütiges Geschick“ habe „neben so vielen Nieten aus dem Losbeutel der Parteien den einen 'Treffer beschert" ${ }^{208}$ Die

206 Ebenda.

207 Hier handelte es sich um einen ganz ähnlichen Vorgang wie innerhalb des westdeutschen Katholizismus. Vgl. Doering-Manteuffel, Kirche und Katholizismus in der Bundesrepublik, S. 123-127.

208 Franzel, Emil: Der Kanzler. Zum 75. Geburtstag Dr. Konrad Adenauers am 5. 1. 1951, in: Neues Abendland 6 (1951), S. 1-3, hier S. 1. Vgl. auch: Ders.: Von Bismarck zu Adenauer, in: Neues Abendland 6 (1951), S. 51-65, hier S. 63, wo der Kanzler als „in abendländischrömischer Tradition fest verwurzelter Katholik“, als „genialer Amateur" und „echter Demokrat“ erschien. Er habe den „Blick für die Realitäten, den Mut zur Verantwortung, die 
positive Beurteilung Konrad Adenauers hatte zwei Grundlagen: Zum ersten sahen die Abendländer, im rheinisch-katholischen Bundeskanzler einen Mann der „richtigen“ Weltanschauung. ${ }^{209}$ Adenauers häufiger Gebrauch des Wortes Abendland, seine Rhetorik vom „christlichen Europa“ interpretierten die Abendländer als Nähe zu den eigenen Konzepten. ${ }^{210}$ Die Tatsache, daß der Kanzler mit seiner auch ideell verankerten Westintegrationspolitik, welche wiederum die Europa-Union an Adenauer band, vielen Überzeugungen der Abendländer widersprach, übersahen sie.211

Einen zweiten Grund hatte die abendländische Sympathie für Konrad Adenauer im Regierungsstil des Kanzlers. Die autoritären Züge im Führungsstil Adenauers, die ihren Niederschlag im Begriff der "Kanzlerdemokratie“212 fanden, entsprachen den abendländischen Vorstellungen von "Autorität“. Gerade das „unkollegiale“ Prinzip, durch welches Adenauer das Kabinett von Entscheidungen fernhielt und als "Quasimonarch" die Herrschaft in Händen hielt, bedeutete den Abendländern die einzige Möglichkeit, die „Diktatur der Parteien“ zu überwinden. Aufgrund dieses Regierungsstils blieb in abendländischen Augen das durch den „Parlamentarismus" drohende Chaos aus. So fanden die Abendländer ihr Plädoyer für autoritäre Führung in der Verfassungsrealität eingelöst durch den ersten Kanzler der Bundesrepublik.

Für die Abendländer war dieses Lob für Adenauers Kanzlerdemokratie eigentlich aufgrund ihrer tiefgreifenden Parteienskepsis nicht zu erwarten gewesen. Seit den zwanziger Jahren forderten sie, der Vermassung einer „Formaldemokratie“ durch Elitenbildung entgegenzutreten, da Demokratie ihnen zuvorderst eine Frage der "Auslese“ war:213 „Die Kraft und Lebensfähigkeit eines Volkes erwächst primär dem geistigen Rang, der Konsistenz und der Fluktuation einer Oberschicht, die volksführend und staatsbestimmend wirkt." ${ }^{214}$ So erachteten es die Abendländer als dringend notwendig, "den Massebrei wieder in eine echte Rangordnung mit dem Ziel der Herausbildung einer wirklichen Elite zu gliedern

Freude am großen Entschluß, die Kaltblütigkeit, die Eleganz des Fechters“ und bringe die Kraft zum „Festhalten am Wesentlichen, die Bereitschaft zum Kompromiß und die taktische Wendigkeit" mit, die ein wahrer Politiker benötige.

209 Doering-Manteuffel, Die Bundesrepublik in der Ära Adenauer, S. 31.

210 Ebenda, S. 32. Zur Verwendung des Begriffes „Abendland“ durch Konrad Adenauer siehe z.B. Doering-Manteuffel, Rheinischer Katholik im Kalten Krieg. Jost, Der Abendland-Gedanke. Weidenfeld, Konrad Adenauer und Europa.

211 Vgl. hierzu die Zusammenfassung.

212 Vgl. zur "Kanzlerdemokratie“ Doering-Manteuffel, Strukturmerkmale der Kanzlerdemokratie.

213 Vgl. z. B.: Laforet, Georg: Verfassungskrisis, in: Neues Abendland 3 (1948), S. 110-115. Kipp, Heinrich: Verfassungsschutz, in: Neues Abendland 3 (1948), S. 369-372. Corolian: Mittlere Demokratie, in: Neues Abendland 5 (1950), S. 31. Ders.: L'état c'est le député, in: Neues Abendland 5 (1950), S. 301. Franzel, Emil: Die nivellierenden Tendenzen der Epoche, in: Neues Abendland 7 (1952), S. 17-30. Herre, Franz: Bundesrepublikanisches Paradoxon, in: Neues Abendland 9 (1954), S. 359-361. Hülsmann, Bernhard: Politische Axiome, in: Neues Abendland 10 (1955), S. 79-86. Ludwig, Heinrich: Gegenwart, Elite und Tradition, in: Neues Abendland 12 (1957), S. 216-224.

214 Hülsmann, Bernhard: Politische Axiome, in: Neues Abendland 10 (1955), S. 79-86, hier S. 86. 
und den politischen Raum mit dem Pathos einer echten Staatsidee zu füllen". ${ }^{215}$ Doch die Vertreter der politischen Parteien stellten nach abendländischem Verständnis eine solche Elite nicht dar. Hier findet das bereits in der Zwischenkriegszeit von den Abendländern an den Tag gelegte "überparteilich-unpolitische“ Verhalten seine Fortsetzung. Die Sehnsucht nach einer „Volksgemeinschaft“, einem dem „Parteienstaat “ gegenüberstehenden „Volksstaat", der nicht von parteipolitischen Interessen „zerfressen“ würde, hatte schon das abendländische Staatsideal der Zwischenkriegszeit geprägt. ${ }^{216}$ Diese grundsätzliche Skepsis Parteien gegenüber, die dem abendländischen Weltbild seit der Zwischenkriegszeit zu eigen gewesen war, begann sich auch in den fünfziger Jahren nur langsam zu wandeln. Endgültig sollten die Abendländer erst im Verlauf der sechziger Jahre zu einem entspannteren Verhältnis gegenüber dem Parteienstaat finden.

Eingeleitet wurde das partielle Arrangement der Abendländer mit der ungeliebten Demokratie und auch mit dem Parteiensystem im Gefolge Adenauers. Der Sieg der Unionsparteien bei der Bundestagswahl 1953 trug hierzu zusätzlich bei. Denn bei aller grundsätzlichen Ablehnung von Parteien konstatierte man nun, in der CDU hätten sich Menschen „aus christlichem Bekenntnis“ und jenseits aller Konfessionalität zusammengefunden.217 Nach dem Wahlerfolg müsse nun der „Unions“-Gedanke „nachträglich mit Bewußtsein gefüllt werden“: Nicht mehr Konfessionalismus, nicht mehr Nationalismus oder Klassenkampf hätten zu gelten, ${ }^{218}$ statt dessen bestünde jetzt die Chance, eine neue Einheit zumindest innerhalb eines Teils des Volkes zu finden. Damit war die Union den Abendländern „kein Zweckbündnis, sondern als Ganzes mehr als die Summe ihrer Teile“. ${ }^{219}$ Sie wurde für die abendländischen Konzeptionen zumindest teilweise vereinnahmt: Indem man ihr den Parteiencharakter absprach, konnte sie nun im abendländischen Sinn als "organische Gemeinschaft" in Dienst genommen werden. Die alte abendländisch-konservative Vorliebe für "Überparteiliches" schlägt hier in der Beurteilung der Unionsparteien in der ersten Hälfte der fünfziger Jahre wieder durch. Zwar täuschten sich die Abendländer Mitte der fünfziger Jahre gründlich, wenn sie glaubten, die Union entspräche ihren eigenen Vorstellungen, wäre also eigentlich gar keine politische Partei, sondern eine „organische Gemeinschaft", für welche die üblichen parteipolitischen Spielregeln keine Gültigkeit hätten. Dennoch sollte die, wenn auch gewissermaßen unter „falschen“ Voraussetzungen stattfindende, Annäherung an die Union langsam aber sicher auch zu einer Akzeptanz von Parteien als Teil des politischen Systems führen - wenn dieser Prozeß auch erst Anfang der sechziger Jahre abgeschlossen war. Jene Abendländer, die aktiv politisch in den Reihen der Union tätig waren, hatten erheblichen Anteil an

\footnotetext{
215 Ebenda.

216 Vgl. bspw. Dempf, Alois: Individualistische und universalistische Staatsauffassung, in: Abendland 2 (1926/27), S. 72-74.

217 Stickrodt, Georg: Tagespolitik und kirchliche Verantwortung, in: Neues Abendland 9 (1954), S. 13-22. Zum Anspruch der CDU auf Überkonfessionalität und den damit auftretenden Problemen siehe: Doering-Manteuffel, Die "Frommen" und die "Linken“.

218 Ibach, Helmut: Meist ist es später, als Du denkst, in: Neues Abendland 9 (1954), S. If., hier S. 2.

219 Herre, Franz: Die Union ist mehr, in: Neues Abendland 9 (1954), S. 101-103, hier S. 103.
} 
dieser Entwicklung. Wenn sich Männer wie Richard Jaeger oder Hans-Joachim von Merkatz in den Reihen der Abendländischen Bewegung engagierten, in der die traditionelle Parteien- und Demokratieskepsis der Zwischenkriegszeit weiterlebte, gleichzeitig aber als Bundestagsabgeordnete oder gar Bundesminister Vertreter dieser Demokratie waren, so entwickelte sich hier eine Dichotomie, die sich nur in den frühen fünfziger Jahren vertreten ließ, als traditionelle Konzepte noch weitgehend akzeptiert waren. In der zweiten Hälfte der fünfziger Jahre, mit der Etablierung der westdeutschen Demokratie, waren es gerade jene offiziellen Vertreter der Bonner Republik, die auf den Boden der Tatsachen fanden und die Abendländische Bewegung in Richtung Akzeptanz des Systems führten.220

Doch bis mindestens Mitte der fünfziger Jahre blieb die „Wiederherstellung einer hierarchisch-autoritären Staatsordnung ",221 in der der Rechtsstaat durch die Bindung an ein göttliches Naturgesetz abgesichert sein, eine Elite „Parteiendiktatur" verhindern und die Volkssouveränität so weit als möglich eingeschränkt werden sollte, das Ziel der Abendländer. Obwohl die Ziele damit ähnlich gesteckt waren wie schon in der Zwischenkriegszeit, scheint es, als hätten die Abendländer nach dem Zweiten Weltkrieg diese Politikkonzeptionen noch deutlicher formuliert als in den zwanziger und dreißiger Jahren. Dies mag mit verschiedenen Faktoren zusammenhängen: Man glaubte bis in die fünfziger Jahre hinein, daß es, angesichts des für eine „Übergangszeit“ gestalteten „Notbaus der Bonner Bundesrepublik“,222 tatsächlich die Möglichkeit einer grundsätzlichen Neuordnung geben werde. Selbst nach Gründung der Bundesrepublik schienen Planungen für die Zeit nach der Wiedervereinigung, wenn das „Provisorium“ des Grundgesetzes aufgehoben würde, legitim. Mitte der fünfziger Jahre sollten die abendländischen Positionen dann erstmals in die Kritik geraten. Und gerade in Reaktion auf diese Kritik formulierten die Abendländer ihre politischen Überzeugungen um so deutlicher, etwa auf der Jahrestagung der Abendländischen Akademie 1956. In den zwanziger und dreißiger Jahren hingegen waren staatspolitische Vorstellungen dieser Art in konservativen Kreisen weit verbreitet gewesen und bedurften keiner weiteren Erläuterung.

\section{Ein erneuerter Konservatismus als Zielpunkt abendländischer Interessen}

Angesichts dieser Positionen verwundert es kaum, daß die in der zweiten Hälfte der vierziger Jahre noch spürbare Zurückhaltung der Abendländer gegenüber dem Begriff „konservativ“ in den fünfziger Jahren aufgegeben wurde. Mit dem Einzug Emil Franzels in die Redaktion erfuhr der Begriff „Konservatismus“ im Neuen Abendland schlagartig eine positive Wertung. Damit griff die abendländische Bewegung gleichzeitig Bezüge zur „Konservativen Revolution“ wieder auf. Schon 1936 hatte Franzel die „Konservative Revolution des Abendlandes“ gefor-

220 Vgl. hierzu Teil I, Kap. II.3.

221 Franzel, Emil: Die nivellierenden Tendenzen der Epoche, in: Neues Abendland 7 (1952), S. 17-30, hier S. 25.

222 Heydte, Friedrich August von der: Die übernationale Ordnung, in: Staat, Volk, übernationale Ordnung, S. 88-99, hier S. 89. 
dert, und er bezeichnete sich und die abendländische Bewegung der Zwischenkriegszeit nach 1945 dezidiert als der „Konservativen Revolution“ zugehörig, der Franzel schon seit den dreißiger Jahren jede geistige Nähe zum Nationalsozialismus absprach; über ihre (und seine eigenen) teils engen Bezüge zum „Dritten Reich" ging er schlicht hinweg.223

Der Konservatismus wurde in den fünfziger Jahren als einzig wertvolle politische Lebensform gegenüber anderen Alternativen bezeichnet: „Es hat sich gezeigt, daß nur der Konservatismus im Stande ist, Freiheit und Würde des einzelnen zu schützen, denn der [...] entartete Liberalismus ist immer in Gefahr, in den Cäsarismus umzuschlagen. Ebenso ist der Sozialismus in allen seinen Formen [...] unfriedlich.“"224 Neben der Rechristianisierung war die konservative politische Grundhaltung für die Abendländer eine unabdingbare Voraussetzung, um im „Zweifrontenkampf“ zu überleben und so die „konservative Wiedergeburt des christlichen Abendlandes" 225 durchzusetzen.

Allerdings stilisierten die Abendländer den Konservatismus bald zu mehr als einer rein politischen Haltung, die man beliebig annehmen oder ablehnen konnte. Er wurde zu einer "Lebensform“, die „sich niemals in begrifflichen Definitionen und rationalen Konstruktionen erschöpfen "226 könne. Damit übernahm die abendländische Bewegung ein für konservatives Denken typisches Argumentationsmuster, welches darin besteht, eben kein politisches Programm oder eine Ideologie zu vertreten, sondern konservativ zu sein. ${ }^{227} \mathrm{Zu}$ den wichtigsten Merkmalen dieser konservativen Lebensform zählte für die Abendländer die enge Verbindung zum Christentum. Der Glaube an eine „ewige, allen Dingen der Schöpfung eingegebene göttliche Ordnung“ und ihre „Analyse“ 228 führte zu den Elementen, die innerhalb des abendländischen Konservatismus konstitutiv waren: die Anerkennung der Schöpfungsordnung und des Naturrechtes, die Einbindung der Gegenwart in die historische Tradition, die Forderung nach Schutz der Familie und der patriarchalen Strukturen, die Anerkennung von gesellschaftlicher und politischer Autorität, damit einhergehend, die Verwerfung abstrakter Gleichheit und Freiheit, die Anerkennung des Privateigentums, des Rechtes auf Heimat, die Ablehnung der Technik als einer „Frucht des Sündenfalls“.229

Mit der positiven Bewertung des Begriffes "konservativ“ ab etwa 1948/49 sahen sich die Abendländer nun gezwungen, ihre eigene Position nach „rechts“ abzugrenzen. So lange man schlicht feststellen konnte, die anderen, die Konservativen stünden rechts, man selbst jedoch sei „föderal“(aber nicht konservativ), hatte diese Positionsbestimmung nicht erfolgen müssen. Den Vorwurf der „Restauration“,

223 Franzel, Abendländische Revolution, S. 256.

224 Zitat Robert Ingrim, in: Neues Abendland 5 (1950), S. 357.

225 Merkatz, Hans-Joachim von: Aufgaben und Möglichkeiten einer konservativen Politik, in: Konservative Haltung in der politischen Existenz, S. 40-49, hier S. 45.

226 Ebenda, S. 41.

227 Grebing, Konservative gegen die Demokratie, S. 22.

228 Stählin, Wilhelm: Konservative Haltung in der politischen Existenz, in: Konservative Haltung in der politischen Existenz, S. 12-26, hier S. 22.

229 Wenger, Paul Wilhelm: Aufgaben und Möglichkeiten einer konservativen Politik, in: Konservative Haltung in der politischen Existenz, S. 50-70, hier S. 59. 
welcher Anfang der fünfziger Jahre in den Frankfurter Heften geäußert wurde und der bald zum Schlagwort avancierte, 230 hatten die Abendländer bereits in den ersten Jahren nach Kriegsende erhoben: Sie prangerten, wie gesehen, in diesen Jahren die „Restauration“ des deutschen Geschichtsbildes an.231

$\mathrm{Ab}$ Anfang der fünfziger Jahre versuchten die Abendländer dann allerdings den Begriff der "Restauration“ positiv zu belegen und als seinen Gegensatz den der „Reaktion“ zu prägen. Auch damit argumentierten sie „klassisch“ konservativ. 232 Als "reaktionär" wurden im Neuen Abendland jene beschimpft, die nur Strukturen oder Denkhaltungen der Weimarer Republik wiederherstellten. Man selbst indes habe diese „Reaktion“ überwunden, und sei statt dessen zu wahrer, wertvoller "Restauration“ zurückgekehrt: mit der Orientierung an vor-nationalstaatlichen Strukturen wie überhaupt der Forderung nach einer Rückkehr zu vormodernen Zuständen. ${ }^{233}$ Hiermit grenzte man sich deutlich von den Frankfurter Heften ab, deren "Linkskatholizismus" die Abendländer zutiefst mißtrauten. Da einer der Herausgeber der Frankfurter Hefte, Eugen Kogon, gleichzeitig auch Präsident der Europa-Union war, deuten sich gravierende Unterschiede in den Stellungnahmen der hier betrachteten Europagruppierungen an. ${ }^{234}$ Die Debatten über „Restauration“, „Reaktion“ und das eigene Staatsverständnis bildeten die ideelle Grundlage für völlig unterschiedliche Europavorstellungen.

Je schwächer der anti-preußische Affekt im Neuen Abendland zu Beginn der fünfziger Jahre wurde, um so deutlicher spürt man die Bemühungen um eine Verbreiterung des konservativen Lagers. Mit der Verschärfung des Kalten Krieges ging es den Abendländern immer weniger darum, sich primär von protestantischen Konservativen abzugrenzen, wie dies noch in den ersten Nachkriegsjahren der Fall gewesen war. Statt dessen kam es nun eher darauf an, eine geschlossene konservativ-christliche Front im Kampf gegen den atheistischen Osten und den liberalen Westen zu bilden. Das „kämpferische Gottlosentum“235 des Ostens wie des Westens ließ für Richtungskämpfe innerhalb der konservativen „Front“ nach abendländischer Vorstellung keinen Raum mehr. Nun kam es den Abendländern darauf an, alle christlichen Kräfte zu sammeln, was sich eben auch in der organisatorischen Ausdifferenzierung der Abendländischen Bewegung niederschlug. Erst die Bemühungen, einen "neuen“ Konservatismus im Kalten Krieg zu schaffen, führten zu einem über die rein publizistische Ebene hinausgehenden Engagement der Abendländer. Denn ebenso wie im „Grundgedanken der Aussprache auf europäisch-abendländischer Ebene" für die abendländische Bewegung der Kern

$230 \mathrm{Vgl}$. Schwarz, Die Ära Adenauer, S. 446-453.

231 Vgl. Teil I, Kap. II.1.

232 Grebing, Konservative gegen die Demokratie, S. 23.

233 Vgl. z. B.: Franzel, Emil: Die restaurativen Tendenzen der Epoche, in: Neues Abendland 6 (1951), S. 529-542. Schütz, Paul: Restauration und Tradition, in: Neues Abendland 9 (1954), S. 221-224.

234 Vgl. Teil II, Kap. II.1. Die Frankfurter Hefte konnten der Abendland-Idee ebensowenig etwas abgewinnen, wie die Abendländer dem Linkskatholizismus. Vgl. rückblickend: Dirks, Das christliche Abendland.

235 Franz Xaver Schönmetzler bei den Jubiläumsfeierlichkeiten der 1000jährigen Wiederkehr der Schlacht auf dem Lechfeld in Augsburg 1955, in: Crux victorialis, S. 70. 
neuer europäischer Gemeinsamkeit begründet lag, mußten auch Konservative verschiedener Richtungen, das hieß in diesem Fall vor allem unterschiedlicher Konfessionen, in "gegenseitigem Verstehenlernen“ zueinanderfinden. ${ }^{236}$

In einem erneuerten Konservatismus sahen die Abendländer auch eine neue Chance, die junge Bundesrepublik nach ihren eigenen Vorstellungen umzugestalten, soweit dies ohne fundamentale Veränderungen möglich war. Die Abendländische Bewegung hoffte, selbst jene Elite bilden zu können, die zur Gesundung des Staates beitragen könne. Man hegte die Hoffnung, durch eine Art „Unterwanderung" einerseits, durch Politikberatung andererseits möglichst breiten Einfluß auf politische Entscheidungen innerhalb der CDU/CSU zu gewinnen. „Wir haben nicht zu fragen, wieviel wir mit der Arbeit unserer Abendländischen Akademie nun unmittelbare politische Wirkungen hervorrufen können. [...] Wir haben nur zu fragen, ob der Same etwas taugt, den wir ausstreuen, Same echter Erkenntnis und echter Verantwortung. Umschwirrt von Fragezeichen, guten Samen in das Land der Politik streuen, das ist konservative Haltung in der politischen Existenz." 237 Die Tatsache, daß die Abendländer neben den von ihnen organisierten offiziellen Veranstaltungen immer wieder bemüht waren, im Einzelgespräch auf Politiker einzuwirken und persönliche Netzwerke unter Konservativen zu spannen, um den „Samen“ (innerhalb der eigenen ideologischen Grenzen) möglichst weit zu streuen, zeugt von diesen Bemühungen. ${ }^{238}$

Der Versuch, einem erneuerten überkonfessionellen Konservatismus in den fünfziger Jahren eine geistige Heimat zu geben und ihre Vertreter gleichzeitig zur „Elite der Kanzlerdemokratie“ zu machen, schien zumindest bis Mitte der fünfziger Jahre durchaus gelungen. Das Schlagwort vom „Abendland“ bot sich wie kein anderes in diesen Jahren an, Konservative unterschiedlichster Provenienz zu versammeln: Über die Verwendung einer europäischen Kategorie, die in der Adenauer-Ära äußerst positiv besetzte Assoziationen, darunter allen voran Antikommunismus und Christentum, in sich trug, gelang es, zahlreiche Konservative für ein viel weitgehenderes Programm zu mobilisieren als die europäische Einigung. Traditionell-konservative Ordnungsvorstellungen erlebten auf diese Weise noch einmal einen erheblichen Aufschwung: Über das „Abendland“ gelang es der Bewegung, weitgreifende Umgestaltungsinteressen in die Gesellschaft zu tragen und damit auch durchaus auf positive Resonanz zu stoßen. Nicht zu unterschätzen ist bei der Suche nach Gründen für diese positive Resonanz gewiß ein ideelles Defizit der beginnenden europäischen Integration, die primär von wirtschaftlichen Fragen bestimmt war. Angesichts der 'Tatsache, daß „Europa“ jahrzehntelang im deutschen Sprachgebrauch hochideologisch aufgeladen war, fiel insbesondere konservativen Schichten die Anpassung an diesen funktionalistischen Ansatz nicht leicht. Plötzlich hieß es Abschied nehmen: Ähnlich wie die „Nation“ sollte

236 Mitteilungsblatt der Abendländischen Akademie, Oktober 1954, BA N 1243/15.

237 Stählin, Wilhelm: Konservative Haltung in der politischen Existenz, in: Konservative Haltung in der politischen Existenz, S. 12-26, hier S. 26.

238 Als Beispiel dafür kann etwa das Bemühen einzelner Abendländer um die Aufnahme diplomatischer Beziehungen der Bundesrepublik zu Spanien dienen, auf die in Teil I, Kap. II.3. einzugehen sein wird. 
sich auch "Europa" von seinen alten ideengeschichtlichen Wurzeln trennen, seine vielfältigen ideologischen Komponenten hinter sich lassen und ausschließlich „funktionalistisch“ definiert werden. Die Frage nach der „Vision“, nach dem Zielbild der europäischen Einigung geriet angesichts der Frage nach dem „Wie“ der Integration eher in den Hintergrund. 239

Hier konnte die Rede vom "Abendland“ in den fünfziger Jahren erhebliche Kompensationsarbeit leisten und sich wohl auch gerade deswegen erheblicher Popularität erfreuen. ${ }^{240}$ Indem man in abendländischen Kreisen die realen Schritte der westeuropäischen Integration durchaus akzeptierte, sie aber als zu kurzsichtig und einseitig diffamierte, indem man gewissermaßen eine Ebene darüber die weltanschaulich-überwölbende Vision des künftigen „Abendlandes“ beschwor, bot man Konservativen "Trost“ angesichts der rein funktionalen Rhetorik des Einigungsprozesses. Dies wiederum erklärt, warum sich in der Abendländischen Akademie auch Mitglieder fanden, die eigentlich nicht unbedingt als rechtskonservativ gelten. Heinrich von Brentano, seit 1955 deutscher Außenminister ist ein solcher Fall: Zwar war er Kuratoriumsmitglied, und gerade an seiner Mitgliedschaft entzündete sich die öffentliche Diskussion, durch die die Akademie im Sommer 1955 erheblich in Mißkredit geraten sollte; doch spiegeln die Quellen, daß er dem Unternehmen zwar freundschaftlich wohlwollend gegenüberstand, aktiv jedoch an Planungen und Konferenzen kaum teilnahm. Seine Mitgliedschaft - ebenso wie die anderer prominenter Politiker - erklärt sich gerade mit dem auf konservativkatholischer Seite in den fünfziger Jahren bemängelten „Ideendefizit“ der anlaufenden europäischen Integration: $\mathrm{Da}$ erst die militärische, später vor allem die wirtschaftliche Einigung im Zentrum des Geschehens stand, scheinen nicht wenige Konservative leitende „Ideen“, wie sie etwa die „abendländische Kultureinheit" darstellen konnte, vermißt zu haben. ${ }^{241}$ Die Mitgliedschaft in einer Organisation, die sich ganz deutlich auf eben jenen Bereich der europäischen Einigung konzentrierte, erschien in diesem Zusammenhang zumindest reizvoll. Konservative wie Brentano, aber auch Theodor Steltzer oder Hermann Pünder kamen auf diesen Wegen zur Abendländischen Akademie, konnten aber gleichzeitig, vermutlich ohne sich der Diskrepanz im Europaverständnis bewußt zu sein, Mitglieder in der Europäischen Bewegung sein.

\section{Aktivitäten der Abendländischen Akademie}

Gerade weil die abendländischen Positionen sich in der ersten Hälfte der fünfziger Jahre in vielem in einen breiten konservativen Konsens einpaßten, erhielt die Abendländische Akademie positive Resonanz, und die von ihr organisierten Vorträge und Tagungen waren meist gut besucht. In den Jahren nach ihrer Gründung 1952 entfaltete sie eine rege Aktivität, wobei etwa monatlich eine Veranstaltung stattfand. Man wollte die Arbeit in drei Hauptgebiete unterteilt sehen: „Tagungen über Grundsatzfragen“, daneben „Tagungen über politische Probleme“, wobei

${ }^{239}$ Vgl. zum Funktionalismus ausführlich Teil II, Kap. II.2.

240 Plichta (jetzt: Conze), Zwischen Rhein und Donau.

241 Ebenda. 
man sich unter "Tagung“ nicht selten einen Vortrag eines Akademiemitgliedes vorzustellen hat. Hinzu kamen, und hier spiegelt sich das abendländische Interesse an Mittel- und Osteuropa einerseits wie der zunehmende Einfluß von Vertriebenen auf die Abendländische Akademie andererseits, „Tagungen der Exilgruppen aus den Ländern hinter dem Eisernen Vorhang ".242 Mit diesen wollte man „den Vertretern aller Exilgruppen und Heimatvertriebenen die Möglichkeit [geben], in Vorträgen und Diskussionen die Problematik Osteuropas zu erörtern." Darüber hinaus arbeitete man bei all diesen Veranstaltungen eng mit dem CEDI zusammen: gemeinsame Veranstaltungen oder auch Vorträge von CEDIMitgliedern in Deutschland waren an der Tagesordnung. ${ }^{243}$ Schließlich bildete sich, neben den einzelnen Referaten der Akademie, auch ein Gesprächskreis am Bundesverfassungsgericht, an dem mit dem Richter Heinrich Weinkauff ein Mitglied der Abendländischen Akademie tätig war.

Wichtigste und größte Aktivitätsform waren jedoch die Jahrestagungen der Akademie. Die jährlich in Eichstätt stattfindenden Kongresse zogen zwischen 200 und 500 Teilnehmer an. ${ }^{244}$ In jedem Jahr unter einem anderen Themenschwerpunkt stehend, liefen sie immer nach dem gleichen Muster ab: Jeweils mehrere, in der Regel zwei Referenten, äußerten sich zu den selben Themen. Man demonstrierte dabei Überkonfessionalität und europäische Übernationalität, indem man z. B. einen katholischen und einen evangelischen oder einen deutschen und einen ausländischen Redner zu denselben Themen sprechen ließ; eine anschließende Diskussionsrunde vervollständigte den Ablauf. Damit entsprach die Organisation der Jahrestagungen exakt dem propagierten Anliegen der Akademie, das Verständnis für Vertreter anderer nationaler Kulturen im „Abendland“ oder anderer Konfessionen durch Vorträge und Gespräche zu erhöhen und dabei auch Diskussion und Austausch zu fördern. Funktionieren konnte dieses Konzept allerdings nur auf einer gemeinsamen ideellen Grundlage. Sowohl die anwesenden Protestanten wie auch die ausländischen Gäste standen auf dem Boden eines gemeinsamen abendländischen Weltbildes. Die Ausländer waren meist katholisch, die Protestanten gegenüber dem Katholizismus recht offen, und alle miteinander waren sie ausgesprochen konservativ. Nur so konnte man sich im Ergebnis auf gemeinsame Werte und Inhalte des „Abendlandes“ einigen. So stellte die Abendländische Bewegung, im Gegensatz etwa zur Europa-Union, eine durch und durch homogene Gruppierung dar. Während sich in der Europa-Union Vertreter ganz unterschiedlicher Parteien und Weltanschauungen zusammenfanden, blieb der Kreis jener, die die Abendländer ansprechen wollten, bewußt beschränkt auf Vertreter des konservativen Lagers.

242 Vgl. die Übersicht über Veranstaltungen der Abendländischen Akademie im Jahre 1954, BA N 1005/538.

243 Z.B. die gemeinsame Tagung von Abendländischer Akademie und CEDI zur „europäischen Wirtschaftspolitik" 1955 auf Schloß Sterkenburg/Holland, vgl. Mitteilungsblatt: Die Abendländische Akademie, Nr. 5, Dezember 1954, BA N 1243/15, oder die Vorträge des Marqués de Valdeiglesias über „Spanien und Europa“, zitiert nach: Veranstaltungen der Abendländischen Akademie im Jahre 1954, BA N 1005/538.

244 Vgl. die verschiedenen Angaben in: Schildt, Zwischen Abendland und Amerika. 
Die Jahrestagungen der Akademie widmeten sich grundsätzlichen Fragen, ganz im Sinne der eigenen Zielsetzung, nicht nur „die geistige Gemeinsamkeit der europäischen Völker über dem engen Nationalismus [...] sondern das eigentliche Wesen wahrer abendländischer Kultur in Vergangenheit und Gegenwart, die Ursachen des Jahrhunderte währenden Verfallsprozesses, die echten oder scheinbaren Ansätze einer heutigen Erneuerung im Für und Wider, in Gesprächen und Referaten zu klären".245 1952 rief die Abendländische Akademie daher zu ihrer ersten Tagung unter dem Titel „Werte und Formen im Abendland“, 1953 stand das Thema „Der Mensch und die Freiheit“ im Mittelpunkt. 1954 widmete man sich der Frage „Staat, Volk und übernationale Ordnung“ und 1955 schließlich betrachtete man „Das Abendland im Spiegel seiner Nationen“. Einen Bruch mit diesen theoretisch, "unpolitisch" angelegten, weltanschaulichen Themen finden wir erst im Jahr 1956, als sich die Abendländer in Eichstätt mit der „Konservativen Haltung in der politischen Existenz" auseinandersetzten. Obwohl ebenfalls recht allgemein formuliert, spiegeln sich in dieser Themenwahl aktuelle Ereignisse, war doch die Abendländische Akademie im Laufe des Sommers 1955 unter Beschuß eines Teils der bundesdeutschen Medien geraten.

\section{Die „Schlacht auf dem Lechfeld" 1955}

Mit der Arbeit der ersten Jahre war man in Kreisen der Abendländischen Akademie zufrieden. „Wir [...] blicken auf eine zweijährige Tätigkeit zurück. Es liegt uns fern, uns selbst ein Zeugnis auszustellen, aber wir glauben, daß wir doch einiges dazu beigetragen haben, im Inneren die gemeinsame Grundlage aller christlichen Bekenntnisse in ihrer Zusammenarbeit zu stärken und durch das Anknüpfen internationaler Beziehungen und Arbeitskontakte der Zusammenarbeit und Verständigung der christlichen Völker des Abendlandes gedient zu haben." $246 \mathrm{Als}$ sich Mitte der fünfziger Jahre die Gelegenheit bot, in sehr viel größerem Rahmen die eigenen Ordnungsvorstellungen verbreiten zu können, nutzten die Abendländer diese Chance, ihre bisher rein theoretisch-intellektuelle Aktionsebene zu verlassen: In Augsburg war im Sommer 1955 das 1000jährige Jubiläum des Sieges Ottos I. gegen die Ungarn auf dem Lechfeld Anlaß von Gedenkveranstaltungen. Die offiziellen Feierlichkeiten der Stadt Augsburg Anfang August verblaßten jedoch geradezu gegenüber dem Ausmaß an katholischem Gedenken, das sich vom 2.-11. Juli 1955 im Rahmen einer Festwoche abspielte. Diese Festwoche, von der katholischen Kirche im dazu erklärten Ulrichs-Jahr ausgerichtet, lockte zahlreiche geistliche Würdenträger, aber auch politische Prominenz des konservativen Lagers nach Augsburg. ${ }^{247}$ Der Sieg auf dem Lechfeld war aus katholischer Sicht

245 Abendländische Akademie, in: Neues Abendland 7 (1952), S. 447.

246 Gaupp-Berghausen im Mitteilungsblatt: Die Abendländische Akademie, Nr. 1/Juli 1954, BA NL Walter von Keudell, N 1243/15.

247 Neben dem apostolischen Nuntius Aloysius Muench fanden vier weitere Erzbischöfe, darunter aus Deutschland diejenigen von München und Freiburg, sechs Bischöfe, vier Weihbischöfe, zwei Erzäbte und siebzehn Äbte nach Augsburg. Der neuernannte Außenminister Heinrich von Brentano war ebenso anwesend wie z. B. der bayerische Kultusminister Rucker, Helene Weber (CDU), Josef Müller (CSU), Adolf Süsterhenn 
primär ein Sieg des Christentums über die Heiden, und so ehrte man im heiligen Ulrich den mittelalterlichen Bischof von Augsburg, von dem es hieß, er habe während der Lechfeldschlacht durch seine Gebete dem Volk Vertrauen und den Kämpfenden Kraft gegeben.

Während der Festwoche fanden verschiedene Prozessionen und Wallfahrten statt, welche ihren Höhepunkt in der Überführung des „St. Ulrichsschreins “ vom Dom zum St. Ulrichsmünster fanden, bei der laut Angaben des Festkomitees 80000 Menschen die Straßen säumten. Es gab eine Reihe kultureller Veranstaltungen, darunter besonders prominent ein Freiluftspiel unter großer Beteiligung der Augsburger Bürger als Laiendarsteller. Die Ereignisse der Lechfeldschlacht wurden hier nachgestellt, einschließlich eines Auftritts des Teufels - in Gestalt eines Ungarn. ${ }^{248}$ Darüber hinaus war in der Festwoche jeder Tag einem anderen Thema gewidmet: beginnend mit einer „Wallfahrt der Männer“ zum St. Ulrichsgrab am 3. Juli, über einen „Tag der Priester“, einen „Tag der Caritas und der Frauen“ und einen „Tag der Lehrer und Erzieher“. Es folgten der „Tag der Benediktiner“, der „Tag der bedrängten Kirche“ und schließlich die „Tage abendländischen Bekenntnisses“. Hier wurde, ergänzt durch eine Vielzahl öffentlicher Vorträge, in drei Foren um „die aktuellsten Themen für die künftige Gestaltung des christlichen Abendlandes“ gerungen:249 Die „Soziale Struktur Europas“, „Grundzüge der Rechtseinheit Europas“ und schließlich die „Vielfalt und Gemeinschaft europäischer Kultur“ standen im Mittelpunkt; jedes Forum versammelte zwei Hauptreferenten zum jeweiligen Thema. ${ }^{250}$ Bereits die Form, in der die „Tage abendländischen Bekenntnisses“ abgehalten wurden, erinnert an die Tagungen der Abendländischen Akademie, und tatsächlich waren die Abendländer in Augsburg zahlreich vertreten. Mit Friedrich August Freiherr von der Heydte, Adolf Süsterhenn, Heinrich von Brentano und Joseph Schröffer (Bischof von Eichstätt) waren vier Mitglieder der Abendländischen Akademie mit Vorträgen in das offizielle Programm eingebunden - wer darüber hinaus in Augsburg anwesend war, läßt sich den Quellen nicht entnehmen. Zwar waren die Gedenkfeierlichkeiten zum 1000jährigen Jubiläum der Schlacht auf dem Lechfeld in Augsburg 1955 offiziell eine von der katholischen Kirche getragene Veranstaltung, und es fiel weder der Name der Abendländischen Akademie noch lassen sich in der Festschrift Spuren

(CDU), der Oberbürgermeister von Augsburg Klaus Müller oder Hugo Fink (CSU). Robert Schuman war aus Frankreich angereist - bei ihm mag die Reise nach Augsburg Erinnerungen an seine Jugendkontakte zur Abendländischen Bewegung der Zwischenkriegszeit geweckt haben. Denn Schuman war mit Hermann Platz befreundet gewesen und hatte an den Bemühungen, die Liturgische Bewegung im Deutschen Reich zu verbreiten, teilgenommen. Vgl. Teil I, Kap. I.1.

248 In: Crux victorialis, S. 358-360. Vgl. auch: Drews, Wolfgang: Das Augsburger Jahrtausendspiel, in: Frankfurter Allgemeine Zeitung, 5. 7. 1955. Högel, Max: Mysterium auf moderner Bühne. Zur heutigen Uraufführung des „Augsburger Jahrtausendspiels“, in: Süddeutsche Zeitung, 2. 7. 1955.

249 In: Crux victorialis, S. 194.

250 Die Professoren Linus de Grond, Holland/Gustav Grundlach, Rom, innerhalb des ersten Forums, Friedrich August von der Heydte/Luis Sanchez Angeta, Granada, im Rahmen des zweiten und schließlich Paulus Lenz-Médoc, Paris/Bernhard Hanßler, Stuttgart, in der dritten Diskussionsrunde. 
der Organisation finden. Dennoch verweist die Mitwirkung von Akademiemitgliedern und auch die Tatsache, die man später zugab, „daß die St.-Ulrichs-Festwoche in Augsburg in irgendeinem Zusammenhang mit der Abendländischen Akademie gestanden habe",251 darauf, daß die Akademie in Augsburg die Chance ergriff, das abendländische Weltbild vor einer breiten Öffentlichkeit zu vertreten. ${ }^{252}$

Möglicherweise wollte man die Feierlichkeiten zum Lechfeldjubliäum als Testfeld für neue Wirkungsformen nützen und zielte damit letztlich auf eine Ausweitung der Akademietätigkeit ab. Oder aber die Feierlichkeiten waren einfach Grund und Anlaß genug, das „Abendland“ zu beschwören, ohne im Namen der Akademie aufzutreten. So ist auch nicht festzustellen, ob das in Augsburg zu konstatierende zurückhaltende Auftreten der Abendländischen Bewegung gegenüber der Öffentlichkeit bewußt angelegt war. In den Jahren nach 1955 sollte es sich jedenfalls zu einem typischen Merkmal abendländischer Organisation ausbilden. Immer wieder verwiesen die verantwortlichen $A$ bendländer intern darauf, daß es besser sei, Einzelpersonen im eigenen Namen die abendländischen Ordnungsvorstellungen vertreten zu lassen, als die dahinterstehende Bewegung beim Namen zu nennen.

Doch kann dieses Verhalten in den späten fünfziger und sechziger Jahren auch auf die Erfahrungen von 1955 zurückzuführen sein, denn die „Schlacht auf dem Lechfeld" sollte für die Akademie ein Nachspiel haben. Das öffentliche Interesse richtete sich im Anschluß an die Feierlichkeiten auf die Bewegung - allerdings in ganz anderer Form, als man sich dies gewünscht hatte. Dies lag vor allem an der Rede, welche Heinrich von Brentano, gerade ernannter Außenminister der Bundesrepublik Deutschland und Kuratoriumsmitglied der Abendländischen Akademie, am letzten Tag der Festwoche im Augsburger Rosenaustadion vor $60000 \mathrm{Zu}$ hörern gehalten hatte und die vor abendländischem Antikommunismus und typisch abendländischen Geschichtsbildern nur so strotzte. „Damals standen vor den Toren des Abendlandes [...] die heidnischen Nomadenscharen des Ostens; Verderben und Untergang drohten. Jetzt stehen wiederum, nicht sehr viel weiter von dieser Stadt entfernt, die Massen des Ostens, und wiederum sehen wir der Gefahr ins Auge, daß das Abendland von ihnen überrannt wird und ihnen zur Beute

251 Gaupp-Berghausen, zitiert im Oberbayerischen Volksblatt, 7. 1. 1956, ACDP NL HansJoachim von Merkatz, I-148-146/01.

252 Parallel zu den Feierlichkeiten rührten die Abendländer auch in der Presse die "Werbetrommel“ für das Ereignis: Vgl. Mauer, Otto: Was wir zu verteidigen haben. Lehren der Lechfeldschlacht für die Gegenwart, in: Rheinischer Merkur, 5. 8. 1955. Herre, Franz: Ausgburgs Hohe Straße, in: Rheinischer Merkur, 15.7. 1955. Ders.: Die Lechfeldschlacht, in: Neues Abendland 10 (1955), S. 401-410. Ibach, Helmut: Absage an den Defaitismus, in: Neues Abendland 10 (1955), S. 449f. Gleichzeitig mit der Lechfeldschlacht gedachte man auch des Augsburger Religionsfriedens von 1555, der in den Augen der Abendländischen Akademie aufgrund seiner ökumenischen Komponente ebenfalls der Gegenwart als Leitbild dienen konnte - eine Argumentation, die durch einen Brief Papst Pius XII. anläßlich des Jubiläums noch unterstützt wurde. Vgl. von den evangelischen Akademiemitgliedern: Stählin, Der Augsburger Religionsfriede, in: Rheinischer Merkur, 9. 9. 1955. Asmussen, Hans: Ein Papstbrief und seine Antwort, in: Rheinischer Merkur, 19. 8. 1955. 
fallen kann. In gewisser Beziehung ist die Gefahr noch gewaltiger als damals. Denn nicht vereinzelte Nomadenhorden sind es jetzt, mit denen wir es zu tun haben, sondern ein Block von der Größe eines Erdteils [...]. Und nicht wie damals steht uns das bloße Heidentum wilder Völkerschaften gegenüber. Sondern das neue Heidentum, mit dem wir jetzt zu rechnen haben, ist ein Heidentum des weltlichen Fanatismus [...], ein Messianismus des Diesseits, der durch die Weltrevolution ein irdisches Paradies herbeiführen will, da er an ein jenseitiges nicht glaubt.“ Brentano betonte in Augsburg ausdrücklich ,im Namen des Bundeskanzlers" 253 gekommen zu sein, und da er gleichzeitig deutlich die militärische Stärke des Abendlandes von 1955 betonte, ist seine Rede wohl auch im Zusammenhang mit der bevorstehenden Moskau-Reise Adenauers zu sehen. Gezielt die „Politik der Stärke", die Bedeutung der europäischen Integration und des atlantischen Bündnissses und damit die Grundpositionen der Adenauerschen Außenpolitik vor der Reise des Kanzlers zu den „Heiden“ noch einmal zu beschwören, scheint das Ziel der kämpferischen Rede Brentanos am Vorabend der Aufnahme offizieller Beziehungen zur Sowjetunion gewesen zu sein.

Doch verpackt war dieses Ziel in typisch abendländischen Formulierungen, kombiniert mit antikommunistischen Ausfällen und einem verklärten Bild vom Mittelalter. Und damit hatte Brentano offenbar selbst für die öffentliche Meinung der fünfziger Jahre, für die ein überzeugter Antikommunismus ja durchaus normal war, über die Stränge geschlagen. In einer Artikel-Serie griff der Spiegel 254 das Thema auf. Die Redakteure stießen auf Brentanos Kuratoriumsmitgliedschaft in der Akademie und machten die Abendländische Bewegung zum Aufhänger. Das Blatt erhob den Vorwurf des Monarchismus, der Demokratie- und Verfassungsfeindlichkeit und kritisierte sowohl die Tatsache, daß eine erhebliche Anzahl von Politikern der amtierenden Bundesregierung abendländischen Kreisen angehörte, als auch, daß die abendländischen Aktivitäten durch die Bundeszentrale für Heimatdienst finanziert wurden. ${ }^{255}$ Belegt wurden diese Vorwürfe mit Zitaten aus Schriften Gerhard Krolls und der Abendländischen Aktion. Es entspann sich eine regelrechte „Presse-Fehde“ um die abendländische Bewegung, in der der Rheinische Merkur die Hauptverteidigung übernahm. Daß sich dabei vor allem Paul Wilhelm Wenger und Otto $B$. Roegele hervortaten, verwundert kaum, waren sie doch beide ebenfalls Mitglieder der Abendländischen Bewegung. ${ }^{256}$ Gleichzeitig

253 Crux Victorialis, S. 303.

254 Siehe die beiden Artikel: Die Missionäre Monarchie, in: Der Spiegel, 10. 8. 1955. Abendländische Akademie - Wo hört der Unsinn auf, in: Der Spiegel, 15. 2. 1956. Vgl. auch die Leserbriefe in: Der Spiegel, 24. 8. 1955; 31. 8. 1955; 22. 2. 1956.

$255 \mathrm{Vgl}$. zu dieser Finanzierung auch: Waldburg-Zeil, Aufgabe und bisherige Arbeit der Akademie, in: Konservative Haltung in der politischen Existenz, S. 9-11.

256 Vgl. etwa: Wenger, Paul Wilhelm: Jacobinische Gespensterjagd. Zum Kesseltreiben gegen die Abendländische Akademie, in: Rheinischer Merkur, 10. 2. 1956. Ders.: Exegese über Schafsköpfe, in: Rheinischer Merkur, 17. 2. 1956. Franzel, Emil: Zorins leichte Artillerie, in: Deutsche Tagespost, 6./7. 1. 1956. Heueck, A.: „Wir sind keine Klerikalfaschisten“. Der Generalsekretär der Abendländischen Akademie weist erhobene Angriffe zurück, in: Oberbayerisches Volksblatt, 7. 1. 1956. Kroll, Gerhard: Eine Akademie im Widerstreit. Feldzug gegen eine sonderbare Verschwörung, in: Münchener Merkur, 21. 2. 1956. Vgl. zur "Pressefehde“ um die Abendländische Bewegung außerdem: Stehle, Hans-Jakob: 
kam es zu einer Anfrage im Bundestag, die eine mögliche Verfassungsfeindlichkeit der Abendländer betraf und die einen parlamentarischen Untersuchungsausschuß nach sich zog.

Die Angriffe mußten zu einer Reaktion der abendländischen Bewegung führen. Einerseits bot die Akademie dem Verfassungsschutz Einblick in alle Unterlagen an, war man sich doch „in keiner Weise irgendwelcher verfassungsfeindlicher Tätigkeit bewußt“, sondern vielmehr der Auffassung, „sehr viel für die europäische Verständigung beigetragen $\mathrm{zu}$ haben ". ${ }^{257}$ So vermuteten die verantwortlichen Abendländer auch, daß man es bei den Angriffen nicht allein mit „bloßer Sensationsmache, sondern mit einer planmäßigen Offensive gegen christlich-konservative Kreise zu tun" habe. ${ }^{258}$ Andererseits ging die Akademie in der Öffentlichkeit zur Verteidigung über, indem die Verantwortlichen vor allem darauf abhoben, daß die Vorwürfe des Spiegels ausschließlich mit Zitaten aus den Schriften Gerhard Krolls belegt worden seien. Die Abendländische Akademie aber habe mit der Abendländischen Aktion nicht das geringste zu tun; vielmehr habe man sich eindeutig von den dort vertretenen Zielen distanziert. Auf einer Pressekonferenz in Bonn, bei der von der Akademie Georg Fürst Waldburg-Zeil, Hans-Joachim von Merkatz, Richard Jaeger, Theodor Steltzer und der Völkerrechtler Ulrich Scheuner anwesend waren, wurde diese Verteidigungsstrategie mit zum Teil subtilen letztlich aber nicht überzeugenden Argumenten - verfochten. ${ }^{259}$ Man spürt deutlich die Unsicherheit der Abendländer, war es in der Tat doch nicht ganz einfach, sich angesichts der realiter recht engen Verbindungen zwischen Aktion und Akademie nun aus der Affäre zu ziehen.

Gerhard Kroll, der sich bereits unmittelbar nach den Spiegel-Artikeln gegen die Vorwürfe mit dem Hinweis gewehrt hatte, die Zitate seien aus dem Zusammenhang gerissen, ${ }^{260}$ mußte die Rolle des Bauernopfers übernehmen, das die bundes-

Nebel über dem „Abendland“. Reichsphantasien mit habsburgischem Hintergrund, in: Frankfurter Allgemeine Zeitung, 9. 2. 1956. Henrich, Klaus: Die Revolutionäre Reaktion. Was sich gewisse Herren unter konstruktivem Verfassungsschutz vorstellen, in: Frankfurter Rundschau, 4. 2. 1956. Hilpert, Wilhelm: Eine Vereinigung erregt Ärgernis. Der Verfassungsschutz interessiert sich für die Ziele der Akademie, in: Süddeutsche Zeitung, 14. 1.1956.

257 Brief Georg Fürst Waldburg-Zeil an Bundesinnenminister Gerhard Schröder, 10. 2. 1956, ACDP, Nachlaß von Merkatz, I-148-146/01. Vgl. ebenda auch den Brief Georg Fürst Waldburg-Zeils an Bundesinnenminister Gerhard Schröder vom 19. 3. 1956, der finanzielle, organisatorische und personelle Zusammenhänge zwischen Abendländischer Aktion und Akademie weitgehend bestritt.

258 Brief Merkatz an Gaupp-Berghausen, 17. 1. 1956, ACDP, Nachlaß von Merkatz, I-148146/01.

259 Hans-Joachim von Merkatz beispielsweise bemerkte in nuancierendem Scharfsinn: „Die Abendländische Aktion ist eine Aktion. Die Abendländische Akademie ist eine Akademie. Darin sind ganz große Wesensunterschiede." Vgl.: Ist die Abendländische Akademie verfassungsfeindlich? Pressekonferenz in Bonn vom 9.3. 1956, in: Mitteilungsblatt Die Abendländische Akademie, 3 (1956), Nr. 1, ACDP, Nachlaß von Merkatz, I-148-146/01.

260 Erklärung Gerhard Krolls als Reaktion auf die Spiegel-Artikel, 17.10. 1955, ACDP, Nachlaß von Merkatz, I-148-146/01. Die Kontakte zwischen Kroll und der Abendländischen Bewegung blieben übrigens trotz der „Bauernopferrolle“ Krolls bestehen: Im Juni 1956 beispielsweise hielt Kroll auf Einladung des CEDI einen Vortrag in Spanien mit dem 
republikanische Presselandschaft jedoch nur zögerlich annahm. Angesichts der nicht verstummenden Kritiken warf der Vorsitzende der Akademie, von der Heydte, im Februar 1956 das Handtuch und trat von seinem Amt zurück. Dieser Rücktritt bedeutete „keineswegs eine Absage an die Ziele der Akademie“. Von der Heydte verwies jedoch auf die Notwendigkeit, der Akademie eine straffere Führung zu geben, um in Zukunft zu verhindern, „daß die eindeutigen Zwecke der Akademie von Gegnern einer europäischen christlichen Politik absichtlich oder unabsichtlich mißdeutet werden". 261

Als der Untersuchungsausschuß, der eine mögliche Verfassungsfeindlichkeit der Abendländischen Bewegung überprüfen sollte, im Oktober 1956 seine Ermittlungen mangels Verdacht einstellte, ${ }^{262}$ hätte sich die öffentliche Diskussion um die Abendländer eigentlich beruhigen können. So bemühten sich diese ungeachtet der Unruhe, ihre Aktivitäten weiterzuführen. Die Jahrestagung der Akademie wurde im Sommer 1956 mit viel Selbstbewußtsein abgehalten. In direkter Reaktion auf die Ereignisse des vergangenen Jahres entschied man sich, öffentlich und aktuell über die Frage der „Konservativen Haltung in der politischen Existenz" zu debattieren und verließ damit erstmals die rein theoretische Ebene der früheren Tagungen. ${ }^{263}$ Doch trotz dieses selbstbewußt-trotzigen Auftretens haben die Ereignisse im Anschluß an die Rede Brentanos in Augsburg 1955 ihre Spuren in der Abendländischen Akademie hinterlassen.

\section{Nachspiel}

Die internen Protokolle der Abendländischen Akademie spiegeln die Auseinandersetzungen um die Neuausrichtung der Organisation nach dem Debakel des Sommers 1955. Eine ganze Reihe früherer "Sympathisanten“ aus Politik, Wissenschaft und Publizistik zog sich nach der heftigen Kritik der westdeutschen Medien aus der Akademie zurück. Man hatte erhebliche Probleme, einen Nachfolger für den ausgeschiedenen Vorsitzenden Heydte zu finden, und die Tatsache, daß das Neue Abendland ab 1956 nur noch quartalsweise, nun wieder unter der Redaktion Emil Franzels, erschien, deutet auf cinen Leserschwund hin. ${ }^{264}$ Damit läuteten die Auseinandersetzungen um das „Lechfeld“ den Niedergang der Akademie ein. Möglich war dies, weil sich das intellektuelle Klima in der Bundesrepublik zu wandeln begonnen hatte: Antiliberale und antimoderne Ordnungsvorstel-

Titel „Über Verfall und Erneuerung des Abendlandes. Versuch einer Bestimmung der Maßstäbe für die Beurteilung menschlicher Geschichte. Vgl. das Manuskript in: ACDP, Nachlaß Gerhard Kroll, I-153-001/7.

261 Brief von der Heydtes an die Mitglieder der Abendländischen Akademie, 24. 2. 1956, BA N 1005 , S. 538.

262 Vgl. Pressemeldung vom 25. 10. 1956, BA, Nachlaß Walter von Keudell, N 1243/11.

263 In diesem Sinne auch: Schildt, Zwischen Abendland und Amerika, S. 61. Eigentlich war für den Sommer 1956 eine Tagung über die Beziehungen des Christentums zum Islam geplant gewesen. „Die Pressekampagne war dann der Grund, das Thema der Konservativen Haltung auf das Programm zu setzen." Vgl.: Sitzung des Vorstandes, Beirates und Kuratoriums der Abendländischen Akademie am 17.6. 1956, ACDP, I-148-146/01.

264 Wilhelm Stählin übernahm schließlich den Vorsitz, allerdings von vornherein nur befristet. 
lungen verloren in der zweiten Hälfte der fünfziger Jahre langsam den Rückhalt einer breiten Öffentlichkeit, der Anfang des Jahrzehnts noch bestanden hatte. Statt dessen begannen sich Pluralismus und eine betont „ideologiefreie“ Grundstimmung durchzusetzen - wenn es sich auch bei dieser wiederum um eine „Ideologie des Ideologieverzichts" handelte. ${ }^{265}$ In dieser sich langsam wandelnden westdeutschen Gesellschaft erschien die Rede vom „Abendland“ zunehmend überholt.

Innerhalb der Akademie begab man sich daher auf die Suche nach neuen Wirkungsformen und -möglichkeiten. Bei diesen Überlegungen wurden Spannungen zwischen zwei Richtungen deutlich, die der Abendländischen Akademie bereits von Anfang an innegewohnt, in den ersten Jahren jedoch nebeneinander existiert hatten: der europäischen und der ökumenischen Komponente. Hatte es 1954 geheißen, „die Abendländische Akademie soll [...] Mittlerin und gemeinsame Arbeitsbasis der Christen der verschiedenen Bekenntnisse und Mittlerin zwischen Ländern des Abendlandes" sein,266 so läßt sich Ende der fünfziger Jahre ein zunehmendes Übergewicht derjenigen - unter ihnen mit Georg Fürst WaldburgZeil einer der wichtigsten Abendländer - feststellen, die der Meinung waren, daß „das Schwergewicht der Akademie auf der evangelischen und katholischen $\mathrm{Zu}$ sammenarbeit" und damit „innerdeutschen Fragen“ beruhe. ${ }^{267}$ Es deutete sich ein Umdenken innerhalb der Abendländischen Bewegung an: Die Aktivitäten derjenigen, die das „Abendland“ als europäische Kategorie verstanden wissen und Einfluß auf die europäische Einigung nehmen wollten, konzentrierten sich fortan zunehmend auf das CEDI - dies wohl auch in der Überzeugung, daß das verlorene Renommee der Akademie in der Bundesrepublik eine erfolgreiche Arbeit für das "Abendland" unmöglich machen würde. Die Zuständigkeitsbereiche zwischen Akademie und CEDI trennten sich; zwar existierten auch fortan personelle Überschneidungen, und die Familie Waldburg-Zeil betrachtete auch weiterhin sowohl die Akademie wie auch das CEDI als „Pflegekinder“.268 Doch „Europa“ war fortan in der Akademie seltener Thema, so daß die weitere Geschichte der Abendländischen Akademie hier nur noch zu skizzieren ist.

Diese Geschichte ist eine des Niedergangs. Zwar plante die Akademie immer wieder neue Anfänge und neue Projekte: etwa 1957 die Gründung eines „Zeitgeschichtlichen Studienbüros“, um „möglichst breite Schichten der Bevölkerung mit dem konservativen Gedanken vertraut zu machen “. ${ }^{269}$ Doch im selben Jahr fand bereits nur noch eine interne Arbeitstagung unter dem Titel „Warum pflegen wir die Zusammenarbeit der Christen im deutschen Raum?" statt, 1958 entfiel die Jahrestagung ganz. Ende 1958 wurde das Erscheinen des Neuen Abendlandes eingestellt, die Leser wurden aufgefordert, fortan die Dokumentation der Woche des

265 Schildt, Ankunft im Westen, S. 174. Vgl. hierzu auch: Teil II, Kap. II.2.

266 Mitteilungsblatt: Die Abendländische Akademie, Nr. 3, Oktober 1954, BA N 1243/15.

267 So Karl Bernhard Ritter auf der Sitzung des Vorstandes, Beirates und Kuratoriums der Abendländischen Akademie am 17.6. 1956, ACDP, I-148-146/01. Hier auch die Äußerung Georg Fürst Waldburg-Zeils.

268 Brief Alois Waldburg-Zeil an Merkatz, 7. 7. 1969, ACDP, I-148-146/01.

269 Brief Gaupp-Berghausen an Merkatz, 23. 4. 1957, ACDP, I-148-146/01. 
CEDI zu abonnieren. Zu diesem Niedergang trug auch bei, daß die Akademie 1957/58 erneut negativ ins Blickfeld der Presse geraten war, nachdem Konrad Adenauer vor der Bundestagswahl $1957 \mathrm{im}$ Neuen Abendland einen kurzen Artikel veröffentlicht hatte, den man leicht als Wahlkampfaufruf verstehen konnte.270 Die FDP machte dies zum Wahlkampfthema, und die Presse schlachtete alles weidlich aus - zum weiteren Schaden der Akademie, deren öffentliches Ansehen damit wohl endgültig diskreditiert war. ${ }^{271}$

Zwar gelang es im November 1958 mit Walter von Keudell, zu dieser Zeit Vorsitzender des Bundesvertriebenenausschusses der CDU, einen neuen Vorsitzenden, mit Hans Hutter einen neuen Stellvertreter und mit Alois von Waldburg-Zeil einen neuen Generalsekretär zu gewinnen. Dennoch agierte man vorwiegend intern, erst im Herbst 1960 fand in Mainz wieder eine öffentliche Tagung statt, der 1961 auch wieder eine Jahrestagung in Eichstätt folgte. ${ }^{272}$ Anfang der sechziger Jahre bemühte sich die Abendländische Akademie dann vor allem um Profilierung und Anerkennung als ökumenische Bildungsinstitution, litt jedoch konstant unter finanziellen Schwierigkeiten. ${ }^{273}$ Mit Walter Werr, der gerade sein Studium beendet hatte, fand sie noch einmal einen engagierten Generalsekretär, doch auch er konnte der Akademie auf Dauer kein neues Leben einhauchen. Im Oktober 1963 fand die letzte Jahrestagung in Eichstätt unter dem Titel „Die Gesellschaft und ihr Recht" statt, danach wurden alle geplanten Veranstaltungen mangels Teilnehmerinteresse abgesagt. So versank die Abendländische Akademie langsam in Bedeutungslosigkeit, nachdem sie eigentlich schon Ende der fünfziger Jahre ihre Inhalte und ihren Zusammenhalt verloren hatte.

\section{3. „Wie eine geistige Familie, Männer, die treu zueinander stehen ...":274 das Europäische Dokumentations- und Informationszentrum (1952-1970)}

Ende der fünfziger, Anfang der sechziger Jahre begann sich das politische und kulturelle Klima in der Bundesrepublik zu wandeln. Angesichts der „Entdramatisierung" 275 des Kalten Krieges nach Kuba- und Berlin-Krise sowie Mauerbau

\footnotetext{
$270 \mathrm{Vgl}$. Adenauer, Konrad: Entscheidung über Deutschland, in: Neues Abendland 12 (1957), S. 97.

271 Vgl. die Reaktionen der Abendländer: Angriffe gegen die Abendländische Akademie. Eine Stellungnahme des Generalsekretärs, 1.2. 1958, BA N 1243/11.

272 Unter dem Thema „Abendländische Verantwortung heute“ und „Pluralismus, Toleranz und Christenheit“. Vgl. die Liste der jeweiligen Referenten in: Zusammengefaßte Übersicht über die Arbeit der Abendländischen Akademie, Stand: Oktober 1962, ACDP, I-148-146/02.

273 Vgl. z.B. den Jahresabschluß der Abendländischen Akademie, 31. 12. 1962, ACDP, I-148-146/01.

274 Habsburg, Otto von: Ziele und Arbeitsmethoden des Europäischen Dokumentationszentrums. Rede gehalten anläßlich der Gründungssitzung des CEDI Liechtenstein am 22. 12. 1958, BA N 1243/30. Es handelte sich allerdings um eine Familie ohne Frauen.

275 Schildt, Konservatismus, S. 236.
} 
1962/63 wurde die Bundesrepublik zwar offiziell immer noch als „Provisorium“ bezeichnet - im Leben der Westdeutschen jedoch wurde sie zu einer Realität, von deren wirtschaftlicher Prosperität man profitierte. Gleichzeitig warfen die unruhigen sechziger Jahre ihre Schatten voraus. Im Verlauf dieses Prozesses konnte langsam neues "westliches" Gedankengut in die bundesrepublikanische Gesellschaft einfließen. ${ }^{276}$ Dies galt auch für die deutschen Europa-Vorstellungen. Das „Abendland" verschwand langsam aber sicher aus dem öffentlichen Sprachgebrauch. Wer über europäische Zusammenhänge redete, gebrauchte nun auch den Begriff „Europa“, und sprach nicht mehr vom „Reich“ und auch nicht mehr vom "Abendland“. Seinen Grund fand dies nicht zuletzt in der sich langsam durchsetzenden „Ideologie des ideologiefreien“ Denkens, welche das Zeitalter der grundstürzenden Ideologien für beendet erklärte. Ideologisch aufgeladene Konzepte, wie es das „Abendland“ eines war, fanden angesichts dieser Entwicklung immer weniger Rückhalt. Funktionalismus trat - auch im Hinblick auf Europa - an seine Stelle.

So geriet traditionell "deutsches“ Denken, so wie es sich seit der Zwischenkriegszeit in vielem erhalten hatte, zunehmend in den Hintergrund. Dieser Prozeß konnte an der hier in ihrer Entwicklung seit den zwanziger Jahren betrachteten konservativ-katholischen Idee des „Abendlandes“ nicht unbemerkt vorübergehen. Nachdem sich die Idee in der ersten Hälfte der fünfziger Jahre durchgehend breiter Zustimmung im konservativen politischen Lager erfreut und auch die Presse wohlwollend über Veranstaltungen der Abendländischen Bewegung berichtet hatte, kam es in der zweiten Hälfte des Jahrzehnts zu deutlicher Kritik an den von ihr geäußerten Ordnungsvorstellungen. Fortan setzte die deutsche Presse „abendländisch" mehr oder weniger mit "reaktionär" gleich, von Blättern wie dem Rheinischen Merkur, dem Bayern-Kurier oder der Deutschen Tagespost einmal abgesehen, in deren Redaktionen vielfach Vertreter der Abendländischen Bewegung saßen. Daß das Neue Abendland wohl auch als Fernwirkung auf diese Kritik 1958 sein Erscheinen einstellte und die Abendländische Akademie über immer erneute Versuche, sich zu reorganisieren nicht hinauskam, hat bisher in der Literatur durchgängig zu der Vermutung geführt, die Zeit des „Abendlandes“ sei Ende der fünfziger Jahre vorbei gewesen: „Der Versuch, eine im ersten Nachkriegsjahrzehnt durchaus kräftige und nicht einflußlose politisch-kulturelle Strömung in die Zeit nach dem Ende der ,Ära Adenauer "zu transformieren, ging geräuschlos zu Ende, " behauptet beispielsweise Axel Schildt.277

Doch ist diese Sicht der Dinge nur begrenzt richtig. Sicher, die Abendländische Bewegung verlor in der zweiten Hälfte der fünfziger Jahre an öffentlicher Unterstützung und Zuspruch und damit auch einen Teil ihres Zusammenhalts und ihrer öffentlichen Wirksamkeit. Und die Idee vom „Abendland“ konnte nun tatsächlich nicht mehr als europäische Leitvorstellung dienen, so wie sie es seit der Zwischenkriegszeit bis in das Jahrzehnt nach dem Ende des Zweiten Weltkrieges ge-

276 Vgl. hierzu allgemein: Doering-Manteuffel, Wie westlich sind die Deutschen. Schildt, Ankunft im Westen. Schwarz, Die Ära Adenauer. Vgl. ansonsten Teil II, Kap. II.2, hier auch mit weiteren Literaturangaben.

277 Schildt, Zwischen Abendland und Amerika, S. 82. 
tan hatte. Die Zeiten hatten sich geändert: an hochideologisch aufgeladenen Ordnungsvorstellungen, wie es das „Abendland“ seit spätestens dem Ersten Weltkrieg gewesen war, bestand kein Bedarf mehr.

Doch betrachtet man die Abendländische Bewegung, so zeigt sich, daß ein „harter Kern" von Abendländern auch nach dieser Krise den organisatorischen und ideellen Zusammenhalt aufrechterhielt. Zwar könnte man dies auch als Nachwehen einer abgeschlossenen Epoche deuten. Doch erscheint eine andere Interpretation plausibler: In dem Jahrzehnt zwischen 1958 und 1968 „modernisierte“ ein kleiner Kreis der Abendländischen Bewegung, meist unter Ausschluß der Öffentlichkeit, seine Ordnungsvorstellungen, nahm von unzeitgemäßen Elementen Abstand oder gewichtete sie zumindest anders. So gelang es schließlich sogar, den Anschluß an die Tagespolitik wiederherzustellen und zum Beginn der siebziger Jahre eine neue Phase gesellschaftlicher Wirkung einzuleiten. Dies allerdings geschah, trotz personeller und ideeller Kontinuität, bereits nicht mehr unter dem Schlagwort „Abendland“ und unter dem Dach der Abendländischen Bewegung. Vielmehr orientierten sich die Abendländer im Gefolge Otto von Habsburgs nun in Richtung der Paneuropa-Union von Richard N. Coudenhove-Kalergi. Nach dessen Tod im Jahre 1972 übernahm von Habsburg das Präsidium des Verbandes und entwickelte ihn zur Europa-Bewegung konservativer politischer Kreise in der Bundesrepublik. Damit übernahm die Paneuropa-Union in Westdeutschland Klientel und Ideengut der ehemaligen Abendländischen Bewegung, wobei es ihr indes gelang, ihre Wirkungskreise weit über jene der Abendländer der fünfziger Jahre hinaus auszuweiten und insbesondere Jugendliche anzusprechen.

Die Entwicklung des „Abendlandes“ zwischen den zwanziger und den fünfziger Jahren paßt exakt auf das ideenhistorische Interpretationsmuster einer Transformationsphase, an deren Ende „überkommene“ Konzepte in Rückzugspositionen gerieten und zunehmend von "neuen" Denkmodellen abgelöst wurden. Die fünfziger Jahre erscheinen so als ",Schwanzstück' eines historischen Abschnitts“, das insgesamt von dem "manchmal verzweifelten Ringen der Zeitgenossen um akzeptable und allgemein konsensfähige Ordnungsmodelle, aber auch [von dem] scharfen Konflikt entgegengesetzter Entwürfe der Gesellschaft" geprägt war. ${ }^{278}$ Wenig beachtet jedoch ist bisher die Tatsache, daß nicht nur die zunehmende Akzeptanz westlich-pluralistischen Gedankenguts die Denkmuster der Bundesrepublik in den sechziger Jahren prägte, sondern daß es den "traditionell“ deutschen Vorstellungen, in diesem Fall dem konservativ-katholischen „Abendland“, durchaus gelang, sich weitgehend zu transformieren und auch weiterhin bestimmten Bevölkerungsgruppen als Identifikationsmuster zu dienen. Dabei wurden bestimmte Grundvorstellungen, die, wie etwa der Antiparlamentarismus, in traditioneller Weise zum „deutschen“ Denken insbesondere Konservativer gehört hatten, abgelegt. Andere Elemente blieben jedoch erhalten und widersetzten sich dem "Westen“" und westlichen Leit- und Wertvorstellungen auch weiterhin. Die Bedeutung, die das „Abendland“ von der Zwischenkriegszeit bis zur Mitte der fünfziger Jahre besessen hatte, sollte es indes nicht mehr erlangen.

278 Zum „Schwanzstück“ vgl. Schildt, Moderne Zeiten, S. 32. Restliches Zitat: Nolte, Gesellschaftstheorie und Gesellschaftsgeschichte. S. 285 f. 


\section{Die „realpolitische Wende“ der abendländischen Idee}

Offensichtlich wurde den Abendländern durch die öffentliche Mediendiskussion um ihre Ideen bewußt, daß die Zeiten, in denen das Geraune vom „Sacrum imperium" als Vorbild der europäischen Einigung auf Zustimmung stieß, allmählich ihrem Ende zugingen. Dem paßte man seinen Sprachgebrauch langsam aber sicher an. Unrealistische Mittelalterschwärmereien etwa verloren sich ebenso wie die oben beschriebene Sehnsucht nach einem ,abendländischen Kaiser“. Man ging die Politik der europäischen Einigung nun pragmatischer an, kritisierte die europäischen Institutionen nicht mehr ausschließlich, sondern entwickelte zunehmend auch konkrete Konzeptionen. Diese gingen fortan aus vom gegebenen Stand der europäischen Integration - und nicht mehr von der Forderung einer grundsätzlichen Neuordnung der Einigung. Stärker als je zuvor begriffen die Abendländer das Europa der Römischen Verträge als „Wirklichkeit, die sich nicht mehr zurückdrehen läßt" ${ }^{279}$ Indem mit dem Neuen Abendland jenes Organ eingestellt worden war, das innerhalb der Bundesrepublik als Plattform zur Verbreitung abendländischen Denkens gedient hatte, verstummten auch die früher deutlich zu spürenden gesellschaftlichen Neugestaltungsansprüche gegenüber dem jungen Staat. Zwar kritisierten die Abendländer auch weiterhin bestimmte Elemente der parlamentarischen Demokratie, doch verschwand die Vision einer gesamtgesellschaftlichen Rechristianisierung, mit der auch eine ständische Staats- und Gesellschaftsreform einhergehen sollte, allmählich aus dem abendländischen Denken. Sicherlich blieben diese Elemente in den Köpfen der Abendländer als Ideale vorerst weiterhin erhalten; in öffentlichen Äußerungen jedoch hielt man sich, zumindest im Vergleich mit der ersten Hälfte der fünfziger Jahre, nun weitgehend zurück. Statt dessen gelangte man zu einem - für abendländische Verhältnisse - zum Teil recht offenen Umgang mit der Moderne und ihren Ausprägungen. Dieses sich auf abendländischer Seite entwickelnde "realistische Konzept von Europa“280 entsprach dem Zeitgeist. Funktionalismus statt Ideen, so könnte man es überspitzt formulieren, war nun gefragt: Die europäische Einigung in kleinen Schritten voranzutreiben, nicht in großen Worten zu beschwören, entsprach dem politischen Zeitgeist. Und diesem paßte sich selbst das „Abendland“ an.

Ein jahrzehntelanger ideengeschichtlicher Abschnitt, den wir seit der Zwischenkriegszeit verfolgt haben, war damit zu Ende. Waren die abendländischen Denkmuster in dieser Zeit mehr oder weniger unverändert erhalten geblieben und hatten sich den jeweiligen Zeitumständen immer nur graduell angepaßt, so war um das Jahr 1960 tatsächlich ein tiefgreifender Einschnitt erreicht. Dies spürte auch der westdeutsche Konservatismus allgemein, der just in dieser Zeit darum bemüht war, sich in "technokratischer" Form zu modernisieren.281 Der traditionelle Antimodernismus und Kulturdünkel geriet dabei in den Hintergrund, an seine Stelle trat die zunehmende Akzeptanz der modernen Gesellschaft. So

279 Schulz, Werner: Europa in drei Monaten, in: Aconcagua 1 (1965), S. 273-279, hier S. 274.

280 Resolutionen des CEDI-Kongresses 1959, zitiert nach: Dokumentation der Woche, Sonderausgabe Dezember 1959, BA 1243/30.

281 Zum „modernen“ oder „technokratischen“ Konservatismus vgl. mit umfassenden Literaturangaben: Schildt, Konservatismus, S. $240 \mathrm{f}$. 
schwammen die „übriggebliebenen“ Abendländer durchaus im Strom der Zeit. Sie vollzogen den tiefgreifenden Wandel des deutschen Konservatismus seit Anfang der sechziger Jahre zumindest teilweise mit. Man begann auch hier über eine Erneuerung des Konservatismus nachzudenken und, wenigstens in Ansätzen, eine Aussöhnung mit der Moderne zu vollziehen - was in den Jahrzehnten zuvor undenkbar gewesen war. ${ }^{282}$

\section{Die Gründung des CEDI}

Vorangetrieben wurde diese Entwicklung vor allem durch das Centre Européen de Documentation et Information (CEDI), deutsch: Europäisches Dokumentations- und Informationszentrum, das seit Anfang der fünfziger Jahre eng mit der Abendländischen Akademie verbunden gewesen war und deren Aufgaben es nach dem Debakel auf dem Lechfeld weitgehend übernahm. Das CEDI war etwa zum gleichen Zeitpunkt entstanden wie die Abendländische Akademie. Im Sommer 1952 fand an der Universität Santander, Spanien, eine Sommerakademie statt. Dort beschloß eine kleine Gruppe von Teilnehmern, eine europäische Organisation zu gründen, die den Austausch und Kontakt zwischen Konservativen der europäischen Länder fördern sollte. Daß die Idee und der Name dieser Organisation von dem Spanier Alfredo Sanchez-Bella, dem Direktor des Instituto de Cultura Hispánica, ${ }^{283}$ zur Diskussion gestellt wurde, ist kein Zufall. Denn Spanien war nach der internationalen Ächtung in den ersten Nachkriegsjahren erst Anfang der 50er Jahre, und dann auch nur teilweise, in die internationale Gemeinschaft zurückgekehrt. Gerade in Europa bestanden gegenüber dem Franco-Regime in diesen Jahren noch immer große Vorbehalte, und die spanische Regierung suchte nach Möglichkeiten, unterhalb der offiziellen Ebene Kontakte ins europäische Ausland zu knüpfen, um auf diesem Wege die internationale und europäische Isolierung des Landes zu überwinden. Als Teil einer "Substitutions-Diplomatie“ konnte unter anderem eine europäisch angelegte Organisation wie das spätere CEDI dienen. ${ }^{284}$

Die spanischen Avancen im Sommer 1952 fanden bei einer kleinen Gruppe Deutscher und Österreicher Gefallen: Michael Schmaus, der uns als „Reichskatholik" Anfang der dreißiger Jahre und als Vorstandsmitglied der Abendländischen Akademie bereits begegnet ist, der ebenfalls bekannte Erich Fürst Waldburg-Zeil und sein rühriger Organisator Georg Ritter Gaupp-Berghausen standen zusammen mit Sanchez-Bella an der Wiege des CEDI. Letzter Teilnehmer dieser Gespräche schließlich war Otto von Habsburg. So war das CEDI eine Gründung spanischer, deutscher und österreichischer konservativer Katholiken - Vertreter

282 Beispiel dafür wäre etwa die 1962 in der Zeitschrift „Monat“ geführte Debatte „Was ist konservativ", an der sich Hans-Joachim von Merkatz beteiligte: Ders.: Konservatives Denken - pseudokonservative Theorie, in: Der Monat 14 (1962), S. 54-56. Vgl. auch: Ders., Die konservative Funktion.

283 Das Instituto de Cultura Hispánica war Teil der spanischen Außenpolitik, welche in den Jahren der Isolation vornehmlich über kulturelle Kanäle lief, vgl. Weber, Spanische Deutschlandpolitik, S. 189-204.

284 Zum Begriff der „Substitutionsdiplomatie“ vgl. Aschmann, „Treue Freunde“, S. 434. 
anderer Nationen kamen erst dazu, als die Idee bereits geboren war. Die Organisation gab sich zunächst keine juristische Form, vielmehr wurden in verschiedenen europäischen Ländern nationale Sektionen gebildet, die die Hauptarbeit leisteten. Die deutsche Sektion, in München ansässig, wurde Anfang der fünfziger Jahre von exakt dem gleichen Personal wie die Abendländische Akademie geleitet: Friedrich August Freiherr von der Heydte, Georg Fürst Waldburg-Zeil und Georg von Gaupp-Berghausen. Früh stießen weitere Protagonisten hinzu, die fortan mit den Genannten den deutschen CEDI-Kreis bestimmen sollten: Vor allem Hans-Joachim von Merkatz, Richard Jaeger, Otto Roegele, Ewald von Kleist und Alois von Waldburg-Zeil hielten dem CEDI bis zum Ende der sechziger Jahre die Treue. Auch die Vertreter anderer Länder, die sich in der ersten Hälfte der fünfziger Jahre im CEDI zusammenfanden, blieben meist bis zum Ende der sechziger Jahre dem "harten Kern" verbunden: Von spanischer Seite sind hier neben dem genannten Sanchez-Bella vor allem Alberto Martin Atarjo, seit 1945 spanischer Außenminister, und José Ignacio Escobar (Marques de Valdeglesias), spanischer Staatsrat, zu nennen. François de la Noë war der erste Franzose, der noch in den frühen fünfziger Jahren zum CEDI stieß - andere, vor allem Gaullisten, kamen erst später hinzu. Auch in Österreich, Belgien, der Schweiz, in England, Schweden, später auch Liechtenstein, Portugal und Finnland entstanden (wenn auch im Vergleich mit den deutschen, spanischen, französischen und österreichischen Gruppen kleine) nationale Sektionen.

Zur Aufgabe hatte sich das CEDI gestellt, "das gegenseitige Verstehenlernen der Auffassungen der einzelnen europäischen Länder“ und die „Anerkennung und Anpassung der verschiedenen europäischen Gesichtspunkte" zu fördern.285 Ähnlich wie bei der Abendländischen Akademie wollte man also durchaus in Diskussionen unterschiedliche (nationale) Auffassungen aufeinanderprallen lassen und so Verständnis wecken - ebenso wie bei der Akademie allerdings verstand man unter "verschiedenen Auffassungen" ausschließlich konservative Positionen, die jedoch von Nation zu Nation innerhalb Europas erheblich variieren konnten.

\section{Aktivitäten, Wirkungsformen und Selbstverständnis des CEDI}

In den ersten Jahren bestand die Tätigkeit des CEDI vorwiegend in der recht erfolgreichen Durchführung von Vorträgen und Tagungen, entsprach also in den Aktionsformen weitestgehend der Abendländischen Akademie. Vor allem die jährlich in Spanien abgehaltenen öffentlichen Tagungen waren gut besucht. ${ }^{286}$ 1953 fand in Santander erstmalig eine als CEDI-Jahrestagung bezeichnete Veran-

285 Mitteilungsblatt: Die Abendländische Akademie, Nr. 3, Oktober 1954, BA N 1243/15.

2861956 beispielsweise zählte der Beobachter des deutschen Auswärtigen Amts auf der Jahrestagung des CEDI 157 Gäste aus verschiedenen europäischen Ländern, darunter die meisten aus Deutschland (26) und Spanien (87). Vgl. den Bericht der Botschaft Madrid an das Auswärtige Amt, 27. 8. 1956, PAAA, Ref. 201/506. 1957 kamen aus Deutschland 28 Besucher zur Tagung des CEDI, aus Frankreich 15. Vgl. die Teilnehmerliste in ACDP, I-148-131/03. 1958 fanden 203 Teilnehmer zur Tagung, darunter bildeten die Deutschen wiederum - nach den Spaniern - die zweitgrößte Gruppe, vgl. Dokumentation der Woche für Weltpolitik und Wirtschaft. Sonderausgabe August 1958, BA N 1243/11. 
staltung unter dem Titel „Europäische Union - Iberoamerikanische Union“ statt. 1954 konzentrierte man sich auf „den föderalistischen Aufbau eines christlichen Europas", ein Thema, das angesichts der unmittelbar zuvor erfolgten Ablehnung der EVG durch die französische Nationalversammlung von der Diskussion um die Tagespolitik überlagert wurde. ${ }^{287}$ Im Mai 1955 trafen sich die europäischen Abendländer dann zu ihrer vierten Jahrestagung, die unter dem Titel „Europa und das Problem der Koexistenz" stattfand. Erstmalig hatte die spanische Regierung das CEDI eingeladen, die Tagung im Escorial abzuhalten. Die Ortswahl unterstreicht die Bedeutung, die das Franco-Regime der Organisation beimaß.

Vor der nächsten Jahrestagung unter dem Thema „Europa im Atomzeitalter“, die im Juni 1956 wiederum im Escorial stattfand, lagen die „Schlacht auf dem Lechfeld" und die sich daran anschließende Auseinandersetzung um die Abendländische Akademie. Zwar bot die Tagung im Juni 1956 „den gewohnten Anblick früherer Jahre “, 288 doch intern ließen die Auseinandersetzungen um die Akademie in Deutschland auch das CEDI nicht unberührt. Das war angesichts der deutschen Präsenz und des deutschen Einflusses innerhalb der Organisation nicht verwunderlich.

Man begann über zukünftige Ziele und Aufgaben des CEDI nachzudenken.289 Unter dem Eindruck der verheerenden Diskussion nach dem öffentlichen Auftritt der Abendländer in Augsburg scheint es, als habe man in Kreisen des CEDI nun einer anderen Wirkungsform zunehmendes Gewicht beigemessen: dem internen Austausch des engeren abendländischen Kreises. Schon früher hatte man das jährliche Zusammentreffen in Spanien genutzt, im Vorfeld die allgemein anstehenden, das CEDI betreffenden Fragen zu besprechen, etwa Entscheidungen über zukünftige Tagungsthemen zu treffen. Schließlich war dies die naheliegendste Gelegenheit, das europäisch angelegte, jedoch ohne übernationales Gremium agierende Zentrum durch die Zusammenkunft möglichst vieler Vertreter der nationalen Sektionen zu organisieren.

Im Januar 1956, auf dem Höhepunkt der Pressedebatte um die Abendländische Akademie in Deutschland, schlug Gaupp-Berghausen im Namen des CEDI den Mitgliedern vor, der nächsten Jahrestagung eine „streng vertrauliche“ Tagung voranzustellen, auf der den Teilnehmern ein „Überblick über die politische, soziale und Presselage in Europa“ gegeben werden sollte. Hier sollte eine „wirkliche und aufrichtige Aussprache von wichtigen Persönlichkeiten der christlich-konservativen Richtung in Europa " gelingen, während die sich anschließende öffentliche Tagung vor allem „propagandistischen Charakter" haben sollte. 290 Diese „konspirative“, persönliche Komponente sollte für das CEDI in den kommenden Jahren immer wichtiger werden. Otto von Habsburg beschrieb sie 1959 als eigentliche

287 Mitteilungsblatt: Die Abendländische Akademie. Bericht über die Dritte Tagung des Europäischen Dokumentationszentrums, Pressespiegel, Nr. 3, Oktober 1954, BA N 1243/ 15. Vgl. hier auch die Einzelthemen und ihre jeweiligen Referenten.

288 Botschaft der Bundesrepublik Deutschland in Madrid an das Auswärtige Amt, 27. 8. 1956, PAAA Ref. 201/506. Auf das Interesse des Auswärtigen Amts am CEDI wird weiter unten noch einzugehen sein.

$289 \mathrm{Vgl}$. bspw. den Brief Valdeglesias an von Merkatz, 14. 3. 1957, ACDP I-148-131/03.

290 Brief Gaupp-Berghausen an von Merkatz, 24. 1. 1956, ACDP I-148-131/03. 
Aufgabe des Zentrums: „Es [das CEDI] hat niemals versucht, eine Massenbewegung zu werden. Es war bestrebt, die Elite des europäischen politischen, geistigen und wirtschaftlichen Lebens zusammenzuführen. [...] Es hat sich langsam wie eine geistige Familie entwickelt, Männer, die treu zueinander stehen und sich gegenseitig im Dienst der großen gemeinsamen Ziele unterstützen. "291 Auch bei den öffentlichen Jahrestagungen kam nun dem „persönlichen Kennenlernen, Erfahrungsaustausch“ am Rande der Veranstaltung eine immer größere Bedeutung in Augen des CEDI zu. ${ }^{292}$ Ende der sechziger Jahre betonte Gaupp-Berghausen: „Ehemalige Minister, aktive Minister, kommende Minister, Abgeordnete, Wirtschaftsführer, Universitätsprofessoren, Publizisten, Militärs, Geistliche begegneten sich auf diesen Kongressen, nahmen Kontakt auf, und nicht selten entwickelten sich aus diesen Kontakten engere Bindungen und auch Freundschaften. [...] Das nicht schriftlich festgelegte Programm des CEDI ist die Schaffung einer bewußten europäischen Atmosphäre durch menschliche Kontakte, durch das Gespräch, den Gedankenaustausch und das gegenseitige Verständnis." 293

In dieser Organisationsform spiegelt sich letztlich die konservative Grundstruktur der abendländischen Gruppierungen. Es handelte sich bei den Abendländern immer um einen relativ kleinen, elitären Kreis von Protagonisten, die keinen Wert darauf legten, diesen Kern zu erweitern. Zwar wollte man durchaus die eigenen Ordnungsvorstellungen und Interessen verbreiten, doch sollte dies zu keinem Zeitpunkt über eine große Organisation, gar eine Massenbewegung geschehen. Die Bezeichnung Abendländische Bewegung ist zwar eine Selbstbezeichnung des Kreises aus der Zwischenkriegszeit; in der Zeitschrift Abendland findet sie sich gelegentlich, um den Bemühungen jener Protagonisten einen Namen zu geben, die sich um das Blatt versammelten. Im „Dritten Reich“, als sich der organisatorische Zusammenhalt des Abendland-Kreises endgültig verlor, verschwand in Konsequenz auch ihre Bezeichnung als „Bewegung“. Nach 1945 ist die Selbstbezeichnung als „Bewegung“ dann kaum noch zu finden. Eher noch ordneten kritische Presseberichte das „Abendland“ einer „Bewegung“ zu. Auch das Auswärtige Amt bezeichnete das CEDI bzw. die Abendländische Akademie als „europäische Bewegung", und der Begriff hat sich mittlerweile auch in der Forschung eingebürgert.294

Die Abendländer selbst standen dem Begriff jedoch eher skeptisch gegenüber zumindest nach 1945. Dabei war der 'Topos „Bewegung“ in der Weimarer Republik in konservativen Kreisen, vor allem in den Reihen der „Konservativen Revolution“ noch durchaus positiv besetzt gewesen.295 „Bewegung“ wurde von konservativer Seite bis 1945 als „über den Parteien stehend" und damit „unpolitisch“

291 Habsburg, Otto von: Ziele und Arbeitsmethoden des Europäischen Dokumentationszentrums. Rede gehalten anläßlich der Gründungssitzung des CEDI Liechtenstein am 22. 12. 1958 , BA N 1243/30.

292 Franzel, Emil: Europa im Escorial, in: Deutsche Tagespost, 25. 6. 1956.

293 Bericht des Generalsekretärs des CEDI in Schloß Pouy am 24./25. 6. 1967, ACDP I-148$132 / 02$.

294 Vgl. den Vermerk des Ref. 300 vom 7. 10. 1961 zum CEDI, PAAA Abt. West 2, Ref. 201 (IA1), 302/86.50.

295 Vgl. etwa Mohler, Die Konservative Revolution, S. 12-15 und S. 150-153. 
interpretiert. Man assoziierte damit ähnliche „einheitsstiftende“ Wortfelder wie mit „Gemeinschaft" und „Volk“. Vor allem aus ideologischen Überzeugungen sahen sich die Abendländer indes nach 1945 nicht als „Bewegung“, assoziierte man doch nun mit dem Begriff, in Konfrontation mit der sich selbst als „Bewegung“ bezeichnenden „Europäischen Bewegung“, vorwiegend Lobbyismus. In typisch konservativer Manier lehnte man dies in abendländischen Kreisen ab. Wie in den zwanziger Jahren nahm man für sich auch in den fünfziger und sechziger Jahren eine ganz andere Haltung in Anspruch: „Unpolitisch“ weigerte man sich, als Massenbewegung am politischen Prozeß teil- und als Interessengruppe Einfluß zu nehmen, vielmehr wollte man elitär gezielt auf einzelne Politiker wirken. ${ }^{296}$ So grenzten sich die Abendländer nicht zuletzt gegen die „europäische Bewegung“ und die Europa-Union ab, der man vor allem "Interessenvertretung“ vorwarf und das Bedürfnis, „selbst eine internationale politische Rolle [...] spielen“ zu wollen. ${ }^{297} \mathrm{Zwar}$ sah man sich in den fünfziger und sechziger Jahren durchaus als Teil der verschiedenen Bemühungen um die Einigung Europas. Im Gegensatz zur Europa-Union jedoch verstanden sich die Abendländer als „Männer ohne Doktrin, Programm, Ideologie, aber mit Haltung und gutem Willen". ${ }^{298}$ Ebenso wie man sich in den zwanziger Jahren von der "rein politischen Bewegung" der Paneuropa-Union abgesetzt und für sich in Anspruch genommen hatte, eine "durchaus unpolitische Organisation" zu sein, ${ }^{299}$ war man noch in den sechziger Jahren stolz darauf, kein politisches Programm zu haben: „Das CEDI hatte es bewußt vermieden ein europäisches Programm aufzustellen [...]. Ich wage zu sagen, daß das CEDI gerade weil es kein Programm hat, 15 Jahre überdauerte. "300 Und wie in der Zwischenkriegszeit war auch in den sechziger Jahren diese Absage an das „Politische" eine im Kern zutiefst politische Grundhaltung.

Parallel zu dieser zunehmenden Bedeutung, die der Binnenkontakt innerhalb des CEDI gewann, strukturierte sich das Zentrum auch organisatorisch neu. Im Dezember 1957 konstituierte sich das Dokumentationszentrum auf Schloß Zeil als juristische Vereinigung mit Sitz in München und bildete erstmals übernationale Gremien. Mit der Gründung eines internationalen Vorstands, eines Beirats und Sekretariats ging man den Austausch innerhalb des CEDI nun gezielter an als in den Jahren zuvor, in denen man ohne festen Rahmen vorwiegend bei Treffen und Tagungen anstehende Probleme besprochen hatte. ${ }^{301}$ Der Vorstand bestand ganz überwiegend aus dem bekannten Personenkreis, der sich bis Ende der sechziger

296 Dies ist hier ganz unabhängig von der Frage, ob es den „Abendländern“ überhaupt hätte gelingen können, eine Massenbewegung aufzubauen, zu konstatieren.

297 Gaupp-Berghausen, Georg von: An die nationalen Zentren des CEDI. Betrifft: Die junge Generation, 30. 9. 1964, ACDP I-148-132/01.

298 Franzel, Emil: Europa im Escorial, in: Deutsche Tagespost vom 25. 6. 1956.

299 Vgl. etwa die Auseinandersetzung Karl Anton Rohans mit Coudenhove-Kalergi im Abendland: Rohan, Karl Anton: System und Leben. Eine Auseinandersetzung mit Coudenhoves "Paneuropa“, in: Abendland 1 (1925/26), S. 173-175, hier S. 173.

300 Bericht des Generalsekretärs auf der Sitzung des Internationalen Rates des CEDI am 24./ 25. 6. 1967, ACDP I-148-132/02.

301 Ebenda. 
Jahre in seiner Zusammensetzung kaum veränderte. ${ }^{302}$ Die zu vergebenden Ämter wie Präsidium, Vizepräsidenten und Schatzmeister wechselten innerhalb des Vorstands in regelmäßigen Abständen. ${ }^{303}$ Dabei entsprachen die Wahlen innerhalb des CEDI, aber auch innerhalb der anderen abendländischen Organisationen, allerdings eher formalen Prozeduren, deren Ergebnis meist vorher feststand. Der relativ kleine Kreis von Abendländern, in sich durch und durch homogen in einer konservativen weltanschaulichen Gesinnung verankert, legte aufgrund seiner weltanschaulichen Überzeugungen auf demokratisch-pluralistische Ordnungsstrukturen seiner Organisation schlicht und einfach keinen Wert.

Auf den Sitzungen des internationalen Vorstands des CEDI referierten in den folgenden Jahren Vertreter der verschiedenen Nationen zur jeweiligen Lage im eigenen Land, und immer wieder verwiesen die Protokolle darauf, diese Referate doch vertraulich zu behandeln. Auch diese Referate waren Bestandteil der geschilderten „inoffiziellen“ Wirkungsweise, und bedenkt man die Tatsache, daß sich innerhalb des CEDI doch eine ganze Reihe regierungsnaher Persönlichkeiten der verschiedenen Länder versammelte, so kann man wohl tatsächlich davon ausgehen, daß die CEDI-Mitglieder recht gut über die innenpolitische Situation in den Nachbarländern informiert waren. Somit dienten internationaler Vorstand und Beirat vor allem als "Vermittlungsstelle" $z$ wischen den nationalen Sektionen und ihren Mitgliedern.

3021959 gehörten zum Internationalen Präsidium: Otto von Habsburg als Präsident, Alberto Martin Artajo, François de la Noë, Georg Fürst Waldburg-Zeil als Vizepräsidenten. Das Generalsekretariat teilten sich Marques de Valdeglesias und Georg von Gaupp-Berghausen. Schatzmeister wurde Marcel de Roover. Dem Internationalen Beirat gehörten von deutscher Seite an: Hans-Joachim von Merkatz, Richard Jaeger, Hermann Josef Abs, Otto Roegele, Ewald Heinrich von Kleist, Alfons Dalma. Hinzu kamen jeweils etwa vier bis fünf Vertreter der österreichischen, belgischen, spanischen, französischen, griechischen, britischen, liechtensteinischen, schweizerischen und schwedischen CEDI-Sektionen. Vgl. die CEDI-Broschüre von 1959, ACDP I-148-131/03.

3031961 kam von deutscher Seite Alois Waldburg-Zeil in den Internationalen Rat hinzu. 1962 akklamierte das CEDI Otto von Habsburg zum Ehrenpräsidenten, neuer Präsident wurde Albert Martin Artarjo. Zu den bisherigen Vizepräsidenten stieß der Franzose Edmond Michelet, der vorher bereits Mitglied des Internationalen Rats gewesen war. Vgl. das Sitzungsprotokoll des Vorstandes und Internationalen Rates des CEDI am 23.6. 1962, ACDP I-148-131/03. Bei der selben Sitzung wurde Edmond Michelet zum neuen Präsidenten für das Jahr 1963 gewählt. Neuer Vizepräsident an seiner Stelle wurde der Österreicher Josef Klaus, vgl. Tagung des Vorstandes und Internationalen Rates des CEDI am 8./9. 12. 1962, ACDP I-148-131/03. Walter Werr, der Studienleiter der Abendländischen Akademie, war in den Internationalen Rat aufgerückt. 1963 gehörte auch Friedrich Zimmermann dem Internationalen Rat an, vgl. das Sitzungsprotokoll des Vorstandes und Internationalen Rates des CEDI am 9.6.1963, ACDP I-148-132/01. 1964 schließlich wurde Hans-Joachim von Merkatz Präsident des CEDI, an seine Stelle rückte der Brite John Rodgers in die Gruppe der Vizepräsidenten, Gaupp-Berghausen übernahm ab 1964 das Generalsekretariat allein. Vgl. das Sitzungsprotokoll des Vorstandes und Internationalen Rates des CEDI am 7. 7. 1963, ACDP I-148-132/01. Ab 1966 übernahm John Rodgers die Präsidentschaft, aus Deutschland stieß Franz Heubl (seit 1964 Präsident des deutschen CEDI) in den internationalen Rat vor. Vgl. die Broschüre des CEDI von 1966, ACDP I-148-132/01. 1968 schließlich wurde mit Adriano Moreira ein Portugiese Präsident. Vgl. das Sitzungsprotokoll des Vorstandes und Internationalen Rates des CEDI am 20./21. 7. 1968, ACDP I-148-132/02. 
Gleichzeitig mit der internationalen Organisation gründeten die Abendländer in Deutschland auch ein „Europäisches Institut für politische, wirtschaftliche und soziale Fragen". Dieses Institut übernahm nun offiziell jene Aufgabe, die vormals die Abendländische Akademie innehatte, nämlich nationale Sektion des CEDI in der Bundesrepublik Deutschland zu sein. Auch hier sind die Nachwirkungen der "Lechfeld-Affäre" spürbar. Ganz offensichtlich zog man es von deutscher Seite nun vor, das CEDI in Deutschland von der Akademie abzukoppeln, es aber andererseits auch nicht unter seinem eigenen Namen auftreten zu lassen. Dies mag damit zu begründen sein, daß im Zuge der Pressekampagne gegen die Abendländische Akademie 1955/56 auch das CEDI mit in die Kritik gerückt war, wenngleich nur am Rande. Offenbar schien es den Beteiligten vernünftiger, die CEDI-Aktionen in Deutschland künftig unter einem neuen, unverfänglichen Namen stattfinden zu lassen. Die Präsidentschaft des Instituts übernahm mit Hans-Joachim von Merkatz allerdings ein Altbekannter, dem mit Alois Waldburg-Zeil ein in unserem Zusammenhang nicht weniger bekannter Generalsekretär zu Seite stand.

\section{Abendländische Interessen: das francistische Spanien}

Das CEDI unterhielt - die jährlich dort stattfindenden Tagungen zeigen es - enge Beziehungen zu Spanien. Dies entsprach voll und ganz abendländischen Interessen. Aufgrund ihrer autoritär-korporatistischen Gesellschaftskonzepte und ihrer Wertschätzung von „Führung " und „Elite" hatten sich die Abendländer bereits seit den zwanziger Jahren für ständisch-autoritäre Systeme wie zum Beispiel den österreichischen Ständestaat eingesetzt. Ebenso wie sie das Portugal Salazars als "den bestregierten Staat Europas“ bezeichneten, in dem ihnen die „Ideale einer christlichen Gesellschafts- und Staatsordnung" verwirklicht und damit das „[liberale] 19. Jahrhundert bereits weitgehend überwunden" schienen, begeisterten sich die Abendländer auch für das francistische Spanien. ${ }^{304}$ Dieses Interesse wurzelte nicht zuletzt in der Propagandaarbeit Hans-Joachim von Merkatz' in der Deutsch-Spanischen-Gesellschaft während des Zweiten Weltkrieges. Sicher, man wird diese Tätigkeit eines einzelnen Abendländers nicht überbewerten dürfen, wenn man nach Kontinuitäten des abendländisches Einsatzes für das Franco-Regime fragt. Schließlich handelte es sich bei der Arbeit der Deutsch-Spanischen Gesellschaft im „Dritten Reich“ um eine offizielle Interessenvertretung des Deutschen Reiches. Es ging um eine möglichst enge Bindung Spaniens an das Deutsche Reich im Zweiten Weltkrieg, welche durch eine halboffizielle Stelle auf propagandistischem Wege gestärkt werden sollte. Dies läßt sich nicht vergleichen mit der Tätigkeit der Abendländischen Bewegung nach 1945.

Die Kontakte der DSG hatten sich, insbesondere aufgrund der persönlichen Beziehungen ihres Präsidenten Faupel, vor allem auf falangistische Kreise kon-

304 Franzel, Emil: Portugal, der bestregierte Staat Europas, in: Neues Abendland 7 (1952), S. 266-272. Zur Geschichte Portugals unter Salazar siehe: Raby, D.L., Fascism and Resistance in Portugal. Sänger, Portugals langer Weg nach Europa. 
zentriert. ${ }^{305}$ Demgegenüber entstammten die Ansprechpartner der Abendländischen Bewegung in den fünfziger Jahren vor allem dem spanischen Katholizismus. Dieser hatte nach Kriegsende durch umfangreiche Neubesetzungen in der Regierung die Oberhand über die Falangisten gewonnen, als das Franco-Regime nicht zuletzt aufgrund des Drucks der Weltöffentlichkeit - auf deutlich faschistische Symbole und ihre Vertreter verzichtete. In den folgenden Jahren wandelte sich das System „von einer faschistisch-totalitären Frühphase zu einer konservativ-autoritären Entwicklungsdiktatur". 306 Der "Nationalkatholizismus" und seine politische Vertretung Associación Católica Nacional de Propagandistas (ACNP) stimmte zwar in zentralen Punkten mit der (ursprünglich) faschistischen Falange überein, grundsätzlich bildeten die beiden Strömungen jedoch „die beiden ideologischen Antipoden innerhalb der francistischen Regimeideologie“.307 Das „autoritär-korporatistische Ordnungsdenken“ der ACNP lehnte im Gegensatz zur Falange jedes sozialrevolutionäre Vorgehen ab - eine Position, die die Gründe für die Nähe der spanischen Nationalkatholiken zu deutschen Abendländern bereits andeutet. Das Weltbild der Spanier und Deutschen stimmte in den allermeisten Punkten überein: katholisch, konservativ, autoritär, elitär - diese gemeinsamen Positionen ermöglichten eine partiell kongruente Interessenkonstellation in den fünfziger Jahren. 308

Dabei waren die deutsch-spanischen Kontakte unmittelbar nach dem Ende des Zweiten Weltkrieges erst einmal abgebrochen: Einerseits war es für Deutsche unmöglich, nach Spanien zu reisen, andererseits fanden sich in Deutschland kaum öffentlich geäußerte Sympathien für das francistische Regime. Damit entsprach das deutsche Verhalten jenem der Schutzmacht USA und der übrigen westlichen Weltöffentlichkeit, die nach 1945 bemüht waren, Spanien zu isolieren. Das negative Bild Spaniens begann sich in Deutschland und anderswo erst zu ändern, als der Wind des Kalten Krieges heftiger zu blasen anhob. Die strategisch wichtige Lage Spaniens machte spätestens mit Beginn des Korea-Krieges eine weitere Ausgrenzung Spaniens unmöglich: Die UN hoben 1950 ihren 1946 gefaßten Boykottbeschluß auf; 1953 folgte das Konkordat mit dem Vatikan; 1955 wurde Spanien in die UN aufgenommen und schloß ein Stützpunktabkommen mit den USA. Der von Spanien immer wieder ins Feld geführte Verweis auf die jahrzehntelange antikommunistische "Tradition“ des Landes unterstützte diesen Wiedereingliederungsprozeß wirksam.

Auch in Deutschland fanden sich seit Ende der vierziger Jahre wieder Spanien

305 Vgl. Teil I, Kap. I.2. Siehe auch den Tätigkeitsbericht der DSG für das Geschäftsjahr 1939/40 einschließlich der Monate April und Mai 1940, BA R 64-I/12.

306 Weber, Spanische Deutschlandpolitik, S. 23 und S. 29.

307 Ebenda, S. 218.

308 Zwischen den Jahren des Zweiten Weltkrieges, als Hans-Joachim von Merkatz für die DSG Propagandaarbeit leistete, und den abendländischen Bemühungen um Spanien in den fünfziger Jahren hatte sich also die Situation innerhalb des spanischen Machtgefüges grundsätzlich verändert. Insgesamt wird man wohl formulieren können, daß nicht der abendländische Einsatz für Spanien nach 1945 in der Kontinuität der Merkatzschen Arbeit im Zweiten Weltkrieg stand, sondern daß Merkatz zur abendländischen Bewegung auch aufgrund seiner eigenen Erfahrungen in der Deutsch-Spanischen Gesellschaft fand. 
freundlich Gesinnte, vor allem in der Presse. ${ }^{309}$ Nicht zuletzt das Neue Abendland tat sich schon bald mit lobenden Artikeln hervor: Dabei forderte man nicht allein eine Eingliederung Spaniens in die westliche Welt aufgrund seiner historischen „Verdienste", sondern pries schon bald auch das spanische Regierungssystem als vorbildlich. 310 Hier kamen nun auch Interpretationsmuster einer deutsch-spanischen Freundschaft wieder an die Oberfläche, die bereits die deutsche Propagandatätigkeit im Zweiten Weltkrieg bestimmt hatten - und insofern weist von Merkatz' Tätigkeit eben doch über rein individuelle Erfahrungen hinaus. Dazu gehörte vor allem die Beschwörung eines gemeinsamen Bollwerks gegen den Bolschewismus. War es in den Kriegsjahren der "gemeinsame Kreuzzug gegen die bolschewistischen Horden, der in Spanien begann und [...] in der endlosen Weite Rußlands seine Fortsetzung findet“, welcher eine „Waffengemeinschaft geschaffen [hat], die die beste Grundlage auch für die geistig-kulturelle $\mathrm{Zu}$ sammenarbeit der Völker bildet",311 so hatte sich das Bild in den Jahren des Kalten Krieges kaum gewandelt: „Spanien und Deutschland sind die beiden einzigen Nationen des noch freien Europas, die den Bolschewismus ohne Maske erlebt haben, auf ihrem eigenen Grund und Boden. Spanien und Deutschland sind daher auch am meisten immun gegen Versuchungen aus dem Osten. Spanien und Deutschland haben - vom Unterschied in der Schuldfrage abgesehen - Perioden hinter sich, in denen sie internationale Ächtung und Diffamierung ertragen mußten. Sie verstehen einander und ihre jeweiligen Positionen vielleicht besser als zwei beliebige andere Nationen Europas. Was liegt daher näher, als daß die Spanier hoffen, daß es der Bundesrepublik gelingt, ihnen den Weg in jene internationalen Gemeinschaften zu ebnen [...].“312

Tatsächlich entwickelte Spanien im Verlauf der fünfziger Jahre ein starkes Interesse daran, sich den entstehenden europäischen Institutionen anzunähern, und es hoffte, nicht zuletzt durch einen engen Kontakt mit Westdeutschland diese Annäherung leichter vollziehen zu können. Je deutlicher sich die junge Bundesrepublik politisch festigte und als Bündnispartner in der Atlantischen Allianz eine Rolle zu spielen begann, je mehr es mit der deutschen Wirtschaft „bergauf“ ging, desto anziehender wurde Westdeutschland für die spanische Außenpolitik. Bereits im Vorfeld der 1958/59 in Spanien erfolgten „Wende“ in Form einer Regierungsumbildung und der sich anschließenden wirtschaftlichen Liberalisierung, die schließlich 1962 auch zu einem Gesuch auf Assoziation an die EWG führte, war Spanien

309 Aschmann, „Treue Freunde“, S. 105-109. Vgl. auch: Briesemeister, Die iberische Halbinsel und Europa. Ders., Spanien in der deutschen Essayistik und Zeitungsberichterstattung.

310 Das Neue Abendland wurde übrigens (vermutlich auf Kosten der Familie WaldburgZeil) kostenlos den deutschen Schulen in Spanien und den deutschen Lektoren an spanischen Universitäten zur Verfügung gestellt. Vgl. Aschmann, „Treue Freunde“, S. 427, FN 213.

311 Deutsch-spanische Kulturarbeit im Kriege, BA R 64-I/27.

312 Otto B. Roegele im Rheinischen Merkur vom 24. 9. 1954 über die dritte CEDI-Tagung, zitiert nach: Mitteilungsblatt der Abendländischen Akademie Oktober 1954, BA N 1243/ 15. Zum Stereotyp der Beschwörung einer „treuen “ Freundschaft zwischen Spanien und Deutschland, welches die Abendländer in der Nachkriegszeit nicht als einzige verwandten, vgl. die Arbeit Birgit Aschmanns, „Treue Freunde“. 
an Kontakten ins westliche Europa gelegen. Nicht zuletzt dazu diente die CEDIGründung 1952, an der Alfredo Sanchez Bella mitgewirkt hatte: Die konservativkatholischen Politiker in der abendländischen Bewegung konnten den Spaniern helfen, sich den Weg in deutsche Amtsstuben und Zeitungen zu bahnen, und ihnen nicht zuletzt direkte Kontakte zur konservativen politischen Elite der Bundesrepublik verschaffen.

Den Abendländern bot das CEDI die Möglichkeit, das politische „Vorbild“ Spanien in konkreter, politisch wirksamer Form zu unterstützen, ganz abgesehen davon, daß der direkte deutsche Kontakt mit Spanien, der bis etwa 1958 durchaus noch nicht fest diplomatisch etabliert war, den Deutschen auch die Möglichkeit bot, konkrete politische Interessen zu vertreten. Das abendländische Interesse an Spanien in den fünfziger Jahren speiste sich zusätzlich aus der antikommunistischen Überzeugung, Europa müsse Spanien in die „Abwehrfront" des Abendlandes integrieren: aufgrund seiner strategischen Position, aber auch aufgrund des vermeintlich gefestigten Katholizismus, der, so hofften die Abendländer, die in Europa erschütterten Grundfesten des Glaubens zu festigen helfen könne.

Mit Gründung des CEDI 1952 entwickelte sich dieser Teil der Abendländischen Bewegung zu einem nicht unwichtigen privaten Instrument im Bereich der deutsch-spanischen Beziehungen. Tatkräftig gingen die deutschen CEDI-Mitglieder daran, auch in der westdeutschen Öffentlichkeit für ein stärkeres politischdiplomatisches Engagement der Bundesrepublik in Spanien zu werben. Dazu trugen nicht zuletzt die CEDI-Tagungen bei, auf denen bundesdeutsche Minister zwar offiziell privat, aber dennoch öffentlichkeitswirksam nach Spanien reisten in einer Zeit, in der noch keine hochrangigen deutschen Politiker das Land besucht hatten. In den Jahren ab 1953 wurden Richard Jaeger, Hans-Joachim von Merkatz und auch Eugen Gerstenmaier während der CEDI-Tagungen von Franco empfangen. Darüber wiederum berichteten Journalisten aus den Reihen des CEDI in ihren jeweiligen Organen (wie etwa dem "Rheinischen Merkur“ oder der "Deutschen Tagespost") ausführlich und lobend. Aber auch andere, "nicht-abendländische" Zeitungen griffen die Nachrichten an hervorgehobener Stelle auf. 313

Im Rahmen dieser Gespräche bemühten sich die abendländischen Politiker, die deutsch-spanischen Beziehungen zu verbessern und ihre Etablierung voranzutreiben. Dabei hielten sie durchaus engen Kontakt zu ihrer Regierung. So betätigte sich beispielsweise Richard Jaeger „als Kurier zwischen der Bundesregierung bzw. Adenauer und dem spanischen Außenministerium". Denn der spanische Außenmister Atarjo stand als CEDI-Mitglied ja in direkter Verbindung zu Jaeger. ${ }^{314}$ Dieser berichtete dem Kanzler regelmäßig über die Gespräche im Umfeld der

313 Vgl. bspw. die Presseberichte in den Mitteilungsblättern der Abendländischen Akademie Oktober 1954, Juli 1955 und August 1958, BA N 1243/15.

314 Weber, Spanische Deutschlandpolitik, S. 251. Richard Jaeger hat Frau Weber zur Bestätigung dieser These Einblick in sein Privatarchiv gewährt. Vgl. auch die Angaben Birgit Aschmanns zum Briefwechsel Jaeger-Adenauer in: „Treue Freunde“, S. 224 f. Hans-Joachim von Merkatz ließ seine im Rahmen der CEDI-Tagungen zu haltenden Vorträge von Heinrich von Brentano Korrektur lesen, um Änderungswünsche des Auswärtigen Amts einbringen zu können. Vgl. Brief Merkatz an Brentano, 30. 5. 1956, ACDP I-148-131/03. 
CEDI-Tagungen und versuchte gleichzeitig, im Sinne des spanischen Interesses an einem offiziellen Besuch Adenauers auf diesen einzuwirken. Dabei behielt Jaeger jedoch die deutschen Interessen im Blick: So schlug er angesichts des von spanischer Seite wiederholt geäußerten Wunsches, Adenauer möge offiziell nach Madrid reisen, vor, einen solchen Besuch von einem Entgegenkommen der Spanier in der Mitte der fünfziger Jahre noch immer ungelösten Frage deutschen Eigentums in Spanien abhängig zu machen. ${ }^{315}$ Gerade die Eigentumsfrage, welche die abendländischen Politiker auch bei ihren Gesprächen mit Franco im Umfeld der CEDITagungen thematisierten, macht deutlich, daß es den Abendländern in diesen Unterredungen durchaus auch um politische Interessen der Bundesrepublik Deutschland ging. ${ }^{316}$ Gleichzeitig förderten die Abendländer Gegenbesuche spanischer Politiker in der Bundesrepublik und bedienten sich dabei des CEDI als Instrument - und nicht zuletzt auch als Financier. So luden etwa Hans-Joachim von Merkatz und Georg Fürst Waldburg-Zeil den Internationalen Rat des CEDI im Oktober 1963 zu einer Tagung nach Stuttgart ein, wo die Spanier mit dem stellvertretenden CDU-Vorsitzenden und baden-württembergischen Ministerpräsidenten Kurt-Georg Kiesinger zusammentrafen. ${ }^{317}$ Schließlich erstreckte sich die abendländische Vermittlungstätigkeit für Spanien auch auf die europäische Ebene: So kündigte Gaupp-Berghausen im Februar 1958 beim Auswärtigen Amt an, mit „drei oder vier spanische[n] Herren, darunter einem Staatsrat Marques de Valdeglesias, Anfang März [...] nach Straßburg reisen zu wollen, um dort mit dem Europarat Kontakte aufzunehmen". 318

Bis Mitte der fünfziger Jahre nahm das Auswärtige Amt von diesen Aktivitäten des CEDI kaum Notiz, was die abendländischen Publizisten durchaus bissig kommentierten. So schrieb Otto B. Roegele: „Das Auswärtige Amt hatte zu diesem [vierten] Kongreß [des CEDI 1955] keinen Vertreter entsandt, obwohl er, wie die Erfahrung der letzten Jahre lehrt, die beste, ja die einzige Möglichkeit zu direkten Gesprächen mit spanischen Politikern [...] bietet.“319 Bereits 1956 hatte sich jedoch die Aufmerksamkeit deutscher Diplomaten dem CEDI zugewandt, und die westdeutsche Botschaft in Madrid urteilte, „daß die spanische Regierung sich des Dokumentationszentrums als eines Sprachrohrs“ bediene. Der Wert des CEDI liege darin, die „einzige Stelle in Spanien [zu sein], an der einmal im Jahr

315 Zur Eigentumsfrage, die lange Zeit innerhalb der deutsch-spanischen Beziehungen als Hemmschuh wirkte, vgl. Aschmann, „Treue Freunde“, S. 120-128.

$316 \mathrm{Vgl}$. Spaniens Stellung zum Westen. Europäisches Dokumentationszentrum tagt in Madrid, in: Süddeutsche Zeitung, 5.6. 1956. Zitiert nach: Mitteilungsblatt der Abendländischen Akademie Nr. 2 1956, BA N 1243/15.

317 Protokoll der Sitzung des Vorstandes und des Internationalen Rates des CEDI vom 9.6. 1963, ACDP I-148-132/01. Ebenso finanzierte das CEDI eine Reise des spanischen Informationsministers Manuel Fraga Iribarne, ebenfalls CEDI-Mitglied, nach Bonn und München, wo er Richard Jaeger, Franz Heubl, Friedrich Zimmermann, Franz Joseph Strauß und Kurt Georg Kiesinger traf, vgl. Aschmann, „Treue Freunde“, S. 434.

318 Aufzeichnung Dr. v. Nostitz, 12. 2. 1958, betr.: Angebliche Bitte spanischer Kreise an die Abendländische Akademie von Kontakten mit dt. Vertretern beim Europarat in Straßburg, PAAA Ref. 212/292.

319 Otto B. Roegele im Rheinischen Merkur vom 24.6. 1955, zitiert nach: Mitteilungsblatt der Abendländischen Akademie Juli 1955, BA 1243/15. 
politisches Gedankengut anderer Länder [...] vorgetragen werden kann“. Daher sei es wichtig, „über diesen, wenn auch sehr begrenzten Weg, politisch interessierte Spanier aus ihrer nationalstaatlichen Befangenheit heraus- und an den Europa-Gedanken heranzuführen“ “. 320 Gleichzeitig bemerkte man erfreut, daß „in den Reden und Ansprachen [auf den Tagungen des CEDI] auch die besonderen Anliegen der deutschen Außenpolitik zur Sprache" gekommen seien. ${ }^{321}$ Hier wird erneut deutlich, wie sehr das CEDI in seiner speziellen Wirkungsweise dazu diente, deutsche Interessen zu vertreten und im vertraulichen Gespräch deutsche Positionen zu vermitteln. In den folgenden Jahren attestierte das Auswärtige Amt dem CEDI daher „erhebliche politische Bedeutung“".322 Insgesamt also bot das CEDI deutschen Politikern die Möglichkeit, eine „Substitutions-Diplomatie“ zu betreiben, „die eine Intensivierung bilateraler Beziehungen auch ohne aufsehende Politikerreisen ermöglichte". ${ }^{323}$ Somit scheint sich die von den Abendländern bewußt gewählte Organisations- und Aktionsform durchaus als erfolgreich erwiesen zu haben - wenn sie eben auch auf eine ganz bestimmte politische Richtung, nämlich Vertreter der Unionsparteien, beschränkt blieb. Zumindest aber solange die Union unangefochten die führende bundesdeutsche Regierungspartei war, erwiesen sich die Kontakte des CEDI im vordiplomatischen Raum als durchaus nützlich.

Als nach der Unterzeichnung des Eigentums-Vertrages 1958 Außenminister Brentano erstmals offiziell nach Spanien reiste, verlor das Auswärtige Amt langsam das Interesse an der abendländischen Ersatz-Diplomatie. ${ }^{324}$ Auch auf seiten der spanischen Regierung hatte mit dem „Kurswechsel“ 1958/59 das dringende Interesse am CEDI - anscheinend - nachgelassen, standen die Kontakte zu Deutschland doch nun auf offiziellem diplomatischen Boden. Die spanische Politik hofierte die Abendländer fortan weniger. Dies bemerkte auch die Presse, die in der Tatsache, daß das CEDI seinen Jahreskongreß 1959 „Die europäische Solidarität in der Erprobung" erstmals nicht mehr im Escorial abhielt, sondern in der nahegelegenen Hospederia de Cuelgamuros, ein deutliches Zeichen für diese Entwicklung sah. ${ }^{325}$ Bei genauerem Betrachten jedoch verschoben sich die Interessen nur: Die abendländische Bewegung orientierte sich in den kommenden Jahren stärker auf General de Gaulle und seine Europa-Politik. Die gaullistische Präsenz und Aktivität im CEDI stieg in diesen Jahren deutlich. Und gerade an diesen Kontakten hatten auch die Spanier Interesse, bot ihnen doch das gaullistische Konzept einer intergouvernementalen Kooperation der europäischen Nationen unter möglichst vollständiger Wahrung der Souveränität die einzige Möglichkeit, an einem gemeinsamen Europa mitwirken zu können. Jede supranationale euro-

320 Botschaft Madrid an das AA, 27. 8. 1956, PAAA Ref. 201/506, zitiert nach Aschmann, "Treue Freunde", S. 431, FN 238.

321 Aufzeichnung von Legationsrat Klein, Ref. 303, 30. 5. 1956, PAAA Ref. 206/42.

322 Aufzeichnung von Schmidt-Schegel, 31.5. 1957, zitiert nach Aschmann, "Treue Freunde“, S. 429, FN 224.

323 Aschmann, „Treue Freunde“, S. 434.

324 Ebenda.

325 Vgl. den Pressespiegel zur VIII. Jahrestagung des CEDI, in: Dokumentation der Woche für Weltpolitik und Wirtschaft, Sonderausgabe Dezember 1959, BA 1243/30. 
päische Lösung wäre im nationalistischen Franco-Regime auf unüberwindbare Widerstände gestoßen. ${ }^{326}$ In den Jahren zwischen 1958 und etwa 1964 nutzten daher deutsche und spanische Politiker gemeinsam das CEDI, um „fern von indiskreten Ohren" mit französischen Gaullisten im engen Austausch zu stehen. ${ }^{327}$ So verschob sich das in den fünfziger Jahren primär auf deutsch-spanische Beziehungen orientierte CEDI in Richtung Frankreich. Die eingespielten und etablierten Kontakte kamen nun den deutschen Interessen an der französischen Politik zugute.

\section{Europa als abendländische "Weltmacht"}

Die Annäherung des CEDI an Frankreich schlug sich auch in der Entwicklung der Abendland-Idee der sechziger Jahre nieder. Stärker als im Jahrzehnt zuvor vertrat man in den sechziger Jahren das Ziel eines politisch starken, gegenüber den USA weitgehend selbständigen Europas. Begonnen hatte dieser Prozeß einer stärkeren Orientierung auf machtpolitische Faktoren Ende der fünfziger Jahre, als die bis dahin vorbehaltlose Unterstützung der Westbindungspolitik der Kanzlerschaft Adenauers ins Wanken geriet. Gipfelnd in den Monaten des Mauerbaus von $1961 \mathrm{nahm}$ man offenbar auch in abendländischen Kreisen wahr, daß die Adenauersche „Politik der Stärke“ in eine Sackgasse geführt zu haben schien. Der Wiedervereinigung und auch der Befreiung Mittel- und Osteuropas kam man offenbar mit diesem Konzept kein Stück näher. Während Entspannungstendenzen in der Mitte der fünfziger Jahre bereits Ängste geschürt hatten, eine Annäherung zwischen den Blöcken könne vor allem auf Kosten der Deutschen geschehen und die Wiedervereinigung als politisches Ziel auf ein politisches Abstellgleis geraten, erkannte man zunehmend, daß auch die europäische Einigung von der „Politik der Stärke" auf Dauer nicht profitieren würde. Der sich immer deutlicher herauskristallisierende Bilateralismus zwischen den USA und der Sowjetunion schwächte Europa als politische Instanz - der ewige Juniorpartner in der atlantischen Gemeinschaft zu sein, schien den Abendländern auf Dauer keine reizvolle Aussicht für die "mater occidentalis“. Die noch in der Mitte der fünfziger Jahre gebetsmühlenartig wiederholte Auffassung, das „Abendland“ müsse, wenn schon nicht die militärisch-politische, so doch wenigstens die geistige Führung im westlichen Bündnis übernehmen, wich nun der Forderung nach einer stärkeren Position Europas auch gegenüber den USA.

Hier trafen verschiedene Faktoren zusammen: Zum ersten sah man, daß die mit der beanspruchten geistigen Führung immer einhergedachte Rechristianisierung der europäischen Gesellschaften wohl für immer von der fortschreitenden Säkularisierung verhindert würde und die Amerikanisierung der europäischen Lebens-

326 Hommel, Spanien und die Europäische Wirtschaftsgemeinschaft. S. 201. Außenminister Artajo betonte bereits auf dem 3. CEDI-Kongreß 1954: „Daher ist es für uns wesentlich, daß die Bedeutung der Nationen sowie ihre völlige Unabhängigkeit und ihre volle Souveränität respektiert werden [...]. “ Vgl. Mitteilungsblatt der Abendländischen Akademie Oktober 1954, BA 1243/15.

327 Ziel, Zweck und Aufgabe des CEDI (1960), ACDP I-148-132/01. 
weise unaufhaltsam voranschritt. Statt also im atlantischen Bündnis einen eigenständigen, wichtigen Part, nämlich die geistige Führung zu übernehmen, die in den Augen der Abendländer ja unersetzbar zur militärischen Machtposition hinzugehörte, geriet Europa auch auf diesem Gebiet gegenüber der Schutzmacht im Westen ins zweite Glied. Gleichzeitig wuchs die politische und militärische Abhängigkeit des Kontinents. Es entwickelte sich die Überzeugung, daß nur ein starkes Europa in der Lage sei, die eigenen Interessen, die mit jenen der Vereinigten Staaten eben doch nicht als deckungsgleich angesehen wurden, kraftvoll zu vertreten. Diese Forderung eines politisch starken Europas richtete sich zunehmend auch gegen die USA. Der bereits seit Jahrzehnten in der Abendland-Idee virulente kulturelle Antiamerikanismus kehrte sich Ende der fünfziger Jahre ins Politische. Nachdem sich die Fronten des Kalten Krieges gelockert hatten und die Amerikaner mit der beginnenden Entspannungspolitik signalisierten, daß sie nicht bereit waren, die antikommunistischen Interessen etwa der Abendländer weiterhin wie zu „Hochzeiten“ des Ost-West-Konfliktes zu vertreten, verlor sich auch die in den fünfziger Jahren quasi notgedrungen vorgenommene abendländische Annäherung an die USA und den "Westen“.

Zwar betonten die Abendländer weiterhin, daß das Atlantische Bündnis grundsätzlich von überragender Bedeutung auch für Europa sei, doch forderten sie eine stärkere Position des europäischen "Abendlandes“ gerade in Fragen, die primär Europa angingen. Bereits 1957 konstatierte man, im Nachgang der Suez-Krise, erstmals eine „Krise der atlantischen Welt" 328 und machte auch im Verlauf der sechziger Jahre eine „immer größere Lockerung der Bande innerhalb der NATO“ aus. ${ }^{329}$ Gegenüber der sich seit Beginn der sechziger Jahre abzeichnenden Krise innerhalb der atlantischen Gemeinschaft, die für die Bundesrepublik noch verstärkt wurde durch den Mauerbau und das damit offenkundig werdende Scheitern der „Politik der Stärke“, bezogen die Abendländer konkret Stellung. Nicht nur politisch forderte man eine größere Eigenständigkeit Europas, sondern auch militärisch: Die „Vormacht der USA“ in der NATO, so betonten die Abendländer, „kann auf die Dauer nicht allein das tragende Gerüst bleiben, sondern die Einigung Europas muß einen bedeutenden Anteil an der Verteidigung des Kontinents und des Mittelmeerraumes nehmen".330

328 So der Titel der Jahrestagung des CEDI im Juni 1957.

329 Dalma, Alfons: Europa in drei Monaten, in: Aconcagua 1 (1965), S. 118-123, hier S. 118. So konstatierte Dalma im gleichen Artikel: „Da aber gegenwärtig die USA stärker in Ostasien als in Europa engagiert sind [...], da alle Pläne für die Reform der NATO im Sinne einer besseren ausgewogenen Partnerschaft zwischen den USA und Europa seit Dezember 1964 in den Schubladen der Staatskanzleien ruhen, da die USA zur Stützung des Dollars an die europäischen Partner als unzumutbar empfundene Wünsche richten, da Europa seinerseits den Eroberungszug des amerikanischen Investitionskapitals zu beklagen beginnt, ist die NATO [...] in ihrer militärischen und defensiven Statik zwar unversehrt vorhanden, in ihrer weltpolitischen und strategischen Dynamik aber lahmgelegt." Ebenda, S. 122. Vgl. auch: Jaeger, Richard: Die Krise der nordatlantischen Gemeinschaft, in: Europa-Forum 4 (1967), S. 200-207.

330 Merkatz, Hans Joachim von: Die internationalen Organisationen. Vortrag auf der 6. Jahrestagung des CEDI vom 17.-19. 6. 1957, ACDP, I-148-131/03. 
Immer deutlicher sah man „die Notwendigkeit einer echten dritten Kraft. Diese dritte Kraft, unabhängig und ein Mittler zwischen Ost und West, kann und muß vor allem Europa selbst werden. Ein Europa, das ausgehend von der EWG eine echte politische Gemeinschaft wird“. ${ }^{331}$ Zwar forderte man hiermit nicht den Austritt aus der NATO, dies verbot auch der weiterbestehende Antikommunismus des "Abendlandes“, doch distanzierte man sich im Gegensatz zu den fünfziger Jahren nun deutlich von den USA und ihrem hegemonialen Anspruch innerhalb des atlantischen Bündnisses. So wurde aus dem - jahrzehntelang vorwiegend kulturell beschriebenen - „Abendland“ ein politisch starkes Europa mit einer eigenständigen Verteidigungs-, Außen- und Sicherheitspolitik. „Darum fordert es [das CEDI] eine politische Gemeinschaft Europas, die neben der wirtschaftlichen Einigung nun absoluten Vorrang " haben müßte. Dabei ging es den Abendländern nicht um die Schaffung einer europäischen Föderation, sondern vielmehr um eine „politische Gemeinschaft Europas auf der Grundlage der Kooperation der geschichtlich gewachsenen europäischen Nationen, die ihre Eigenheit nicht verwischt, die aber in den entscheidenden Fragen gemeinsamer Außenpolitik, der Verteidigung und der Wirtschaft ein Handeln als politische Einheit ermöglicht" ${ }^{\text {. }}{ }^{32}$ Solche Positionen wurden in der Bundesrepublik der frühen sechziger Jahre vor allem von jenen geäußert, die sich in den Reihen der deutschen sogenannten "Gaullisten“ befanden - aber darauf wird noch einzugehen sein.

Das starke, machtpolitisch von dem atlantischen großen Bruder weniger abhängige Europa, welches die Abendländer in den sechziger Jahren forderten, sollte seine Interessen nicht nur gegenüber den USA vertreten, sondern auch die Kontakte mit den Ländern der "Dritten Welt“ intensivieren. Wenn Europa, auch durch entwicklungspolitische Maßnahmen, in der Lage wäre, etwa Lateinamerika stärker an sich zu binden, vergrößerte sich das weltpolitische Gewicht des "Abendlandes“. „Afrikaner oder Inder, die einst in Eton, Cambridge oder Oxford studiert [...] haben, bleiben im allgemeinen ihr Leben lang englandfreundlich. Aus ihnen selektiert die britische Regierung die spätere politische Elite [...] des Commonwealth. Warum sollten wir nicht ähnliche oder moderne Wege in Lateinamerika gehen und ganz auf weite Sicht [...] ein ,europäisch-lateinamerikanisches Commonwealth“ anstreben [...]?"333 Auf diese Weise würde Europa „Großmacht" sein - nicht „Schlachtfeld“. ${ }^{334}$ Und diese Großmacht würde dann auch eine solche Anziehungskraft gerade auf den Osten Europas ausüben, daß damit Europa erstmals eine eigenständige Politik auch in Richtung Mitteleuropa, jener traditionell abendländischen Bastion, würde ausüben können.

Diese Politik sollte allerdings nichts zu tun haben mit der sich im Verlauf der sechziger Jahre abzeichnenden ost-westlichen Entspannungspolitik. Denn trotz aller machtpolitisch-realistischen Verschiebung innerhalb der abendländischen

331 Gaupp-Berghausen, Georg von: Iberoamerika und der Nahe Osten, in: Aconcagua 3 (1967), S. 163 f., hier S. 163/164.

332 Ziel, Zweck und Aufgabe des CEDI (1960), ACDP I-148-132/01.

333 Gaupp-Berghausen, Georg von: Österreich - Lateinamerika. Möglichkeiten der Entwicklungshilfe, in: Aconcagua 4 (1968), S. 448-457, hier S. 457.

334 Habsburg, Europa: Großmacht oder Schlachtfeld. 
Idee blieb der rigide Antikommunismus doch auch in den sechziger Jahren erhalten. Er verbot eine Annäherung an den Osten im Sinne der Détente-Politik. „Friedliche Koexistenz im Ideologischen [...] kann es doch nicht geben“ - das blieb Kernpunkt der abendländischen Idee wie in den Jahrzehnten zuvor. ${ }^{335}$ Dennoch aber hoffte man nun, durch regelmäßige Kontakte der Westeuropäer mit Mitteleuropa "möglichst feste Bande“ zu knüpfen, um auf Dauer den mitteleuropäischen Raum aus der Umklammerung der Sowjetunion zu lösen. Im Gegensatz zu den fünfziger Jahren, als sich auch im Denken der Abendländer die beiden Blöcke von Ost und West monolithisch gegenüberstanden, plädierte man nun für eine aktive Mittel- und Osteuropapolitik, bei der „ein starkes, einiges Europa im Lager der Freien Welt tonangebend sein muß“. ${ }^{336}$ Erstmals ging hier das abendländische Denken über das reine Beklagen der Ergebnisse des Zweiten Weltkrieges und die irrationale Vision eines neuen mitteleuropäischen Imperiums hinaus. Im Zuge der "realpolitischen" Wende der Abendländer ging es nun erstmals darum, die eigenen Vorstellungen politisch zu konkretisieren. Auch wenn sich keine ausgefeilten Pläne, wie denn die „möglichst festen Bande“ zu knüpfen seien, an diese Ideen anschlossen, so zeigen sie doch die Wandlung, die die abendländische Idee seit den fünfziger Jahren durchlaufen hatte. Dies bezog sich auch auf die deutsche Frage. Bereits 1959 betrachtete man „die Teilung Deutschlands [...] nicht als einen isolierten Vorgang [...], sondern als einen Aspekt der Teilung Europas “, ${ }^{337}$ und hoffte über eine konsequente Europa-Politik auch die Interessen der Deutschen im Hinblick auf eine Wiedervereinigung durchsetzen zu können.

\section{Die Abendländer als „Gaullisten“}

Die öffentlichen Aktivitäten ähnelten auch Anfang der sechziger Jahre jenen der vorangegangenen Zeit. Im Sommer fanden die jeweiligen Jahrestagungen in Spanien statt, 1960 unter dem Titel „Der Westen vor der Bedrohung - Europa in der weltpolitischen Strategie“, während man sich 1961 „L'Occident à l'heure iberoaméricaine" zuwandte. 1962 ging es um „Das soziale Problem in internationaler Sicht“, 1963 schlicht um „Europa in Bewegung“. 1964 schließlich stand mit "Aspects de la politique de la détente“ die sich international anbahnende Entspannung im Mittelpunkt.

Intern jedoch geriet seit der Rückkehr de Gaulles an die französische Staatsspitze, bei der das CEDI nach Aussagen Otto von Habsburgs politisch mitwirkte, ${ }^{338}$ im Zentrum mehr in Bewegung, als die regelmäßige öffentliche Aktivität vermuten läßt. Denn während in der ersten Hälfte der fünfziger Jahre die Fran-

335 Merkatz, Hans-Joachim von: Das Ringen um die europäische Einheit. Vortrag vor dem österreichischen CEDI am 12. 2. 1960, ACDP I-148-132/01.

336 Habsburg, Europa: Großmacht oder Schlachtfeld, S. 23-51, hier S. 47.

337 Resolutionen des CEDI-Kongresses 1959, zitiert nach Dokumentation der Woche, Sonderausgabe Dezember 1959, BA 1243/30.

338 In der von Otto von Habsburg autorisierten Biographie schreiben Stephan Baier und Eva Demmerle: „Viele [politische] Kontakte seien über das CEDI gelaufen, etwa bei der abenteuerlichen Rückkehr de Gaulles an die Macht in Frankreich." Zitiert nach: Baier/ Demmerle, Otto von Habsburg, S. 241. 
zosen eher schwach im CEDI vertreten waren, entfaltete gerade die französische Seite zwischen 1958 und 1963/64 eine deutlich stärkere Aktivität im CEDI, und alle daran beteiligten Franzosen gehörten zum gaullistischen Spektrum. Bei den im CEDI aktiven Deutschen stieß die Konzeption eines „Europa der Vaterländer“ auf positive Resonanz. Damit verband sich eine große abendländische Wertschätzung de Gaulles, welche sich ganz ähnlich erklären läßt wie jene für Adenauer in den fünfziger Jahren. Vor allem die Tatsache, daß der Regierungsstil des Generals autoritäre Züge aufwies, kam den abendländischen Vorstellungen noch immer entgegen. Die Abendländer sprachen dem General bis weit in die sechziger Jahre hinein, als die Kontroverse zwischen „Atlantikern“ und „Gaullisten“ in der Bundesrepublik bereits wieder abgeflaut war, eine „wegweisende“ Position auf dem Weg Europas zur politischen Gemeinschaft zu. ${ }^{339}$ Selbst wenn sich die deutschen Abendländer mancher Skepsis angesichts des immer wieder irritierenden Verhaltens de Gaulles nicht enthielten, übernahm man doch grundsätzlich seine Forderungen nach einem starken Europa.

So standen die Abendländer innerhalb der Auseinandersetzung, die unter dem Schlagwort der „Atlantiker-Gaullisten-Kontroverse“ bekannt geworden ist, eindeutig und ausschließlich auf seiten der „Gaullisten“. Dies lag nicht zuletzt daran, daß jener „feste Kern“, der die „Modernisierung des Abendlandes“ im Verlauf der späten fünfziger und sechziger Jahre umsetzte, zum allergrößten Teil der CSU nahestand oder ihr angehörte. Dabei handelte es sich um Vertreter der bundespolitischen Führungsgruppe um Franz Josef Strauß innerhalb der CSU, welche die europapolitischen Konzeptionen der Partei entwickelten. Mit Richard Jaeger, Franz Heubl (seit 1958 Vorsitzender der CSU-Fraktion, seit 1960 auch Leiter der Bayerischen Staatskanzlei), Friedrich Zimmermann (von 1956 bis 1963 Generalsekretär der CSU, MdB), Emil Franzel und Ewald H. von Kleist (Verleger) versammelte sich ein Großteil der politischen und publizistischen Vertreter des Straußschen Europa-Konzeptes in der Abendländischen Bewegung. ${ }^{340}$ Im Gegensatz zu den fünfziger Jahren, als das Verhältnis zwischen CDU- und CSU-Vertretern in der Abendländischen Bewegung noch eher ausgeglichen war, hatten durch die Verkleinerung der Abendländischen Bewegung die CSU-nahen Vertreter die „Oberhand“ gewonnen. Nun bezog man eindeutig gegen die sich formierende „atlantische“ Gruppierung innerhalb der CDU Stellung.

Indem sich das CEDI auf ihren europäischen Treffen und Kongressen zunehmend mit gaullistischen Positionen zur europäischen Einigung identifizierte, entwickelte es sich auf diese Weise zu einem „Kontaktpool“ deutscher „Gaullisten“ und französischer Gaullisten. ${ }^{341}$ Zwar sollte man die Bedeutung der Abendländi-

339 Vgl. Gaupp-Berghausen, Georg von: Iberoamerika und der Nahe Osten, in: Aconcagua 3 (1967), S. 163 f., hier S. 163.

340 Vgl. Eisner, Das europäische Konzept von Franz Josef Strauß, S. 34-36. Somit wurden im CEDI auch jene Kontakte zwischen Otto von Habsburg und der CSU gepflegt, welche schließlich in von Habsburgs Kandidatur für das Europa-Parlament endeten.

${ }^{341}$ Hinzu kamen von französischer Seite: Louis Terrenoire (1960/62 Informationsminister, später Generalsekretär der U.N.R.), Michel Habib-Deloncle (ebenfalls U.N.R., von 1962 bis 1966 Staatssekretär im Außenministerium). 1964 war Franz Heubl Präsident des deut- 
schen Bewegung als einer relativ kleinen Gruppierung nicht überschätzen, doch angesichts der Tatsache, daß die engsten Mitarbeiter von Franz Josef Strauß Ende der fünfziger Jahre im CEDI regelmäßigen und intensiven Kontakt mit Vertretern der Politik de Gaulles hatten, kann man doch davon ausgehen, daß in diesen Kreisen Konzepte vorgedacht und transformiert wurden, die seit Mitte der sechziger Jahre zur außenpolitischen Konzeption der CSU gehörten. Andererseits trug die CSU zur „Modernisierung“ des Abendlandes bei. Franz Josef Strauß war es, der 1968 forderte, der Konservatismus habe ,an der Spitze des Fortschritts zu marschieren “. ${ }^{342}$ Enge Mitarbeiter Strauß’, die im CEDI Anfang der sechziger Jahre aktiv waren, waren sicherlich daran beteiligt, verkrustete Ideologiemuster langsam abzulösen.

Mit all diesen „realpolitischen“ Wendungen und der Orientierung an den Positionen der CSU unter Franz Josef Strauß in den sechziger Jahren gelang es der Abendländischen Bewegung gleichzeitig auch, sich regional und auf das konservative Spektrum begrenzt, ihr Publikum zu erhalten. Zwar konnte die abendländische Idee nicht mehr auf jene breite öffentliche Unterstützung setzen, die Anfang der fünfziger Jahre möglich gewesen war, doch bot die erfolgte Konzentration auch Vorteile, indem sie die Zustimmung einer zwar begrenzten, aber doch zumindest im süddeutschen Raum einflußreichen Klientel bot. Und selbst auf bundespolitischer Ebene sollten sich damit in den sechziger Jahren neue Möglichkeiten öffnen. Indem aus Abendländern „Gaullisten“ geworden waren, konnten sich Kernbestände der abendländischen Idee weit über das Ende der Nachkriegszeit hinaus erhalten.

Anschauliches Indiz für die Bedeutung, die Frankreich und de Gaulle in den frühen sechziger Jahren für das CEDI erhielt, war die Umsiedlung des Generalsekretariats in der ersten Hälfte der sechziger Jahre. Während in den fünfziger Jahren sowohl in München (Gaupp-Berghausen) wie in Madrid (Valdegleisias) Generalsekretariate angesiedelt waren, schlugen die französischen CEDI-Mitglieder, die 1963 mit Edmond Michelet auch erstmals den Präsidenten des CEDI stellten, vor, Gaupp-Berghausen „aus Gründen der praktischen Wirksamkeit“ nach Paris umziehen zu lassen. Michel Habib-Deloncle, Staatssekretär im französischen Außenministerium beispielsweise betonte, daß „praktische und politische Erwägungen die Übersiedlung nach Paris richtig erscheinen lassen, wie z.B. die zentrale und geopolitische Lage, der Treffpunkt von Persönlichkeiten und politischen Institutionen jeder Art, die häufigen Aufenthalte politisch wichtiger Persönlichkeiten etc" ${ }^{343} \mathrm{Daß}$ dahinter auch der Wunsch der französischen Gaullisten stand, durch einen in Paris ansässigen deutschen Generalsekretär besseren Kontakt und direkteren Einfluß vor allem auf die deutschen CEDI-Teilnehmer zu erlangen, zeigt die Tatsache, daß im Juli 1964 - also im Jahr nach der Verabschiedung der Präambel zum Elysée-Vertrag durch den deutschen Bundestag - nach Ansicht der

schen CEDI. Vgl. ansonsten: Grabbe, Unionsparteien, Sozialdemokratie und Vereinigte Staaten von Amerika. Marcowitz, Option für Paris.

342 Zitiert nach Schildt, Konservatismus, S. 238.

343 Sitzung des Vorstandes und des internationalen Rates des CEDI, 23. 6. 1962, ACDP I-148-131/03. 
Franzosen "die Aufrechterhaltung des derzeitigen Büros in Paris nicht mehr notwendig sei, es würde eine Adresse eines anderen bestehenden Büros genügen" ${ }^{344}$ Parallel zum Rückzug de Gaulles nach dem "Sieg“ der "Atlantiker" in der Bundesrepublik 1963 zogen sich auch die französischen Gaullisten aus dem CEDI zurück. Die Phase des Engagements war vorüber, das CEDI als Instrument nicht mehr nützlich.

Zwischen dem Ende der fünfziger Jahre und 1964 jedoch bemühten sich die Franzosen, die über das CEDI laufenden Kontakte zu den deutschen Abendländern, die ja in den allermeisten Fällen Unionspolitiker oder aber konservative Publizisten waren, zu nutzen. So nahm die französische Regierung das CEDI gezielt in Anspruch, um Informationen über deutsche Entwicklungen zu erhalten. Im November 1960 beispielsweise bat François de la Noë Gaupp-Berghausen und Alfons Dalma dringend um ein Gespräch, das „im Auftrage des Kabinetts de Gaulle's zur Vervollständigung der informativen Vorbereitung des Treffens mit dem deutschen Bundeskanzler" dienen sollte. ${ }^{345}$ Hierbei wurden neben den "persönlichen und psychologischen Eigenschaften und Eigenarten Adenauers und de Gaulles" auch die „wichtigsten offenen Fragen zwischen Frankreich und der Bundesrepublik besprochen". ${ }^{346} \mathrm{Ob}$ diesem Gespräch tatsächlich eine solche Bedeutung zukam, wie François de la Noë suggerierte, wenn er behauptete, „nützliche und wertvolle Anregungen für die Vorbereitungen de Gaulles" erhalten zu haben, so daß nach dem Treffen „einige Punkte der bisherigen Vorbereitungsarbeit des Quai d'Orsay und des Beraterstabes im Elyséepalast ergänzt und korrigiert" werden müßten, ist nicht zu entscheiden. Tatsache jedoch ist, daß man in Paris das CEDI als Kontaktstelle zu Unionspolitikern nach Deutschland nützte und die CEDI-Mitglieder zumindest für wertvolle Informationsgeber hielt: Im Prinzip ist dies nur eine Bestätigung des „elitären“ Funktionsprinzips des CEDI. GauppBerghausen übrigens leitete die Aufzeichnungen über das Gespräch ebenfalls an das Bundeskanzleramt weiter, in dem das CEDI einen Ansprechpartner zu Adenauer besaß. Auch diese „politikberatende“ Funktion auf höchster Ebene entsprach den Vorstellungen des CEDI von seiner eigenen Wirksamkeit.

In eine ähnliche Richtung wiesen die Anfang 1963 geplanten deutsch-französischen Parlamentariergespräche, die die französische CEDI-Sektion forcierte. ${ }^{347}$ Hier ging es - angesichts der deutschen Debatten zwischen „Atlantikern“ und "Gaullisten" - um einen Austausch von Unionspolitikern und französischen Parlamentariern der gaullistischen U.N.R. (Union pour la nouvelle République). Von deutscher Seite sahen die CEDI-Verantwortlichen Heinrich von Brentano, Paul Lücke, Ernst Majonica, Karl Carstens, Hans Furler, Hermann Kopf und Konrad Kraske als Teilnehmer vor, hinzu kamen Richard Jaeger, Hans-Joachim von Merkatz, Friedrich Zimmermann und Alfons Dalma vom CEDI selbst. Damit erwei-

344 François de la Noë auf der Vorstandssitzung des internationalen CEDI am 7.7. 1964, ACDP I-148-132/01.

345 Aufzeichnung der Unterredung am 25. 11. 1960 in Paris zwischen François de la Noë, Dr. Tomicic-Dalma und Gaupp-Berghausen, ACDP I-148-131/03.

346 Ebenda.

347 Brief de la Noë an Gaupp-Berghausen, 2. 2. 1963, ACDP I-148-132/01. 
terte das CEDI erstmals seinen ursprünglichen abendländischen Kern und lud auch solche Politiker zum Austausch, die eher den „Atlantikern“ zuzurechnen waren. Man erhoffte sich von diesen Gesprächen eine Unterstützung "gaullistischer" Positionen in der Union, zumindest jedoch eine durch das persönliche Gespräch geförderte Kompromißfähigkeit der versammelten Parlamentarier: „Il s'agit en fait de promouvir une politique européenne dans l'esprit de celle que a fait l'objet de nos travaux et de nos efforts communs, au CEDI, depuis déjà bien des années." 348

Ob die vom CEDI initiierten Parlamentariergespräche stattfanden, und wie erfolgreich sie waren, ist den Quellen nicht zu entnehmen. Es scheint, als seien tatsächlich Franzosen nach Deutschland gereist, jedenfalls wurde für den April 1963 eine Gegeneinladung nach Paris geplant. Zu diesem Zeitpunkt allerdings tobte in Deutschland die Auseinandersetzung um den Elysée-Vertrag, und nun bat Ernst Majonica (CDU) bei Gaupp-Berghausen um eine Verschiebung, was die Franzosen offenbar als Rückzug der "Atlantiker“ verstanden. ${ }^{349}$ Sie zeigten sich nach Einschätzung von Merkatz „sehr verärgert“ und lehnten eine weitere Zusammenarbeit mit der CDU ab. ${ }^{350}$ Im Anschluß an die Ratifizierung des Elysée-Vertrages verloren die Franzosen das Interesse an weiteren Treffen mit deutschen UnionsPolitikern - und an der Arbeit des CEDI. Die Ende der fünfziger Jahre angestiegene Mitgliedschaft ging wieder zurück, übrig blieb der unerschütterliche de la Noë, der bereits seit den ersten Jahren des CEDI dazugehörte. Im Juni 1967 konnte Gaupp-Berghausen nur noch konstatieren: „In Frankreich hat die Aktivität des CEDI fast gänzlich aufgehört, finanzielle Beiträge sind seit zwei Jahren fast überhaupt nicht mehr geleistet worden." 351 Durch die sich aus dem Rückzug der Franzosen - und wie sich zeigen wird, nicht nur der Franzosen - ergebende Krise stand dem CEDI Mitte der sechziger Jahre, nach dem Interesseverlust der spanischen Regierung Ende der fünfziger Jahre, wiederum eine erzwungene Um- und Neuorientierung bevor.

\section{"Bollwerk" Lateinamerika}

Diese Neuorientierung hing nicht zuletzt mit der Einsicht zusammen, daß in Europa die Säkularisierung und die Moderne wohl kaum mehr rückgängig zu machen waren. Das Ziel einer Rechristianisierung Europas, so wie sie von der Zwischenkriegszeit bis in die fünfziger Jahre hinein im Zentrum abendländischen Denkens gestanden hatte, schien endgültig utopisch geworden zu sein. Dennoch gab man in abendländischen Kreisen das Nachdenken über Fragen der Rechristianisierung nicht auf - nur konzentrierte es sich im Verlauf der sechziger Jahre vorwiegend auf die Länder der „Dritten Welt“. Diese Neuorientierung wurde durch

348 Ebenda.

349 Brief Majonica an Gaupp-Berghausen, 25. 3. 1963, ACDP I-148-132/01.

350 Aufzeichnung: Betr. deutsch-französische Parlamentariertagung (ohne Datum), ACDP I-148-132/01.

351 Bericht des Generalsekretärs des CEDI in Schloß Pouy am 24./25. 6. 1967, ACDP I-148$132 / 02$. 
die Tatsache verstärkt, daß sich der Ost-West-Konflikt in den sechziger Jahren tatsächlich nicht mehr in Europa, sondern an der "Peripherie“, in Stellvertreterkriegen in der „Dritten Welt“ abspielte. Insbesondere Lateinamerika kam dabei große Aufmerksamkeit zu. Anknüpfend an den Stellenwert, den die Länder der iberischen Halbinsel im abendländischen Denken seit 1945 besessen hatten, gerieten nun die südamerikanischen ehemaligen Kolonien Spaniens und Portugals in den Blick - entsprechend sprachen die Abendländer auch vorwiegend von „Iberoamerika". Indem sie ausschließlich die europäischen Ursprünge der lateinamerikanischen Kultur thematisierten, postulierten die Abendländer eine Verbundenheit des südamerikanischen Kontinents mit Europa auch in der Gegenwart; gleiches galt übrigens für den afrikanischen Kontinent, der sich nach abendländischen Vorstellungen insbesondere aufgrund Frankreichs kolonialer Tradition nach Europa orientieren sollte. ${ }^{352}$ Lateinamerika empfahl man, statt in Richtung der USA zu schauen, die "Formen der Alten Welt [...] als Leitbilder". ${ }^{353}$ Gleichzeitig forderten die Abendländer immer wieder eine aktive Politik Europas gegenüber seinen ehemaligen Kolonien. Dieses engere Miteinander Europas und der „Dritten Welt“ würde nicht zuletzt dazu beitragen können, das Gewicht Europas in der Weltpolitik zu stärken.

In den Quellen finden sich exakt jene Argumentationslinien, die in den fünfziger Jahren auf Europa angewendet worden waren, nun bezogen auf Lateinamerika. Die Positionen des „Kalten Krieges“, der Antikommunismus und die „Bollwerkstheorie“, in der in den Augen der Abendländer ja eben auch dem Christentum eine entscheidende Rolle zukam, wurden unverändert in die sechziger Jahre transportiert - nur fanden sie auf Europa selbst bezogen weniger Verwendung. Vielmehr galt es nun, „das Gewicht der ibero-amerikanischen Staatenfamilie“ zu stärken, „denn Ibero-Amerika ist in großer Gefahr, in den Strudel des VölkerKlassenkampfes hereingerissen zu werden“. 354 Gerade weil man den "ganzen Kontinent als ausschließliches Erbe Europas“ 355 und als das „größte und stärkste

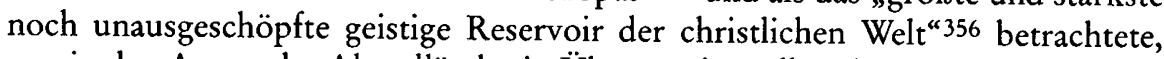
war in den Augen der Abendländer in Übersee ein Bollwerk gegen den Kommunismus zu errichten: „In Ibero-Amerika geht es um die Erhaltung einer bereits bestehenden christlichen Bastion. Der Kommunismus kann nicht allein auf wirtschaftlichem Gebiet bekämpft werden. “357 Ähnlich wie für die Bundesrepublik der fünfziger Jahre ging es den Abendländern für die „Dritte Welt“ der sechziger Jahre um die Schaffung einer auf dem Christentum ruhenden geistigen Gemein-

352 Vgl. den CEDI-Kongreß 1958 unter dem Motto „Die euro-afrikanische Solidarität“ und auch: Habsburg, Afrika ist nicht verloren.

353 Habsburg, Otto von: Partner in der Neuen Welt, in: Aconcagua 1 (1965), S. 303-305, hier S. 304.

354 Merkatz, Hans-Joachim: Westwind, Ostwind und Ibero-Amerika, in: Aconcagua 1 (1965), S. 5-11, hier S. 6.

355 Sánchez Bella, Alfedo: Europa und Iberoamerika, in: Aconcagua 1 (1965), S. 143-154, hier S. 154.

356 Schulz, Werner: Europa im Jahr 1965, in: Aconcagua 1 (1965), S. 548-552, hier S. 552.

357 Merkatz, Hans-Joachim: Westwind, Ostwind und Ibero-Amerika, in: Aconcagua 1 (1965), S. 5-11, hier S. 10. 
schaft als wirksames Mittel gegen kommunistische Propaganda, von der man befürchtete, daß sie im wirtschaftlich schlecht entwickelten Lateinamerika auf fruchtbaren Boden fallen könnte. 358

Hier zeigt sich, daß das abendländische Interesse an Spanien Ende der fünfziger Jahre nicht verlorengegangen war. Vor allem auf die „Hispanidad“-Idee, das imperialistische Ausgreifen Spaniens über die nationalen Grenzen hinaus, gespiegelt im historischen Rekurs auf die glanzvollen kolonialen Zeiten, griffen die Abendländer zurück. Zwar konstatiert Petra-Maria Weber, daß dieses Sendungsbewußtsein als essentieller Bestandteil des Nationalkatholizismus unter Franco im Verlauf der fünfziger und sechziger Jahre zunehmend "nach Europa in antikommunistische Bahnen gen Osten gelenkt“ worden sei: „Der imperialistische Messianismus ging in der Abendland-Ideologie der fünfziger Jahre auf." 359 Diese These scheint aber gerade in Bezug auf das CEDI der späten fünfziger und sechziger Jahre nicht haltbar zu sein - hier spielte die Rolle Spaniens als Bindeglied Europas nach Südamerika eine entscheidende Rolle. Und zwar nicht allein im Sinne einer kulturellen Hegemonie, sondern auch unter ganz konkreten machtpolitischen Auspizien. Diese Position brachten die Spanier von Anfang an in die Arbeit des CEDI mit ein. So betonte Außenminister Atarjo bereits 1954, Spanien sei die „Verbindung zwischen verschiedenen Welten“ und könne als „Brücke“ dienen. ${ }^{360}$ Der ständig wiederholte Verweis auf die Leistungen Spaniens im Rahmen seiner historischen Kolonialpolitik, den sich auch die deutschen Abendländer zu eigen machten, war verbunden mit dem Bemühen, den "Leitgedanken der missionarischen Sendung“ hervorzuheben, der Spanien in seinen Kolonien getrieben habe. Im Gegensatz zu den „rein wirtschaftlich interessierten Kolonialreichen“ habe jeder spanischen Maßnahme „ein sittliches oder religiöses Motiv“ zugrundegelegen. ${ }^{361}$ Auch politisch griffen die Abendländer das Thema auf, und so standen die CEDI-Tagungen etwa 1953 unter dem Titel „Europäische Union - Iberoamerikanische Union“, 1958 unter dem Motto „Die deutsch-afrikanische Solidarität“, 1961 schließlich war es „L'Occident à l'heure ibero-américaine“, der die Abendländer beschäftigte. Zwar anerkannte man auf diesen Kongressen die politische Selbständigkeit der lateinamerikanischen und afrikanischen Länder und betonte, keinerlei imperialistischen Tendenzen das Wort zu reden, doch spiegeln etwa die verabschiedeten Resolutionen und gehaltenen Reden eine stark kulturhegemoniale Strategie: Es ging darum, in Afrika und Lateinamerika das europäisch-christliche, sprich: abendländische Gedankengut zu verbreiten. Nicht zuletzt sollte dies dazu dienen, die Län-

358 In typisch „abendländischer“ Manier beschreibt von Merkatz die kommunistische Agitation in Lateinamerika: „Wie weit die kommunistische Unterwanderung in Ibero-Amerika [...] schon Boden gewonnen hat, ist von Europa aus schwer abzuschätzen. Aber kein Zweifel besteht, daß gründliche Vorarbeiten sowohl von Moskau wie von Peking aus im Gange sind. Kaderführer werden in den beiden kommunistischen Zentren ausgebildet. Sie bauen eine unheimliche Maschinerie entschlossener, zu blindem Gehorsam erzogener Stosstrupps auf, die im Bedarfsfall eingesetzt werden können.“ Ebenda, S. 8/9.

359 Weber, Spanische Deutschland-Politik, S. 228.

360 Rede Martin Atarjos auf dem dritten CEDI-Kongreß 1954, zitiert nach: Mitteilungsblatt der Abendländischen Akademie Oktober 1954, BA N 1243/15.

361 In diesem Tenor gehalten: Habsburg, Afrika ist nicht verloren. 
der der „Dritten Welt" vor den „Versuchungen“ und „Gefahren“ des Kommunismus zu schützen. Hinzu traten jedoch sicherheits- und machtpolitische Aspekte: die Stärkung der westlichen Welt. Doch während in den fünfziger Jahren tatsächlich an die Stärkung der atlantischen Gemeinschaft gedacht war, verweist die Forderung, "Eurafrika“ zu schaffen, 1958 bereits auf die abendländischen Positionen in den sechziger Jahren. ${ }^{362}$ Die "Großmacht" Europa sollte ihr politisches Gewicht nicht zuletzt gegenüber den USA durch eine engere Anbindung der ehemaligen Kolonien Spaniens, Portugals und Frankreichs stärken - und dazu eben konnte ein enger Kontakt zu Spanien von großem Nutzen sein. 363

So nutzten die Abendländer das CEDI, um den europäischen Einfluß auf Lateinamerika zu stärken. Vermehrt wurden Anfang der sechziger Jahre lateinamerikanische Teilnehmer zu den Kongressen eingeladen: 1961 etwa reisten 40 Besucher aus Übersee an. ${ }^{364}$ Gleichzeitig gingen die Abendländer daran, durch gezielte Aktionen ihren Interessen an der Bindung Lateinamerikas an Europa zur Durchsetzung zu verhelfen. So bemühten sie sich seit 1961, eine ständige Wirtschaftskommission bzw. ein „Syndicat international d'Etudes pour le Dévelopement de L'Amérique latine“ zu errichten, welches einerseits mit dem „Studium über die wirtschaftlichen sowie technischen Hilfsmöglichkeiten für lateinamerikanische Staaten" beauftragt war, in einem zweiten Schritt aber wohl auch europäischen Firmen wirtschaftliche Kontakte nach Südamerika sichern sollte. ${ }^{365}$ In dieselbe Richtung ging auch die Gründung einer ibero-amerikanischen Kulturkommission. ${ }^{366}$ Im Zusammenhang mit der Absicht, Kontakte und Verständnis zwischen Europa und Lateinamerika zu wecken, stand auch die Gründung der Zeitschrift

362 Otto B. Roegele im Rheinischen Merkur, zitiert nach: Dokumentation der Woche, Sonderausgabe August 1958, BA N 1243/15. Vgl. auch die Resolution des 8. CEDI-Kongresses 1959, in der es heißt: „Das CEDI wünscht, daß die Verwirklichung eines großen europäischen, ja selbst eines euro-afrikanischen Marktes [...] verfolgt wird.“ Dokumentation der Woche, Sonderausgabe Dezember 1959, BA N 1243/30.

363 Eine solche Überzeugung stand übrigens in Kontinuität zur Arbeit der Deutsch-Spanischen Gesellschaft vor 1945: „Besonders zu betonen ist, daß der Gedanke des ,imperio“, d.h. der Wiedergewinnung des kulturellen Einflusses Spaniens in seinen alten süd- und mittelamerikanischen Kolonien nicht nur in Spanien selbst immer mehr an Boden gewinnt, sondern auch von der anderen Seite, also von den spanisch sprechenden Ländern Amerikas begrüßt und gern aufgegriffen wird. [...] Es unterliegt keinem Zweifel, daß ein Deutschland befreundetes Spanien in kultureller Hinsicht für uns als eine wichtige Brücke nach Ibero-Amerika zu betrachten und auszunützen ist. Deutschland und Spanien haben das gleiche Interesse daran, dem englischen und französischen, vor allem aber dem nordamerikanischen Einfluß in Ibero-Amerika entgegen zu treten." Vgl. den Tätigkeitsbericht der DSG für das Geschäftsjahr 1939/49 einschließlich der Monate April und Mai 1940, BA R 64-I/12.

364 Vgl. den Tätigkeitsbericht des Generalsekretärs des CEDI für das Jahr 1961, ACDP I-148-131/03.

365 Zitat aus dem Protokoll über die Tagung des Vorstandes und internationalen Rates des CEDI am 8./9. 12. 1962, ACDP I-148-131/03. Brief des belgischen CEDI an Merkatz, 13. 12. 1962 und 20. 3. 1962, ACDP I-148-132/01. Vgl. auch die Sitzung des Vorstandes und internationalen Rates des CEDI am 10.7. 1961, ACDP I-148-131/03.

366 Entwurf für eine ibero-amerikanische Kulturkommission des CEDI (1962), ACDP I148-132/01. Vgl. auch die Sitzung des Vorstandes und internationalen Rates des CEDI am 10. 7. 1961, ACDP I-148-131/03. 
Aconcagua durch die abendländische Bewegung 1965, von der man hoffte, sie über die deutschen Vertretungen in Südamerika verteilen zu können. ${ }^{367}$ Aus diesen Ansätzen entwickelte sich schließlich Ende der sechziger Jahre ein Engagement der Abendländer in der Entwicklungshilfe. 1969 kündigte Gaupp-Berghausen an: „Als Herausgeber des Aconcagua habe ich mich mit meinen Freunden ebenfalls dazu entschlossen, mit privater Initiative neue Möglichkeiten des Entwicklungshelferdienstes, speziell für Iberoamerika zu erschließen." Man wollte, „all jenen, die sich verpflichten, einige Jahre Entwicklungshelferdienste in Iberoamerika zu leisten, eine kostenlose, mindestens sechsmonatige Ausbildung für diesen Dienst auf der iberischen Halbinsel ermöglichen“. Hierbei sollten „Sprache, Lebensgewohnheiten und Atmosphäre der iberischen Welt" vermittelt werden. ${ }^{368}$

Ob dieses Programm umgesetzt wurde, muß an dieser Stelle offen bleiben, wären doch zur Beantwortung dieser Frage ganz neue Quellenbestände für die siebziger Jahre auszuwerten gewesen. Aber unabhängig vom Erfolg der geplanten Entwicklungshilfe verließ das abendländische Engagement hier erstmals den europäischen Kontinent. Und doch stand die Idee eines christlich-konservativen Abendlandes, „Bollwerk“ gegen den Kommunismus einerseits, von den USA unabhängige "Großmacht" andererseits, im Hintergrund dieser Entwicklung. Die Wendung der Abendländer in Richtung Südamerika erfolgte auch, weil in Europa selbst die Zeiten eines Engagements für autoritäre Regime vorüber waren. Die letzten dieser Systeme standen am Rande des Zusammenbruchs, in Spanien ging die Kirche 1968 auf Distanz zu Franco, im Jahr darauf ereigneten sich die ersten Unruhen. In Portugal erkrankte Salazar im selben Jahr schwer und verstarb 1970. Und selbst wenn der in den sechziger Jahren blasende Wind der Veränderung diese Regime verschont hätte - ein abendländischer Einsatz hätte sich nicht mehr rentiert. Sowohl in der Bundesrepublik wie auch in Europa war eine autoritäre Alternative zum demokratischen System nicht mehr gefragt, das hatten selbst die Abendländer bereits im Verlauf der sechziger Jahre eingesehen. Auch in diesem Bereich ging insofern Anfang der sechziger Jahre eine abendländische Kontinuitätslinie zu Ende, nämlich der zum Teil mit erheblichem Engagement betriebene Einsatz für ein autoritär-hierarchisches politisches System auf christlicher Grundlage, das den Abendländern von den zwanziger bis in die sechziger Jahre als die bessere Alternative zu Pluralismus und liberaler Demokratie erschienen war. In den sechziger Jahren dienten die etablierten Verbindungen nach Spanien den deutschen Abendländern daher nicht mehr dazu, um innenpolitisch das „Vorbild“ des Franco-Regimes herauszustreichen und damit vielleicht Alternativen für die Zeit nach der Wiedervereinigung zu bieten. Nun ging es vielmehr darum, mit Hilfe Spaniens das Machtpotential Europas zu verstärken und damit einer, stärker als in den fünfziger Jahren vertretenen, abendländischen Europapolitik zum Durchbruch zu verhelfen. Die abendländischen Interessen hatten sich verlagert, die abendländische Idee hatte sich verändert.

367 Brief Gaupp-Berghausen an Staatssekretär Karl-Günther von Hase (Bundespresse- und Informationsamt), 13. 8. 1966, ACDP I-148-132/01

368 Gaupp-Berghausen, Georg von: Editorial, in: Aconcagua 5 (1969), S. 3-6, hier S. 5. 


\section{Auf dem Weg nach „Paneuropa“...}

Doch auch dieser Wandel konnte die Krise, in der sich das CEDI in der zweiten Hälfte der sechziger Jahre befand, nicht mehr überdecken. Diese erwies sich schließlich als so gravierend, daß sie nur durch eine Verschiebung der abendländischen Aktivitäten auf eine andere Organisation, die einer Selbstauflösung des CEDI gleichkam, überwunden werden konnte. Ausgelöst wurde diese „Selbstauflösung" des CEDI durch die Franzosen, und sie stand in engem Zusammenhang mit der Paneuropa-Union Richard Coudenhove-Kalergis.

Nach dem Zweiten Weltkrieg hatte sich Coudenhove immer wieder bemüht, mit seiner Paneuropa-Union an die Erfolge der Zwischenkriegszeit anzuknüpfen, als es ihm vorübergehend gelungen war, sie zur einflußreichsten Europaorganisation der zwanziger Jahre auszubauen. Doch nach seiner Rückkehr aus dem amerikanischen Exil, wo er die Jahre des Zweiten Weltkrieges überdauert hatte, hatten andere Kräfte das Ruder übernommen. Neue Europaorganisationen hatten sich gebildet, mit denen sich die Zusammenarbeit als schwierig erwies. Dies war vor allem der Fall, weil der Graf auf einem absoluten Führungsanspruch beharrte, der ihm in seinen Augen aufgrund seiner "Vorreiterrolle“ zukam. Die Verantwortlichen der Europäischen Bewegung, vor allem die Föderalisten unter ihnen, jedoch standen Coudenhove und seinen Ideen zunehmend skeptisch gegenüber und der Paneuropäer erschwerte seine eigene Position zusätzlich durch seine egozentrische Persönlichkeit. So geriet Coudenhove, trotz ständiger Bemühungen, immer mehr ins Abseits. In den fünfziger Jahren existierte die Paneuropa-Union de facto nur noch auf dem Papier, und in keinem europäischen Land waren staatliche Institutionen oder Industrie und Wirtschaft noch bereit, „Paneuropa“ finanziell zu unterstützen. 369

Nach der Regierungsübernahme de Gaulles in Frankreich jedoch bot sich Coudenhove eine neue Möglichkeit. Denn die neue französische Regierung zeigte bald kein Interesse mehr daran, die föderalistisch orientierten Europa-Organisationen, die sich in der Union européenne des Fédéralistes (UEF) zusammengefunden hatten, zu unterstützen. Das von seiten der Föderalisten proklamierte Ziel einer bundesstaatlichen Zukunft Europas ließ sich mit dem staatenbündischen Konzept de Gaulles nicht vereinbaren. Coudenhove hingegen, der mit de Gaulle seit den letzten Kriegsjahren in Kontakt stand, signalisierte schon bald die Bereitschaft, sich das „Europa der Vaterländer“ zu eigen zu machen. In Reaktion darauf ging man in Paris immer deutlicher dazu über, die Paneuropa-Union als "gaullistische" Europabewegung finanziell zu unterstützen. Die Paneuropa-Union entwickelte erstmals seit Jahrzehnten in Frankreich wieder eine eigenständige, lebensfähige Sektion. In dieser wiederum engagierten sich seit Ende der fünfziger Jahre fast alle französischen CEDI-Mitglieder auch finanziell. ${ }^{370}$ Die engagierten französischen Paneuropäer bemühten sich, die Union nach eigenen Vorstellungen zu reformie-

369 Vgl. zum folgenden: Conze, Richard Coudenhove-Kalergi.

370 So übernahm z. B. das CEDI-Vorstandsmitglied Habib-Deloncle als führendes Mitglied der französischen Paneuropa-Union in den frühen siebziger Jahren auch eines der Vizepräsidentenämter der Internationalen Paneuropa-Union. 
ren und aus ihr eine "modernere" europäische Bewegung zu machen, als dies Coudenhove-Kalergi nach dem Zweiten Weltkrieg gelungen war - was immer wieder zu Spannungen mit dem Gründer führte. Dennoch stellte die PaneuropaUnion in den Augen der Franzosen offenbar die geeignetere Organisation dar, die eigenen europäischen Ziele auch in anderen europäischen Ländern verbreiten zu lassen.

Doch nicht nur die französischen CEDI-Mitglieder waren gleichzeitig auch in der Paneuropa-Union aktiv. Bereits seit dem Ende der fünfziger Jahre hatten CEDI-Verantwortliche anderer Länder Kongresse der Paneuropa-Union besucht, auf Vorstandssitzungen wurde regelmäßig über die Entwicklung der PEU, ihre Kongresse und die Aktivitäten Coudenhove-Kalergis berichtet, der auf Einladung des CEDI wiederholt in der Bundesrepublik sprach. Und nicht zu vergessen ist auch die deutsche Beteiligung an der Paneuropa-Union, insbesondere in Person Hans-Joachim von Merkatz'. ${ }^{371}$

Dieser gehörte seit 1956 dem Zentralrat der internationalen Paneuropa-Union an, gleichzeitig war er einer der wenigen Ansprechpartner Coudenhoves in der Bundesrepublik. Denn der Paneuropäer, der sich seit Anfang der fünfziger Jahre bemühte, seine Paneuropa-Union in Westdeutschland wiederzubegründen, zog nicht zuletzt aufgrund seiner politischen Vorschläge - immer mehr Skepsis auf sich. Zwar konnte man in Kreisen der CDU/CSU (die SPD stand den Ideen Coudenhoves seit den dreißiger Jahren ablehnend gegenüber) über Vorschläge zur Gründung einer unauflöslichen deutsch-französischen Union, einer „Doppel-Republik“ mit "gemeinsamen Organen der Außenpolitik, der Wehrpolitik und der Wirtschaftspolitik“ oder auch den Vorschlag, Europa solle sich dem Commonwealth anschließen, um so die bestehenden europäisch-britischen Probleme mit der Integration zu lösen, noch relativ nonchalant hinweggehen. ${ }^{372}$ Doch warf man dem Paneuropäer, angesichts der Tatsache, daß all diese Vorschläge 1955 innerhalb weniger Monate erfolgten, schon bald die „Dehnbarkeit“ seines Europa-Begriffes vor. ${ }^{373}$ Die Anregung Coudenhoves, die westdeutsche Nationalhymne durch des Grafen eigene Dichtung „unter Anlehnung an die alte österreichische Kaiserhymne" zu ersetzen, rief vorwiegend Lächeln hervor, was Coudenhoves Ruf als politischer Berater freilich nicht unbedingt verbesserte. ${ }^{374}$ Tatsächlich kompliziert jedoch wurde die Situation, als Coudenhove Adenauer 1956 unterbreitete, das Wettrüsten zwischen den beiden deutschen Staaten stelle eine Gefahr für den eu-

$371 \mathrm{Vgl}$. zu von Merkatz Teil I, Kap. I.2.

372 Zur deutsch-französischen Republik vgl. Coudenhoves Memorandum an die Regierungen der Deutschen Bundesrepublik (sic!) und der Französischen Republik zur Frage der Gründung einer Deutsch-Französischen Republik, 20. 9. 1955, ACDP I-148-116/01. Zum Anschluß Europas an den Commonwealth vgl. die Eröffnungsrede CoudenhoveKalergis auf dem VI. Paneuropa-Kongreß in Baden-Baden, FAE D 7. Die Idee einer deutsch-französischen Union ging möglicherweise auf die von Adenauer im März 1950 vorgeschlagene politische Union zwischen Deutschland und Frankreich zurück, auf die Coudenhove schon damals positiv reagiert hatte.

373 Brief Focke an Kogon mit Bericht über den Kongreß Coudenhove-Kalergis in Baden-Baden, 3. 11. 1954, BA N 1384/99.

374 Brief Coudenhove an Merkatz, 15. 11. 1955, ACDP I-148-116/01. 
ropäischen Frieden dar, und dem Kanzler vorschlug, die DDR de facto anzuerkennen und mit ihr ein Abrüstungsabkommen abzuschließen. ${ }^{375} 1959$ sollte er mit seinem Memorandum zur deutschen Frage „Einheit oder Freiheit" an diese Konzepte anschließen. In seinem Memorandum erklärte Coudenhove eine baldige Wiedervereinigung für unmöglich. Die Westdeutschen sollten sich daher von diesem „Wahn“ lösen, auf die Wiedervereinigung vorerst verzichten - die nach Coudenhove nur zum „Neutralismus“ Deutschlands führen würde - und die seit 1949 entstandene Realität akzeptieren: die Existenz zweier deutscher Staaten bzw. die Teilung Europas. Die Westdeutschen müßten endlich die Entscheidung zwischen "Einheit" und „Freiheit" treffen und statt auf die Wiedervereinigung zu hoffen, eine Union mit Frankreich als Ausgangspunkt der „Wiedervereinigung des europäischen Reiches Karls des Großen“" anstreben. ${ }^{376}$ Wenn Coudenhove auch deutlich betont hatte, das Memorandum sei die „persönliche Ansicht des Verfassers“ und ,in keiner Weise das Programm der Paneuropa-Union", half ihm dies in der Bundesrepublik nicht. Coudenhove hatte gegen alle Grundregeln der bundesrepublikanischen Außen- und Deutschlandpolitik der fünfziger Jahre verstoßen, indem er den Verzicht auf die Wiedervereinigung und die Anerkennung der DDR forderte.

So existierte die Paneuropa-Union in Deutschland zwar auf dem Papier, Aktivität entwickelte sie jedoch keine. Der massive Einsatz, mit dem die EuropaUnion versuchte, Coudenhove daran zu hindern, in der Bundesrepublik Fuß (und damit auch Spendengelder) zu fassen, trug zu dieser Situation bei. ${ }^{377}$ Die Lage sollte sich erst in dem Moment ändern, als um 1962 die Fronten zwischen deutschen „Gaullisten" und „Atlantikern“ abgesteckt waren und die Auseinandersetzungen um die außenpolitische Orientierung $\mathrm{z}$ wischen Paris und Washington aufbrachen. Erst als sich in den Reihen der CDU/CSU-Fraktion eine Gruppe von Abgeordneten formierte, die im Gefolge Adenauers eine festere Anbindung der Bundesrepublik an Frankreich anstrebte, wuchs auch das Bedürfnis nach einer Europa-Organisation, die eher der „westeuropäischen“ als der „atlantischen“ Dimension der Integration den Vorzug gab. Die deutsche Europa-Union konnte und wollte die Interessen dieser Gruppe nicht befriedigen: Sie stand eindeutig und unzweifelhaft im Lager der „Atlantiker“. Coudenhove wiederum war sich dieser Konstellation durchaus bewußt und nützte sie, als er im März 1963, nachdem der deutsch-französische Vertrag im Januar unterzeichnet worden war, an die bundesdeutsche Öffentlichkeit trat und verkündete, „die Erneuerung der PaneuropaUnion Deutschland soll künftig jedem deutschen Europäer die Möglichkeit geben, selbst darüber zu entscheiden, ob er Europa mit de Gaulle, das heißt mit Frankreich, oder gegen de Gaulle, errichten will“".378

375 Vgl. Aktennotiz über ein Telefonat Merkatz - Coudenhove, 10. 3. 1956, ACDP I-148$116 / 01$.

376 Coudenhove-Kalergi, Richard: Memorandum zur Deutschen Frage „Freiheit oder Einheit", ADSD EU 141. Vgl. in ähnlicher Weise auch das Memorandum an die Deutsche Bundesregierung zur bevorstehenden Gipfelkonferenz von Richard Coudenhove-Kalergi, FAE CK C2.

377 Vgl. Teil II, Kap. II.3.

378 Brief Coudenhove-Kalergi an Oppenheim, 20. 2. 1963, ACDP I-148-119/01. 
So entwickelte sich die Paneuropa-Union nun, im Schatten und Gefolge der „Atlantiker-Gaullisten-Kontroverse“, erfolgreicher als jemals zuvor in den Jahren nach dem Zweiten Weltkrieg. ${ }^{379}$ Während sich „bekanntere" Politiker mit einem direkten Engagement immer noch zurückhielten, waren eine ganze Reihe von „Gaullisten“ bereit, dem Ehrenkomitee der Paneuropa-Union zumindest ihren Namen zu leihen, darunter Richard Jaeger, Karl Theodor von Guttenberg (CSU), Bruno Heck (CDU), Hermann Höcherl (CSU), Franz-Josef Strauß (CSU), Eugen Gerstenmeier (CDU), Alfons Goppel (CSU) und Alois Hundhammer (CSU), aber auch Erich Mende (FDP) und Hans Christoph Seebohm (CDU). ${ }^{380}$ Auch im internationalen Komitee der Paneuropa-Union waren nunmehr Deutsche vertreten, darunter neben dem wieder gewählten Hans-Joachim von Merkatz auch der Historiker Friedrich Heer und Paul Wilhelm Wenger. 381

Nicht zuletzt hatte die Paneuropa-Union Deutschland mit Karl Friedrich Grau einen rührigen Generalsekretär gefunden, der sich bemühte, die organisatorische Entwicklung und Festigung des Verbandes in der Bundesrepublik voranzutreiben. ${ }^{382} \mathrm{Grau}$ war im übrigen gleichzeitig auch Vorstandsmitglied der Deutschland-Stiftung, in deren Reihen er sich dann wieder mit Hans-Joachim von Merkatz traf. Ein weiterer Abendländer, der Historiker Georg Stadtmüller, war Präsident der Deutschland-Stiftung, und der Chefredakteur des Neuen Abendlandes Emil Franzel gehörte zu ihren Preisträgern. ${ }^{383}$ Die Deutschland-Stiftung stand im Zentrum "rechter Sammlungsbewegungen" in der Bundesrepublik, zu denen nicht zuletzt auch die Abendländische Bewegung gehörte. ${ }^{384}$ Die PaneuropaUnion geriet über ihren Generalsekretär Grau, aber auch über die Abendländer Paul Wilhelm Wenger, Richard Jaeger oder Hans Joachim von Merkatz der im Mai

379 Während Coudenhove weiterhin selbst Präsident blieb, fanden sich unter den Vorstandsmitgliedern der Paneuropa-Union-Deutschland nun unter anderem die Professoren Willy Hartner und Max Horkheimer, beide ehemalige Rektoren der Universität Frankfurt, der Präsident des Arbeitgeberverbandes Paulssen, der Generalsekretär der Frankfurter Handelskammer Christian Krull, der Chefredakteur von Europress, F.W. Engel, und Paul Wilhelm Wenger vom Rheinischen Merkur, vgl. Brief Coudenhove-Kalergi an Oppenheim, 14. 5. 1963, ACDP I-148-119/01.

380 Vgl. die ausführliche List des Generalsekretariates der Paneuropa-Union Deutschland, Mai 1965, PAAA Abt. West 2, Ref. 201 (IA1) 651.

381 Bericht über die Sitzung des Zentralrates der PEU, 14. 12. 1963, FAE CK C3.

382 Der 1922 geborene Grau war seit 1958 Mitbegründer und fortan Geschäftsführer der Studiengesellschaft für staatspolitische Öffentlichkeitsarbeit. Diese konservative Vereinigung orientierte sich an den radikal antikommunistischen, streng konservativen Positionen William S. Schlamms, den Grau auch wiederholt zu Veranstaltungen der PaneuropaUnion heranzog. Anfang der siebziger Jahre geriet die Studiengesellschaft in die Kritik, nachdem Grau sich mit NPD-Funktionären getroffen hatte. In diesem Zusammenhang wurde er schließlich (vorübergehend) aus der CSU ausgeschlossen und mußte auch den Posten des Generalsekretärs der Paneuropa-Union räumen.

3831972 erhielt Coudenhove-Kalergi den Adenauer-Preis der Deutschland-Stiftung, vgl. Baier/Demmerle, Otto von Habsburg, S. 355.

384 Laak, Gespräche in der Sicherheit des Schweigens, S. 58/59. Van Laak verweist auch auf die „Erste Legion“ als „Reservearmee der CDU für einen Staatsstreich von oben“, in der mit Erich Mende, Hans-Joachim von Merkatz und Kurt Georg Kiesinger eine Reihe von Paneuropäern bzw. Abendländern engagiert waren. Zur Deutschland-Stiftung vgl. auch: Bamberg, Die Deutschland-Stiftung e.V. 
1967 das Amt des Präsidenten der Paneuropa-Union übernahm, seit Mitte der sechziger Jahre zunehmend in jene rechten Kreise - und in engen Kontakt mit den Abendländern. So empfahl von Merkatz Coudenhove die deutsche CEDI-Sektion als „Elitetruppe“ in der Bundesrepublik: „Wir brauchen eine solch kleine Elitegemeinschaft, die die Öffentlichkeit für die sehr realistischen, aus der Erfahrung gereiften Vorstellungen des franz. Staatspräsidenten aufschließt, nach der CK [Coudenhove-Kalergi] als einziger den Weg de Gaulles wirklich verstanden hat und zu praktischen Schlußfolgerungen vorgestoßen ist. Ich möchte Ihnen die deutsche Sektion des CEDI für Ihre Pläne zur Verfügung stellen.“385

$\mathrm{Zu}$ dieser Annäherung zwischen Abendländern und Coudenhove-Kalergi trug nicht zuletzt Otto von Habsburg bei, der Präsident des CEDI, der auf dem VIII. Paneuropa-Kongreß 1957 in Bad Ragaz in den internationalen Zentralrat der Paneuropa-Union gewählt worden war. Im Zweiten Weltkrieg hatte sich von Habsburg noch für eine Restitution der Monarchie in Österreich engagiert und eine mitteleuropäische Einigung beschworen, die an die untergegangene Doppelmonarchie erinnerte. Je deutlicher jedoch nach 1945 wurde, daß diese Pläne keinerlei Zukunft hatten, desto stärker verlegte von $\mathrm{Habsburg}$ sein politisches Engagement auf „Europa“, seit 1979 auch als Abgeordneter der CSU im Europaparlament, in das er nach der ersten Direktwahl einzog.

Als nun das CEDI Mitte der sechziger Jahre endgültig in die Krise geriet, erschien die Zusammenarbeit mit der Paneuropa-Union ein durchaus erfolgversprechender Weg, neuen Elan und Schwung in die müden Veranstaltungen des CEDI zu bringen, neue - jüngere - Mitglieder zu werben und so das Zentrum von der „toten Schiene“, 386 auf die es geraten war, wieder herunterzuholen. Denn seit Mitte der sechziger Jahre kriselte es gewaltig im CEDI. Das aktive Engagement für Europa ließ immer deutlicher nach; an seine Stelle traten organisatorische Debatten. Die nationalen Sektionen kamen mehr oder weniger zum Erliegen. Während der internationale Vorstand in Österreich 1961 noch erfreut stärkere Aktivitäten festgestellt hatte, kam es 1964 zu einer heftigen Auseinandersetzung. Ausgangspunkt war die "nach eingehender Beratung und Aussprache auch mit den uns nahestehenden Herren der österreichischen Bundesregierung " getroffene Entscheidung des österreichischen CEDI, zur Jahrestagung 1964 keine Delegation zu entsenden. Bei dieser Entscheidung spielte der „augenblickliche Stand der Habsburger-Frage" die entscheidende Rolle. ${ }^{387}$ Damals ging es, nach der „Verzichtserklärung“ von 1961, um die Einreiseerlaubnis für Otto von Habsburg nach Österreich. Der Vorstand des CEDI stellte sich in dieser Situation erwartungsgemäß hinter seinen Ehrenpräsidenten, indem es „la suspension immédiate des droits et devoirs du centre autrichien vis-à-vis du Comité de Direction international et de ce fait même de sa reconnaissance comme centre national" beschloß.388

385 Brief Merkatz an Coudenhove-Kalergi, 17.7.62, ACDP I-148-116/02.

386 Otto von Habsburg auf der Sitzung des internationalen CEDI-Vorstandes, 20./21. 1. 1968 in Rom, ACDP I-148-132/01.

387 Brief der österreichischen CEDI-Sektion an den internationalen Präsidenten von Merkatz, 26. 4. 1964, ACDP I-148-132/01.

388 Sitzung des internationalen CEDI-Vorstandes am 7. 7. 1964, ACDI I-148-132/01. 
Hinzu kamen finanzielle Probleme, die sich aus der Schwäche der nationalen Sektionen ergaben. Zwar hatte Gaupp-Berghausen als Generalsekretär bereits früher den (freiwilligen) Beiträgen der einzelnen CEDI-Sektionen quasi hinterherlaufen müssen, und zeitweise hatte Waldburg-Zeil das internationale Sekretariat fast ausschließlich alleine getragen. ${ }^{389}$ Nachdem Waldburg-Zeil sich aus der Finanzierung des internationalen Sekretariates 1962 zurückgezogen hatte, um „allein das deutsche CEDI zu unterstützen“, gelang es in den kommenden beiden Jahren nur noch mit Müh’ und Not die Finanzierung sicherzustellen - insbesondere nach dem Rückzug der Franzosen und Österreicher.

Somit stellte sich im Verlauf der sechziger Jahre zunehmend akuter die Frage: „Hat das CEDI in seiner heutigen Form noch eine Berechtigung?" 390 Immer wieder gab es Debatten, wie und in welcher Form möglicherweise veränderte Aktionsformen dem CEDI neue Mitglieder oder mehr öffentliche Wirkung zuführen könnten. Gaupp-Berghausen beispielsweise schlug 1964 die Bildung von "Jugend-CEDIs " in jedem Mitgliedsland vor, die von einem eigenen CEDI-JugendSekretariat geleitet werden sollten. ${ }^{391}$ Tatsächlich fand 1965 eine Jugendwallfahrt nach Santiago de Compostela statt, an der 200 junge Leute aus ganz Europa teilnahmen. Im Anschluß daran gründeten die Teilnehmer einen "Cercle Saint Jacques", der sich zweimal traf, doch damit ging die Aktion auch schon wieder ihrem Ende zu. Frustriert faßte Gaupp-Berghausen 1967 zusammen: „Dann gingen auch mir die zusammengebettelten Mittel aus, und damit mußte die Aktivität zwangsweise eingestellt werden. “392

In Anbetracht der andauernden Probleme schlug Gaupp-Berghausen 1967 vor, das CEDI entweder aufzulösen, oder aber folgende Lösung anzugehen: „Das internationale CEDI arbeitet in den Ländern, in denen es kein aktives nationales Zentrum gibt, mit der Paneuropa-Union zusammen und nimmt von dieser Vertreter in den internationalen Rat auf. Den nationalen Zentren [...] wird nahe gelegt, mit der Paneuropa-Bewegung zusammen zu arbeiten. [...] Auf internationaler Ebene wird eine Kommission des CEDI gebildet, die mit einer ebensolchen Kommission des internationalen Rates der Paneuropa-Bewegung die Basis für eine Zusammenarbeit auf internationaler Ebene vorbereitet und abstimmt. “393 Unterstützt wurde dieser Vorschlag - und das ist für die weitere Entwicklung des CEDI entscheidend - vom Ehrenpräsidenten des CEDI, Otto von Habsburg, der das Verbindungsglied zwischen beiden Organisationen darstellte. „[...] Je soutiens de tout coeur la proposition constructive $[. .$.$] en vue de créer une coopéra-$

389 Protokoll der Sitzung des internationalen CEDI-Vorstandes am 27.1. 1961, ACDI I-148-131/03.

390 Bericht des Generalsekretärs des CEDI in Schloß Pouy am 24./25. 6. 1967, ACDP I-148132/02.

391 Vgl. bspw. die Ausführungen Gaupp-Berghausens vom September 1964 mit der Absicht, CEDI-Gruppen für Jüngere zu gründen, ACDP I-148-132/01.

392 Bericht des Generalsekretärs zu Punkt 2) und 3) der Tagesordnung. Schloß Pouy am 24./ 25. 6. 1967, ACDP I-148-132/02.

393 Bericht des Generalsekretärs des CEDI in Schloß Pouy am 24./25. 6. 1967, ACDP I-148132/02. 
tion effective entre le CEDI et le Mouvement Paneuropéen. “394 Für Otto von Habsburg, und in seinem Gefolge auch für andere Abendländer, zählte angesichts der in Europa stärker werdenden sozialdemokratischen politischen Kräfte, angesichts der Jugendproteste und schließlich der Entspannungspolitik die Notwendigkeit, jene Gruppierungen, die auf konservativer Basis standen, zu einigen: „En vue de cette nécessité urgente de notre continent, il est essentielle d'unifier toutes les forces qui veulent l'unité européenne et d'harmoniser leur actions. Des divergences de détails ne doivent plus compter alors qu'il s'agit d'affaires essentielles." 395

Es waren vor allem die Deutschen, die auf diese Vorgabe eher zögerlich reagierten und auf die „Unvereinbarkeit dieser Organisation [der PEU, V.C.] mit dem CEDI" verwiesen, was vor allem an der Skepsis lag, die in der Bundesrepublik gegenüber Coudenhove-Kalergi bestand. ${ }^{396}$ Sicherlich hatte von Merkatz recht mit seinem Urteil, die Arbeitsweisen und Wirkungsformen von CEDI und PEU seien einfach zu verschieden. Doch obwohl die geplante Kommission, die die internationale Zusammenarbeit beider Organisationen regeln sollte, nur einmal zusammentraf, war der einmal im Raum stehende Vorschlag der Zusammenarbeit nicht mehr aus der Welt zu schaffen. Vielmehr scheint es, als sei die normative Kraft des Faktischen wirksam geworden. Die Auflösungserscheinungen innerhalb des CEDI waren unübersehbar: Die Jahrestagung 1968 fiel aus, das „Europäische Institut für politische, wirtschaftliche und soziale Fragen" wollte sich aus dem CEDI ausgliedern, Gaupp-Berghausen kündigte seinen Rücktritt als Generalsekretär an, und schließlich begannen die treuen CEDI-Mitglieder auch noch wegzusterben. So wurde das CEDI zwar offiziell nicht aufgelöst (es besteht noch heute) ${ }^{397}$ und auch nicht mit der Paneuropa-Union fusioniert, doch konnte man der Vorgabe des verehrten "Otto von Österreich" in den Reihen des CEDI letztlich nicht widerstehen. Die Paneuropa-Union übernahm Personal und Gedankengut der Abendländischen Bewegung weitgehend - auch und vor allem in der Bundesrepublik.

Gleichzeitig ging man daran, die Paneuropa-Union zu reorganisieren, aus der sich die charismatische Gründerfigur Coudenhove-Kalergi nach beinahe fünfzigjähriger Tätigkeit für „Paneuropa“ zurückzuziehen begann; diese Reorganisation wurde mit Coudenhoves Tod 1972 verstärkt fortgesetzt. Im Verlauf dieses Prozesses flossen auch abendländische Ideen in die "neue" Paneuropa-Union ein. Als sich die Paneuropa-Union nach Coudenhoves Tod neu konstituierte, übernahm sie zwar bestimmte Element des alten „Paneuropa“. Der gaullistischen Idee einer "Weltmacht Europa“, die Coudenhove in den sechziger Jahren vertreten hatte, fügte sie aber vor allem zwei unverwechselbare Elemente hinzu, die zuvor in der Bundesrepublik vor allem von abendländischen Kreisen vertreten worden waren: die Befreiung der mittel- und osteuropäischen Länder und die Verteidigung der

394 Brief von Habsburg an Gaupp-Berghausen, 19. 6. 1967, ACDP I-148-132/02.

395 Ebenda.

396 Generalversammlung des CEDI am 20./21. 7. 1968, ACDP I-148-132/02.

397 Petra-Maria Weber bezeichnet Hans Huyn als heutigen Präsidenten des CEDI, vgl. dies., Spanische Deutschlandpolitik, S. 209. 
christlichen Werte. Beide Elemente waren zwar auch in Coudenhoves Gedankengebäude enthalten gewesen, allerdings nur schwach ausgeprägt. Doch nun wurden sie in zuvor ungeahnter Weise auf die Fahnen der Paneuropa-Union geschrieben. ${ }^{398}$ Die neue Organisation empfahl sich „unzweifelhaft als konservativer europäischer Verband“, in eindeutiger Abgrenzung gegenüber der als „links“ diffamierten Europa-Union - während die Europa-Union nicht zögerte, die Paneuropa-Union als "rechts“ auszugrenzen. ${ }^{399}$

Im Verlauf der siebziger Jahre gelang es der Paneuropa-Union, sich in der Bundesrepublik als gefestigte Organisation zu etablieren. Indem vor allem die Vertriebenenverbände der Paneuropa-Union kollektiv beitraten, wuchsen die Mitgliederzahlen der PEU enorm, so daß der Verband nach eigenen Angaben im Mai 1976180000 , im Dezember desselben Jahres 200000 bis 300000 Mitglieder besaß und damit den bis zu diesem Zeitpunkt mitgliederstärksten Europaverband in der Bundesrepublik, die Europa-Union, überrundet hätte. ${ }^{400}$ Gleichzeitig verquickten sich Vertriebenenverbände und PEU organisatorisch, etwa wenn nach Karl Friedrich Grau der Vizepräsident des Bundes der Vertriebenen (BdV), Rudolf Woller, das Generalsekretariat der PEU übernahm. Wenn auch die Organisationsstruktur der PEU unterhalb der nationalen Ebene schwach ausgeprägt blieb, so entwickelte sich seit 1975 eine starke Paneuropa-Jugend, aus deren Reihen die Erneuerung der Paneuropa-Union wesentlich mitgetragen wurde. Es besteht so kein Zweifel daran, daß sich in den siebziger Jahren ein zweiter deutscher Europaverband neben der bis dahin alles dominierenden Europa-Union herausgebildet hatte. In diesem hatten auch die Abendländer eine neue Heimat gefunden.

So gelang dem „Abendland“, wenn auch in veränderter Form, sehr wohl der Sprung in die „neue Bundesrepublik“ der sechziger und siebziger Jahre, in organisatorischer wie ideeller Hinsicht. Hatte die Abendländische Bewegung immer nur aus einer überschaubaren Gruppe bestanden, die auch im eigenen Selbstverständnis keine Großorganisation herausbilden wollte (und vermutlich auch nicht gekonnt hätte), so entwickelte sich in den siebziger Jahren erstmals ein konservativer Europa-Verband mit ansehnlichen Mitgliederzahlen. Zu dieser Entwicklung trugen verschiedene Faktoren bei. Während in den fünfziger Jahren die EuropaUnion der dominierende Europa-Verband der Bundesrepublik gewesen war, der den breiten außenpolitischen Konsens um Westintegration und Hallstein-Doktrin mittrug, änderte sich die Situation, als dieser außenpolitische Konsens in den Unionsparteien durch den Gaullismus aufgebrochen wurde. Während die EuropaUnion auf "atlantischer" Seite Position bezog, entstand ein Bedarf nach einer Organisation, die "gaullistischen“ Interessen diente. Dies zeigt bereits der Erfolg des

398 Vgl. die Straßburger Grundsatzerklärung der Paneuropa-Union vom Mai 1973 und Otto von Habsburgs "4 Punkte-Erklärung“ von 1976, teilweise abgedruckt in: PaneuropaUnion Deutschland 15 (1992), Nr. 3, S. 18/19. Vgl. hierzu auch: Gehler/Ziegerhofer, Richard Coudenhove-Kalergi und die Paneuropa-Union, S. 307. Vgl. auch das Kapitel: Paneuropa gewinnt an Profil, in: Baier/Demmerle, Otto von Habsburg, S. $355 \mathrm{f}$.

399 Europa-Union, Aufzeichnung betreffend Paneuropa-Union, 15. 4. 1977, ADSD EU/105. Vgl. auch das „Schwarzbuch“ des Jugendverbandes der Europa-Union, der Jungen Europäischen Föderalisten: Mobilmachung. Die Habsburger Front.

400 Europa-Union, Aufzeichnung betreffend Paneuropa-Union, 15. 4. 1977, ADSD EU/105. 
CEDI in den sechziger Jahren, als es sich zu einem deutsch-französischen „Kontaktpool“" entwickelte. Die Ereignisse seit Ende der sechziger Jahre verstärkten diese Entwicklung. Der fundamentale Wandel, hervorgerufen durch Entspannungspolitik, gesellschaftliche Liberalisierung, Studentenunruhen und sozialliberale Koalition, löste bei Konservativen tiefgehende Skepsis aus. Erstmals seit den fünfziger Jahren entwickelte sich daraus in konservativen Kreisen der Wunsch nach einer Organisation, die die eigenen europapolitischen Vorstellungen und Forderungen vertrat, verbunden mit klar geäußerten, christlich verankerten Wertvorstellungen.

Es scheint, als sei es den Trägern des konservativ-katholischen abendländischen Gedankengutes erst mit der „neuen“ Paneuropa-Union (und ihren jüngeren Mitgliedern) gelungen, sich selbst aus der Nachkriegszeit herauszuführen, Ballast, der zum Teil noch der Zwischenkriegszeit entstammte, über Bord zu werfen und neue, effektive Wirkungsformen zu entwickeln. Man hatte akzeptiert, daß die Moderne letztlich unumkehrbar war, daß eine vollständige Rechristianisierung der gesamten Gesellschaft ein unerfüllbarer Wunschtraum bleiben würde. Doch selbst daraus schöpfte man Hoffnung: „Unsere überlieferten Werte mußten zwar den Prozeß der Säkularisierung über sich ergehen lassen und erlitten dabei schwere Substanzverluste. Dies darf uns jedoch nicht blind machen für die Tatsache, daß sie auf diese Weise (und nur auf diese Weise?), weltfähig' werden konnten. Ihre Ergebnisse werden heute von den Völkern der asiatischen Hochkulturen ebenso akzeptiert, ja assimiliert, wie von arabischen und mittelafrikanischen Stammesvölkern. Wer weiß, vielleicht bringt es die List der Geschichte fertig, daß mit diesen Ergebnissen auch ein Keim jener geistigen Werte mitübernommen wurde, aus denen unsere Welt einst mit so unvergleichbarer Intensität gelebt hat, deren hohem Anspruch wir uns freilich zu keiner Zeit ganz gewachsen gezeigt haben und die in Zukunft möglicherweise in fernen Gebieten neue Früchte tragen werden." 401 Wenn also auch zahlreiche überkommene, reaktionäre Elemente über Bord fielen, so blieb die abendländische Idee in der Paneuropa-Union jedoch in ihren Grundzügen erhalten - dazu gehörten die konservativ-elitären Gesellschaftsvorstellungen, der Glaube an eine christliche Grundlage als unbedingte Voraussetzung eines geeinten Europas und schließlich ein ausgeprägter Antikommunismus.

Eine Tatsache allerdings sollte in diesem Zusammenhang nicht unerwähnt bleiben. Selbst Trägergruppen der abendländischen Idee verwandten nun, am Ende der sechziger Jahre, kaum noch den Begriff „Abendland“. Der Begriff hatte seine Integrationskraft für den deutschen Konservatismus ebenso verloren wie das „Reich“, das jahrzehntelang eine ähnlich einheitsstiftende Kraft entwickelt hatte. Der Begriff „Europa“ konnte diese Lücke im Konservatismus nicht füllen: Er war von anderen Kräften, mit anderen Inhalten besetzt. Erst das Schlagwort „Paneuropa" ließ daher wieder eine enge Verbindung zwischen Konservatismus und Europa auch in der Öffentlichkeit zu. Insofern war Ende der fünfziger Jahre die Zeit der großen Wirksamkeit der Idee vom „Abendland“, die sich in einem langen Bo-

401 Roegele (Hg.), Die Freiheit des Westens, S. 9. 
gen von der Zeit nach dem Ersten bis in die Zeit nach dem Zweiten Weltkrieg spannte, tatsächlich vorüber. Daß sich bestimmte abendländische Kernelemente, nun unter anderem Namen, über diesen Zeitpunkt hinweg transformiert und erhalten haben, ändert an dieser Tatsache nichts. 